\title{
Heer, Oswald
}

Fossile Flora der Bären

Insel. 


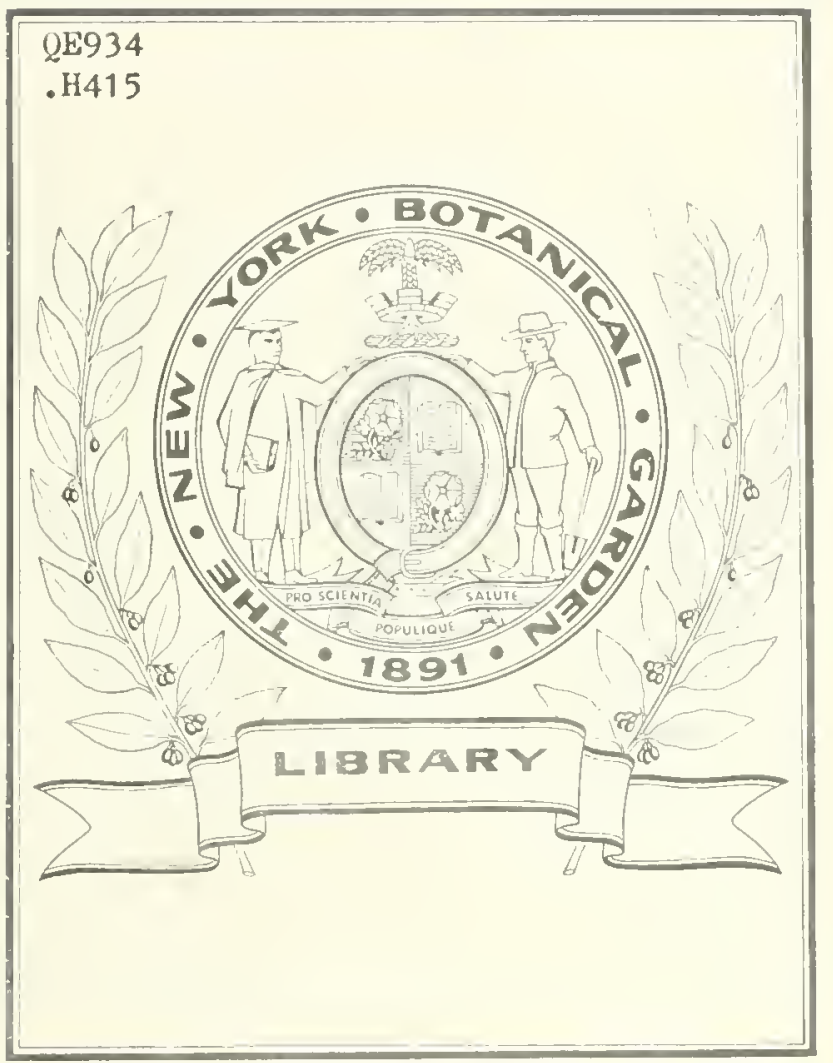



02

Meper

ETaseite eftora

dea -

- Pären Unael

1871 


\title{
FOSSILE FLORA IDER BÄREA INSEL.
}

\author{
101 \\ (1)
}

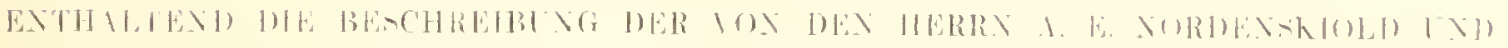

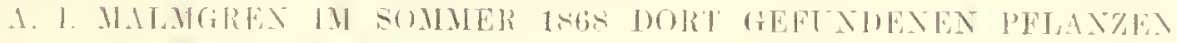

WIT TIS THEL

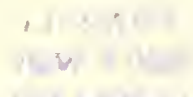

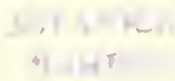

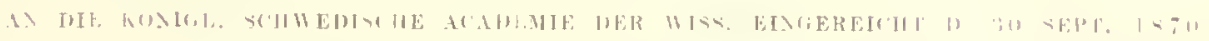

STOCKHOLM. 1Ri1

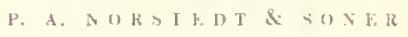


$\therefore=934$

.4415 


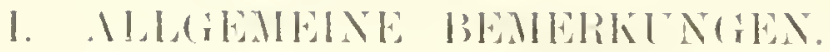

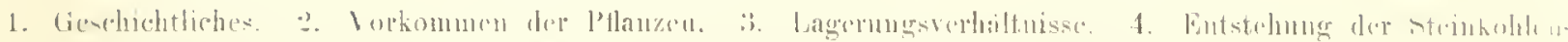

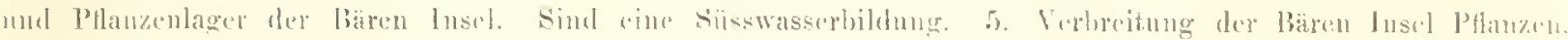

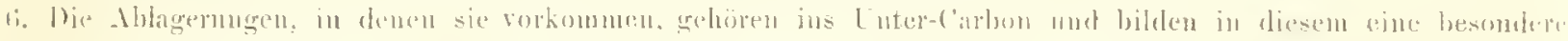

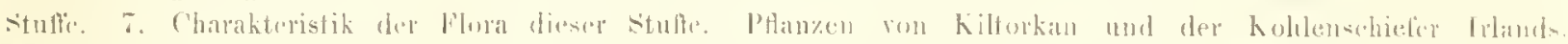

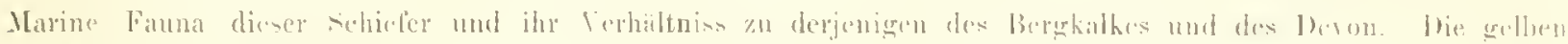

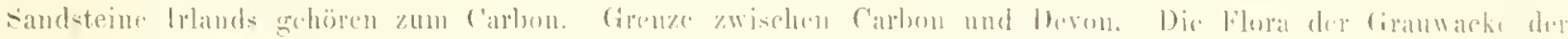

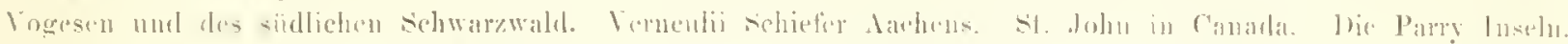

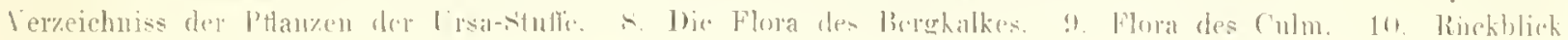

\section{$\mathrm{U}$}

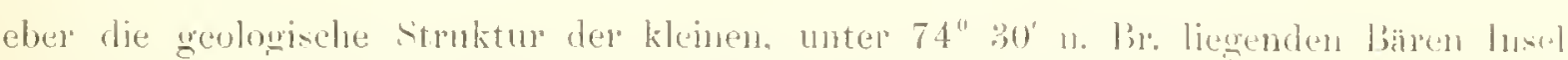

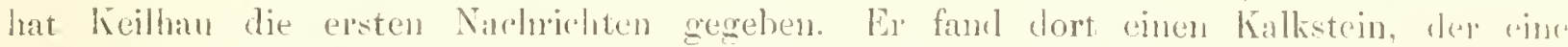
grosse Zahl von Mollusken einschliesst. Die ron ihn nach (hristiania gebrachten tatick

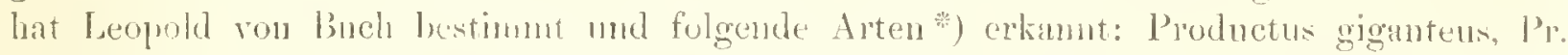
punctatus, Pr. plicatilis, Sprifer Keilhavii, Sp. striatus, Calanopora polymorpha und Fenestella antiqua. Er hat am ihrem Torkommen geschlossen, dass diese formation dem Bergkalk angehören mïsse. Zu dersethen wurden anch die Steinkohlen- und Sandsteinlager serechnet, welche dort gefunden worden. Da aber später dir Kohlen des nathe gelegenen Spitzhergen sich ils. Miocen heransstellten morl dee sie begleitende Sandstein dem

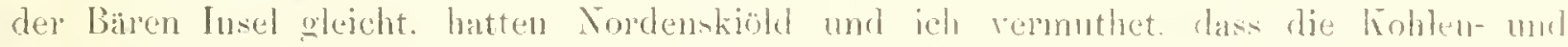

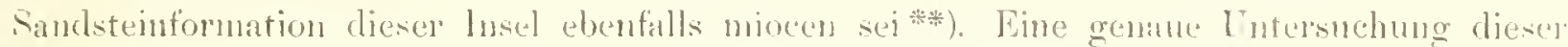

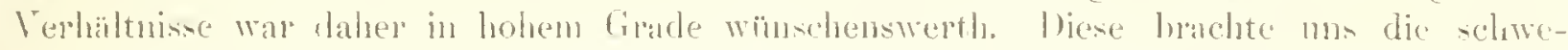
dische Expedition rom Sommer 1868. Es that Herr l'rof. Nordenskiöld die Tagerungs-

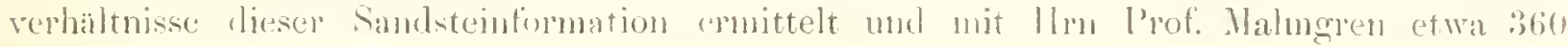

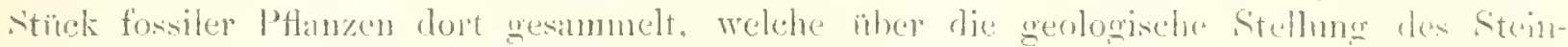
kohlenlagers dic gerrinsclite luskunt geben.

Es teeten diesc I'flanzen in rerschiedenen Dedien anf:

1. Wir finden sie erstens in der liohle selhat. loie seliwarze kohle mit glinzendem

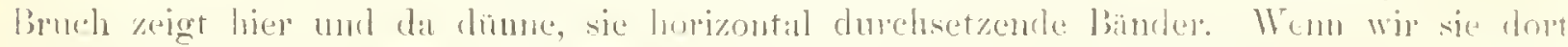

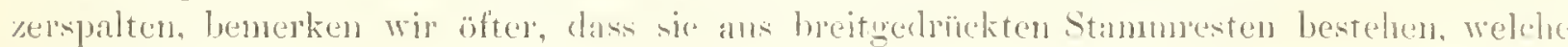

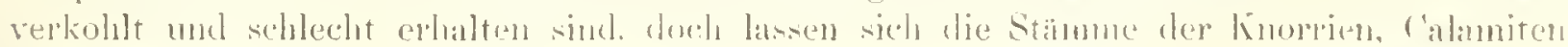

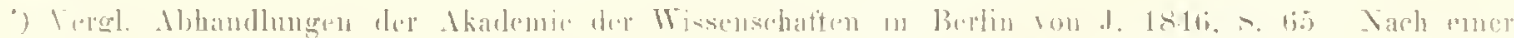

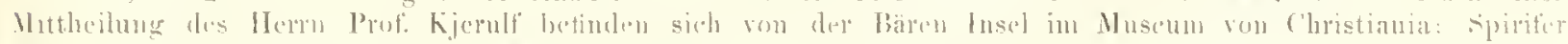

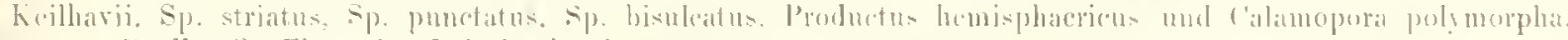

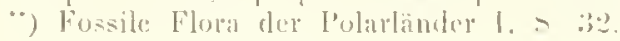


ma Lepidodendren noch erkennen. Lis liegen also diese zum Theil mitten in der Kohle drin und sind in Kohle verwandelt.

2. Stellenweise haben sich zwischen den Kohlen mehr oder weniger dicke Schichten einer schwarzen, schiefrigen Masse abgelagert, welche wohl ursprünglich aus Lettenbändern gebildet, nun die Kohlen durchsetzen. Ans diesen dümnen, aus einer Art Thonschiefer gebildeten, Zwischenlagern kommen die meisten von mir beschriebenen Pflanzen.

3. Unter dem Kohlenlager liegt ein grauschwarzer 'Thonschiefer, der in dünne Platten gespalten werden kann. Dieser Schiefer ist erfült von den grossen Rhizomen des Calamites radiatus, mit ihren Aesten mol Würzelzasern. Hier und da sind ganze Nester von Würzelzasern der Lepidodendren und Blattreste von Cardiopteris. Es hat sich diess Gestein wohl aus den weichen Schlamm grebildet, der aus dem runigen Gewässer sich niederschlug und die lihizome der Calaniten mögen in diesem Schlamme sich in ähnlicher. Weise ausgebrejtet haben, wie diess bei den Wurzelstöcken der lehenden Equiseten der Fall ist, welche oft viele Fuss tief in den Boden eindringen und denselben nach allen Richtungen durchziehen. Es ist dieser ron Pflamenresten erfüllte Thonschiefer Stellenweise ziemlich grobkürnig; danchen kommt aber noch ein sehr feinkörniger, schwarmer Schiefer vor, der in ganz dïnne Blätter gespalten werden kann und sich zu Conservirung zarter Pflanzen voraüglich eignen wïrde. Leider ist dieser aber fast ganz leer; jch fand nur einige wenige Reste von Wurgelaesten des Calamites radiatus in demselben.

4. Ein grobkörniger harter Sandstein von bald weisser, bald aber weissgrauer Farbe mit vielen Quarzörnem. Er enthält Stammeste des Calannites radiatns, die Stigmaria ficoides und Lepidodendron Yeltheimianum.

5. Ein eisenschüssiger, daher aussen röthlich-brauner, answendig aber gran-braunlicher Thon von seh" feinem Korn, der nach Norrlenskiöld knollen in Thonsehiefer bildet. Er entbalt nur wenige Pflanzen. (Sphenopteris Schimperi, Lepidophyllum Römeri und (yciostigna kiltorkense.)

Eeber die Lagerungsverhältnisse dieser l'flanzenführenden Gesteinc, wie über die Verbreitmug des Bergkalkes über die Bären Insel und Spitzhergen giebt uns die Abhandlung des Herm Prof. Nordenskiöld. welche er dieser Arbeit beizufügen die Giite hatte, schrr willkommenen Aufschluss. Sie zeigt ms folgende Reihenfolge:

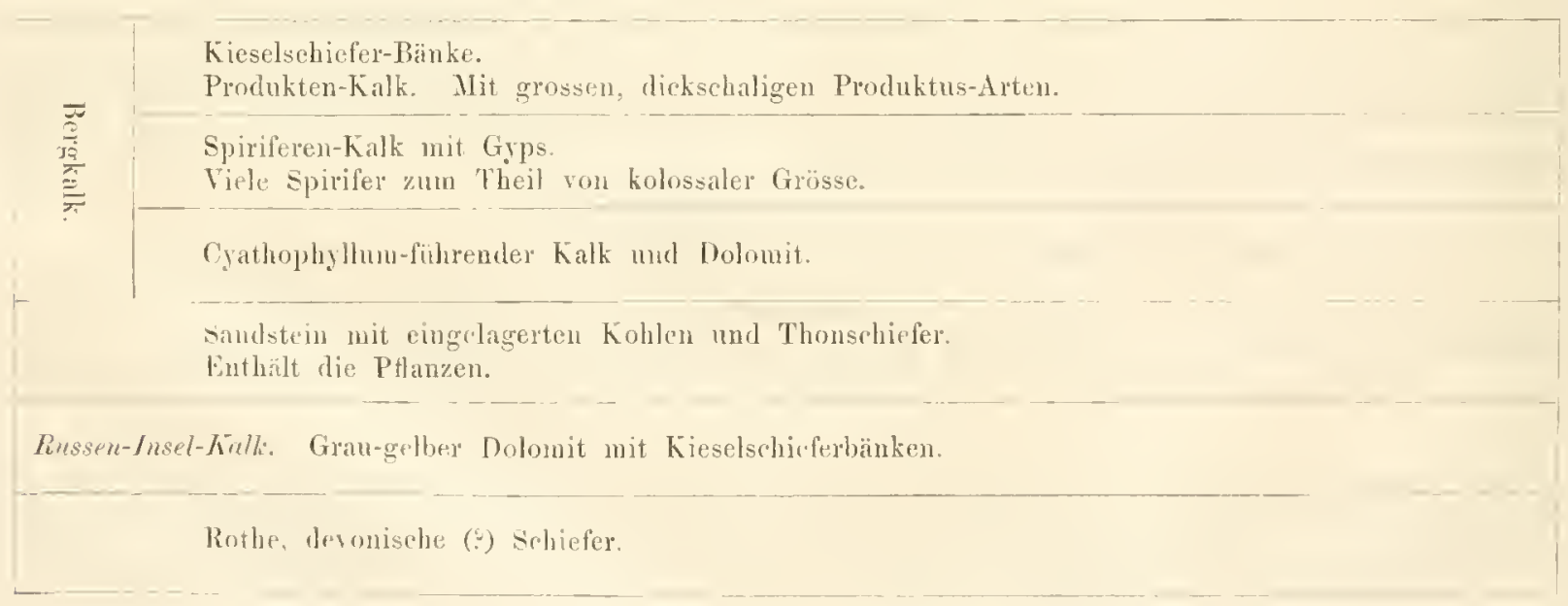




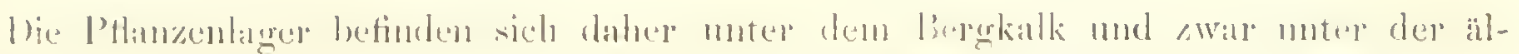

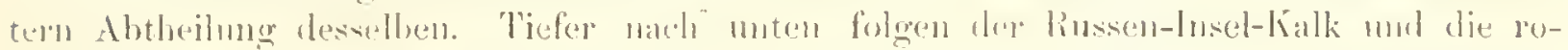

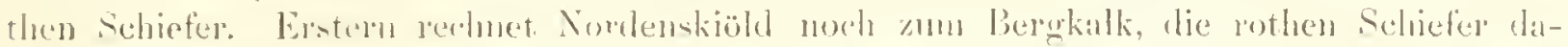

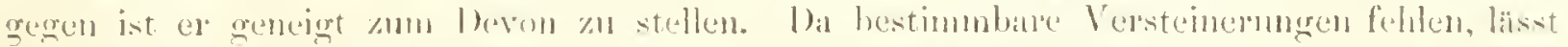

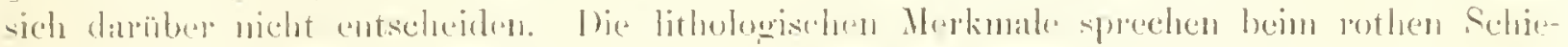

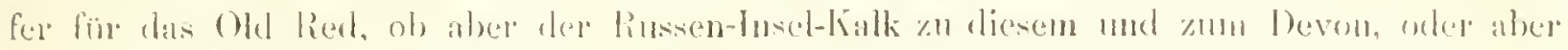

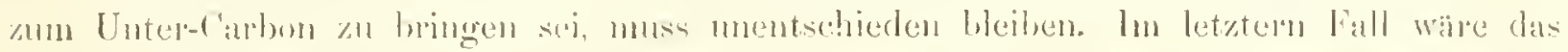

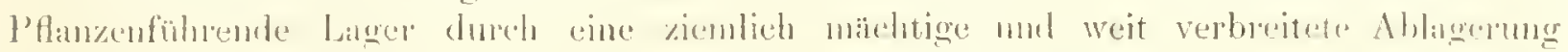

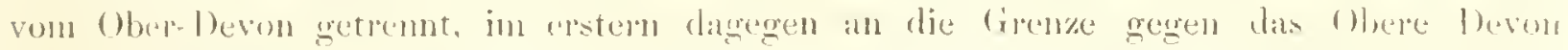

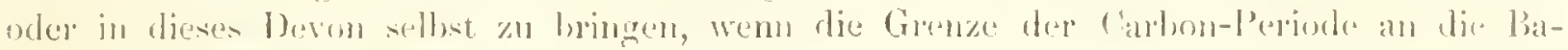

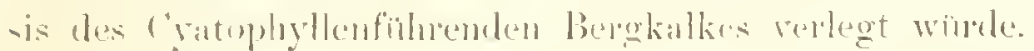

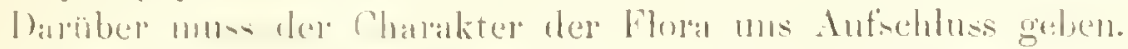

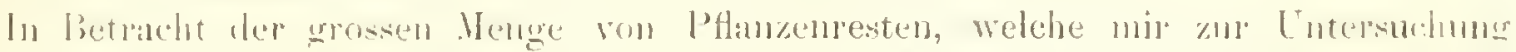

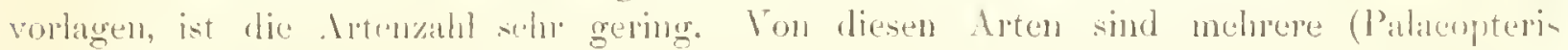

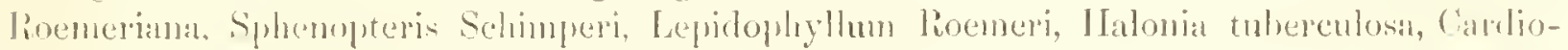

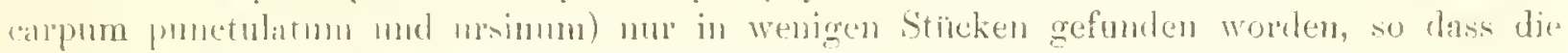

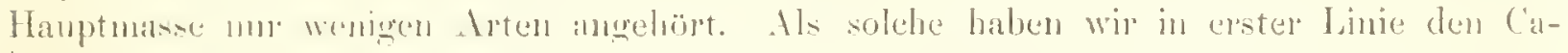
lanites (hornia) radiatus und das lepridodendron Veltheimianum zu nennen, in aweiter: die Konrren, Stignanjen, die ('yelostigmen und Cardiopteris-Arten. Der Calamit hat mit

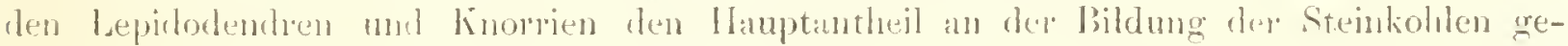
nommen, wie sein läutiges Yorkommen in den liohlen selbst beweist. Ton marinen

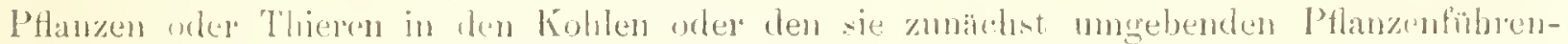

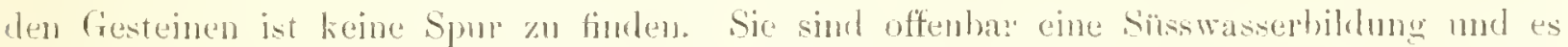
hält nicht schwer aus dem Charakter der Pflanzen und den ron Nordenskiöld mitgetheil-

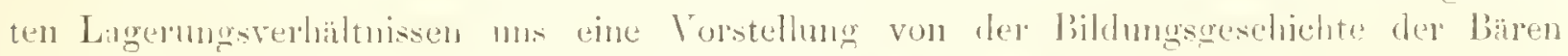

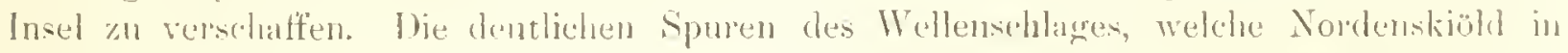
dem untersten, noch keine l'flanzen enthaltenden Sandetcinbager fand. weisen anf eine

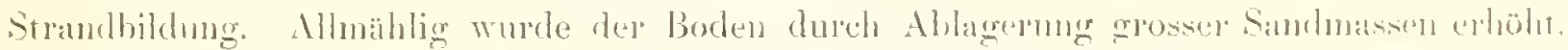

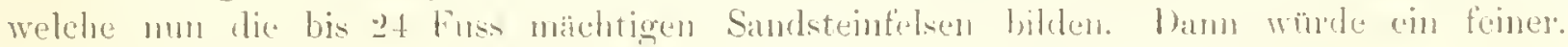

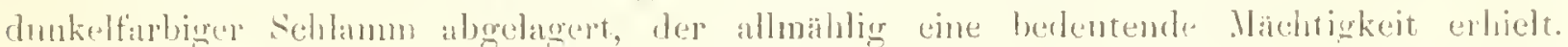

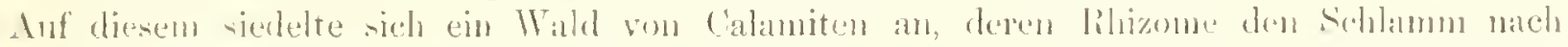

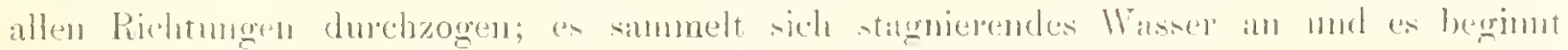

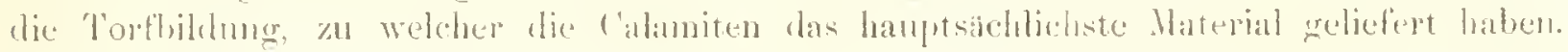
l)as Torflager wird äbersehwemmt und mit einer nenen Lettensehicht äberdeckt, anf wal-

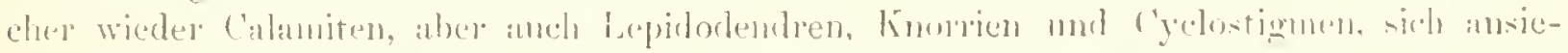
deln und allmablitig vertorfend none Torfmasen al'zengen. Diener Vorgang hat sich zeiten-

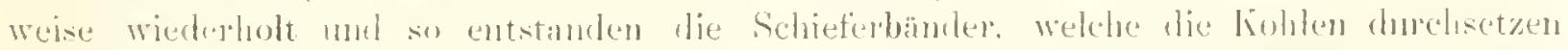

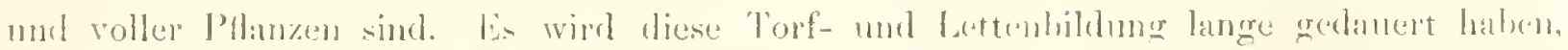

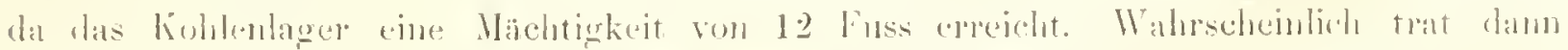

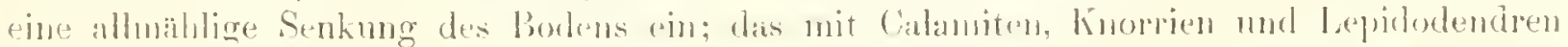

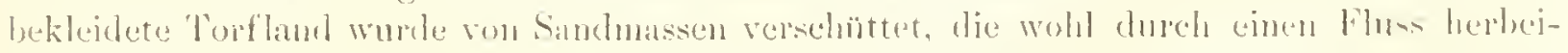

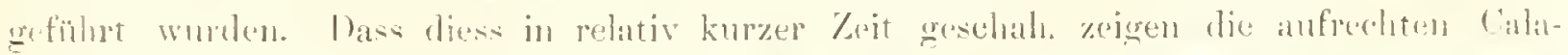

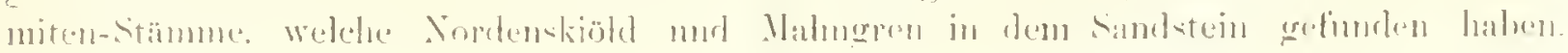


Allmählig sank das Land unter Meer und zwar bis zu sehr betrïchtlicher 'Tiefe, wie aus der grossen Mächtigkeit des Bergkalkes hervorgeht, welcher den Jammerberg bildet und im Meere abgelagert worden ist. Es ist die Bären Insel so klein, dass kamm anzmehmen ist, dass sie das Material zn Bildung der Sandsteine und Kohlenschicfer geliefert labe. Wahrscheinlich wurde es durch einen Fluss herbeigeführt, der auf einen grösseru Unfang der Insel schliessen lässt. Vielleicht stand sie anch mit Nordrussland in Verbindung, wo wir an Weissen Meer, in Flussgebiet der Petschora und am Ural eine alnnliclue Kohlenbildung treffen, die bis in den arctischen lireis hinaufreicht. - Später wurde die Insel wieder gehoben und der marine Bergkalk bildet nun den Boden der Insel. Oh jüngere Abligerungen durch Verwitterung verschwnden sind, oder keine solche sich hier gebildet haben, ist nicht zu entscheiden.

Ueber die Verbreitung der Pflanzen der Bären Insel giebt folgende Zusammenstetlung Aufschluss.

Verbreitung der Bären-Inscl-Pflanzen in der untern liohlenformation.

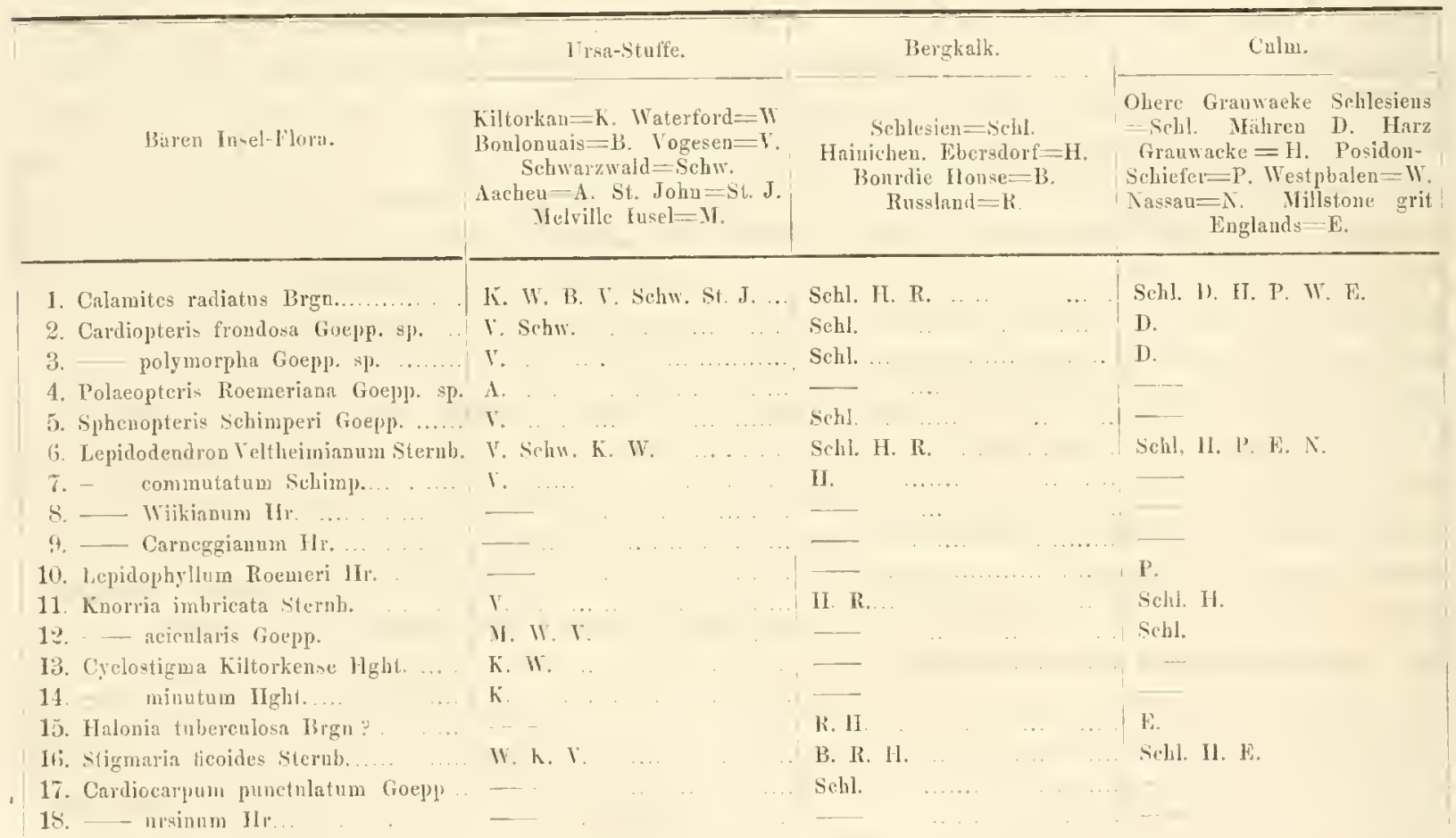

Wir sehen ans dieser Zusammenstellung, dass von den 18 Arten mur drei anderweitig noch nicht nachgewiesen sind; die meisten und alle häntiger anftretenden Pflanzen gehören zu bekannten, zmm Theil wejt verbreiteten Arten mid geben mus dadurch das Vittel an die Hand diese Flora mit derjenigen anderer Länder mad der rerselicedenen Abtheilungen des Steinkohlengebirges zu vergleichen.

leh legte der Tabelle die drei Hauptabtheilnngen des Chter-Carlon zan Gumde, welche meine Untersuchung erreben hat. In den Cum schliesst sich nach Oben das NittelCarbon (die sogenannte prodnktive Steinkohle) an, an die Lrsa-Stuffe nach Unten das 


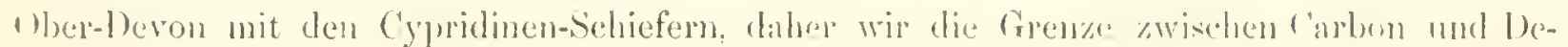

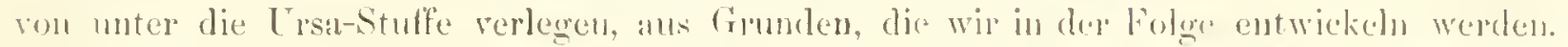

Eine Vergleichung der Bären Insel-Flora mit derjenigen des Mittel-Carbon zeigh uns

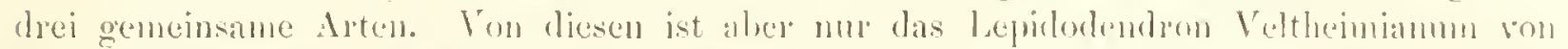

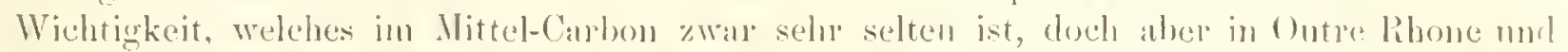
bei Tannge gefunden worde. Die Halonia tubereulosa der Bären Insel ist noch \%weife?haft, und lie Stignmarien rignen sieh als Wurcelstöckr versehiedenes Pflanzen-Arten mul wohl anch Gattungen nicht zn Veglejehnugen, dise anf genane Artbestimmungen sich zu

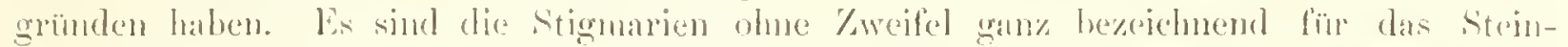

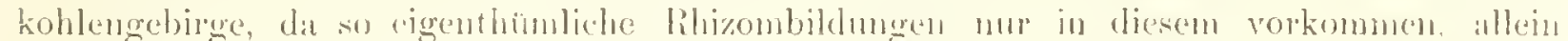

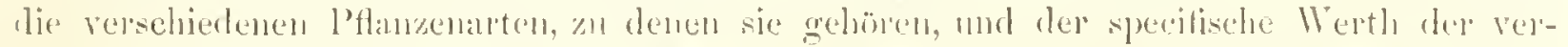
schiedenen Formen sind unch viel zu wenig anfgeklïnt, mu anf letztere Sehlïsse zu banen.

Fis weicht dalier in der That die Bären Insel-Florat sehr wesentlich von der Mlittel(arbon-Flora ah, inden eine einzige sicher bestimnte fre and in dieser sich findet.

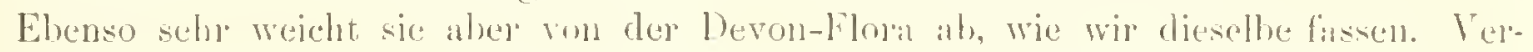
gleichen wir sie nit der litural des (ypridinen-Schiefers von Sialfeld $\left.{ }^{*}\right)$, welche dem ober-

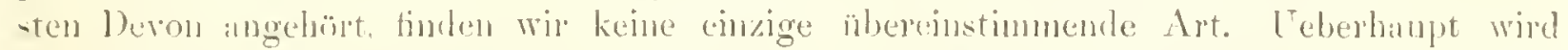
ans dem Devon ron Dentschland nme eine Art der liaren Insel angefouhrt. Es ist diese

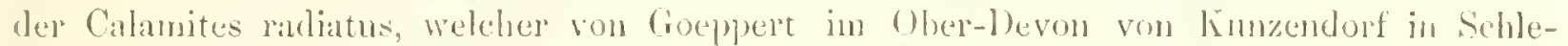
sien angegeben wird. Dieser Fundort wurde abes früher ron Goeprest anm liergkalk gerechnet**) und wohl nur wegen des l'orkommens des Receptuculites Neptuni Defir. später zmm ()ber-1)evon ge\%ogen. Uir abes" will es scheinen, dass der Calannit iln dem UnterCarbon zuweise und somit jener Zoophyt an den zahlpoichen niedern Thieren gehöre, welche vom Devon in dis I Thter-Carbon hinanfreichen.

Aus Anerika ist anch nur eine Bären Insel-Art bekamut, dis: im levon angugeben wird. Ls ist diess das lepidodendron Veltheinianum Stb. Lis hat foeppert einen in der Hamilon-Gruppe (Mittel-Deron) Anerikas gefundenen Zweigrest für die hinorienform dic-

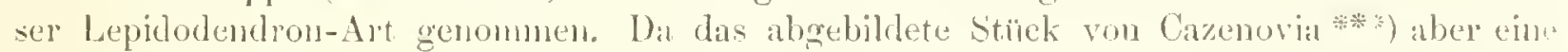

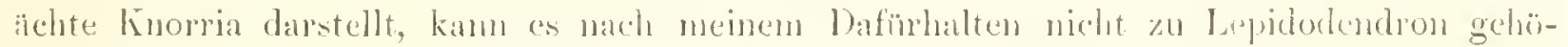

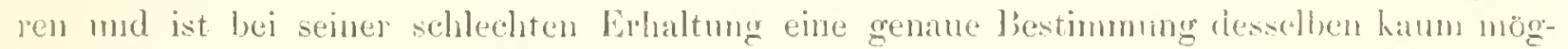
lich. liesser erhalten ist das Lepidodendron chemungense Vamux. an der ChemungGruppe, welches Goeppert zn 1. Yeltheinianm zicht. Aliein diese Chemung- und Katskill-Gruppe Newyorks ist wahluscheinlich mit grösserem liecht mit der Ursa-Stuffe des Unter-Carbon, als mit dem levon an verhinden. Wem man aber anch diess nieht zugeben will und anch hinnzendorf noch ins Ober-Devon stellt, wänden wir nur 2 oher-dero. nische Arten erhalten und zwar gerade 2 Arten, welche durch d:as ganze Inter-Carbon

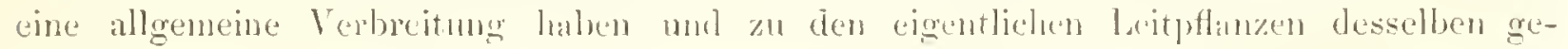
hörell.

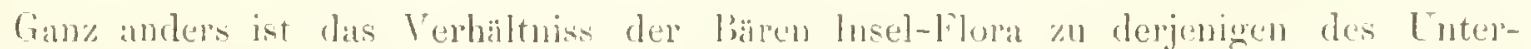
Carbon, wie ein Blick anf die Tabelle \%eigt. Von ihren 18 Arten sind 15 anderweitig in

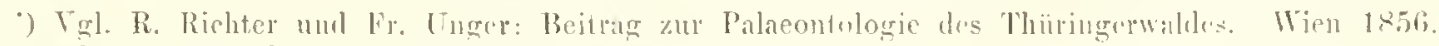

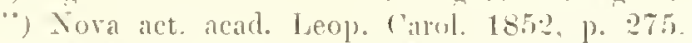

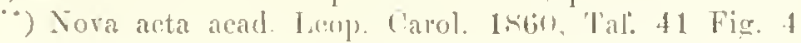


Unter-Carbon nachgewiesen und zwa 12 in der untersten Stuffe, 10 in Burgkalk und 4" in Culı. Es kann daher nicht zweifelhaft sein, es gehört die Bären Insel-Flora ins Lnter-Carbon. Es ist aber von grossem Interresse sie noch mit den einzelnen Fundorten anderer Lünder zu vergleichen, worans sich uns ergeben wird, dass sie, ganz entsprechend den Lagerumgsverhältnissen der sie unschliessenden Gesteine, die grösste Achuliehkeit mit der Flora der ummittelbar unter den Bergkalk liegenden Sandsteine und Schiefer hat und dass diese Flora eine besondere Stuffe des Unter-Carbon bildet. welche den Eubergang zum Ober-bevon rermittelt. Wir nemnen sie die Baren Insel-Stuffe (Ursa-Stuffe) und wollen zumächst die lilor"a derselhen zusammenstellen.

\section{URSA-STLFFE.}

1. FLORA VON KILTURKAN.

Die Flora der liären Insel schliesst sich am nächsten an diejenige der gelhen Sandsteine und der Kohlenschicfer von Sühwest-lrland und an die der Grumwacke der Vogesen all.

Die Hauptfundstätte des irländischen Pflanzen ist bei Kiltorkan, nahe bei Ballyhale. in der Pfarrei Knocktopher. Die Pflanzen liegen hier in einem hellgelben, sehr feinkörnigen Sandstein, so dass er wie ein hellgelber Thon anssieht. Sle sind sehr gut erhalten und heben sich zum Theil durch 'ihre schwaye Farbe seh" schön von dem hellen Gestein ab. Dieser Sandstein rulst umnittelbar anf dem Old Red, der keine Versteinerungen (nithält. Auf den Sandstein folgen nacl Oben:

a) ein dunkelfarbiger Schiefer, der als Kindenschiefer (Carboniferous Slate) bezeichnet wirl und

b) der bergkalk:*); auf welchen, zwa nicht in Kiltorkan, abej in andern Theilen Süd-Irlands, eine Kohlenbildung folgt, welche Jukes zum Mittel-Carbon (coal measures) brarhte, die inclessen viel eher zmu Culm gehörtt, da sie viele Posidonomya becheri enthält.

Der Kohlenschiefer hat bej Kiltorkan eine geringe Mächtigkeit (etwa 150 Fuss), nimnt aber gegen West hin zu und enthält in den untern Lagern Zwischenlager von Gries, welehen dukes als Coomhola-Grit bezeichnet hat. In dem Kohlenschicfer und dem Gries kommt eine reiche marine Fauna vor: Es hat Herr Baily, Palaenutolog der geological survey von Inland, dieselbe bearbeitet and ein Verzeichniss veröflentlicht ***

Ton den genatuer bestimmten 47 Arten wurden folgende anch im Bergkalk lolands gefurclen:

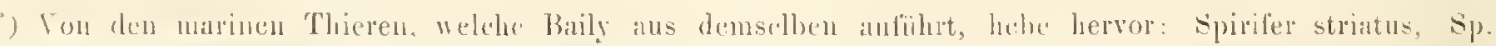
bisulcatus, P'roductus gigantens. Pr. punctatus, Pr. plieatilis, Frnestella antiçua, dir anch im Bergkalk der bären husel naclegewiesen sind.

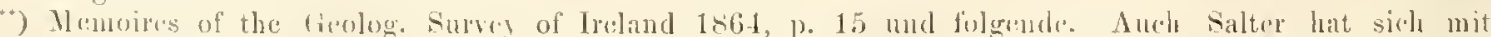

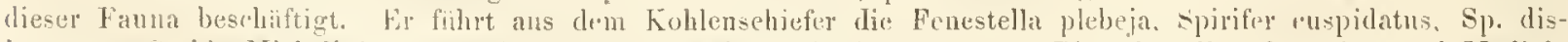
junctus: Orthis Midudini, streptorlynehns crenistria, Athyris syuamosa, Rhynchonella plenrodon mud MIadiola Maeastani an; aus dem Coombola-Grit Rhynchonella pleurodon, Spiriter disjunctus (Sp. Vorneuilii Murelr.) und

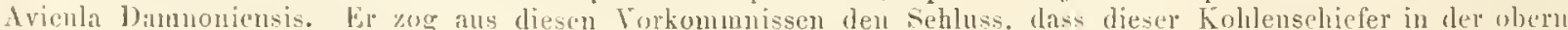

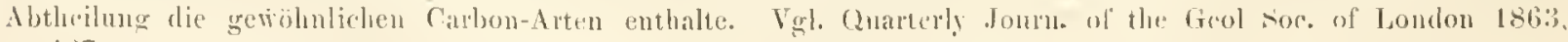
p. $48 \pi$. 


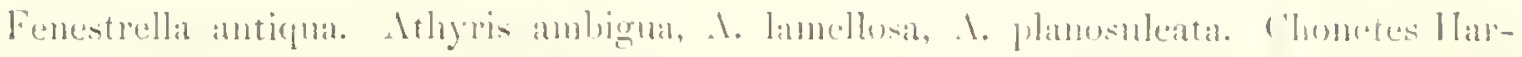

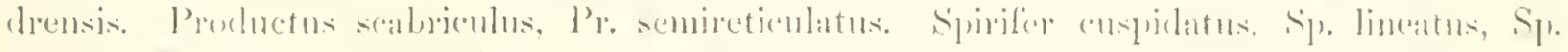

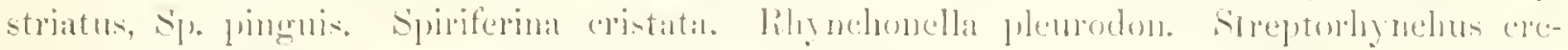

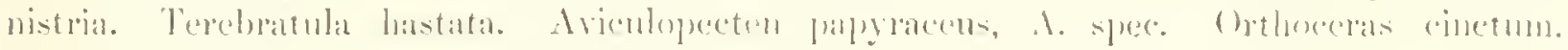

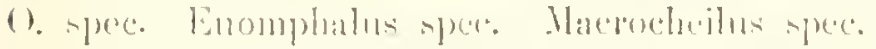

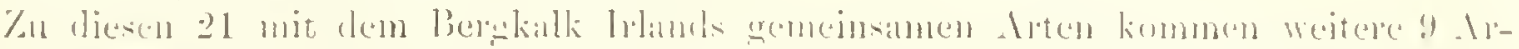

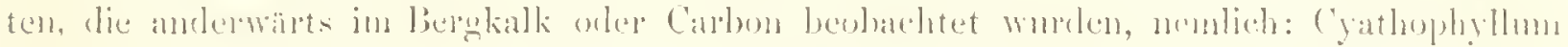

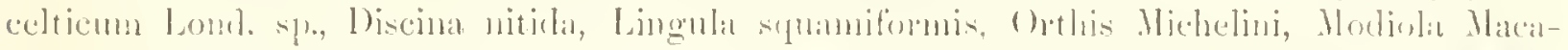

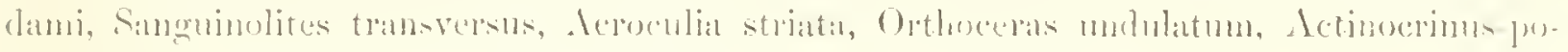
bydactyluk.

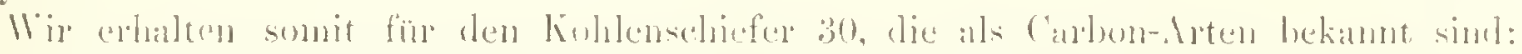

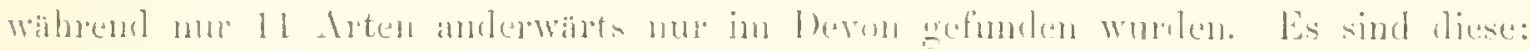

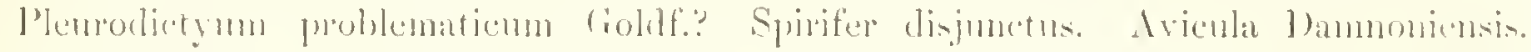

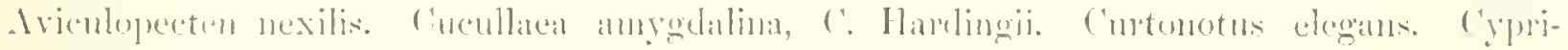

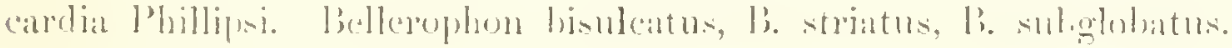

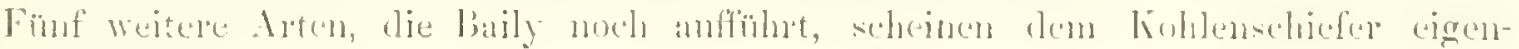
thïmlich 20 s.ims.

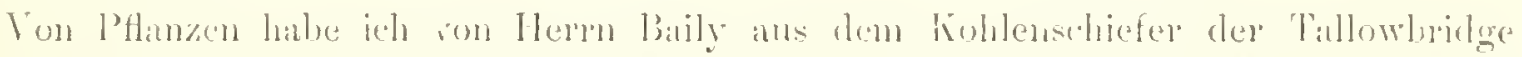

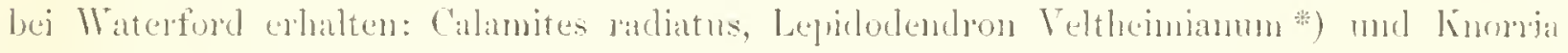

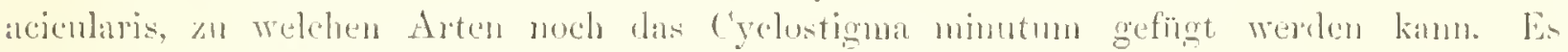

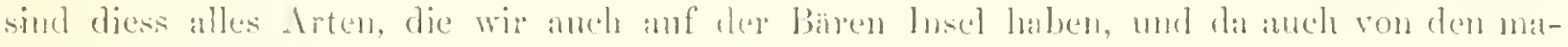

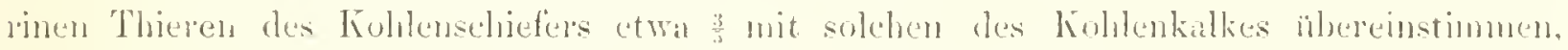
kann er nirht rum Ievon gehören, nondern muss in die untere Abtheilnng des Carbon gebracht werden. Noch weiter geht freilich dukes, wedeher zu zeigen suchte, dars er mur eine Facies des Bergkalkes sei. Er schliesst diess namentled ans dem Umstand, dass der

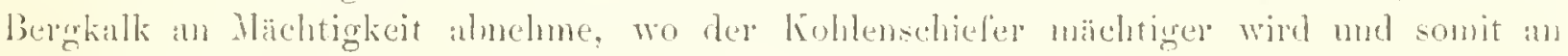

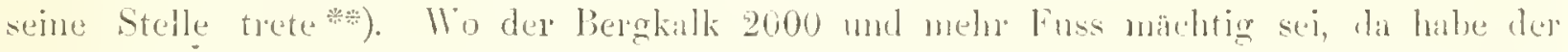

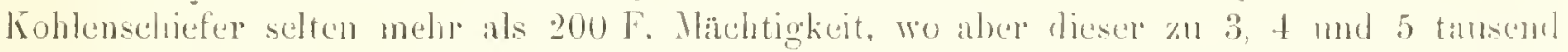
Fuss anschwelle, da liege niemals bergkalk anf demathen, somien mu hier und da Kolt-

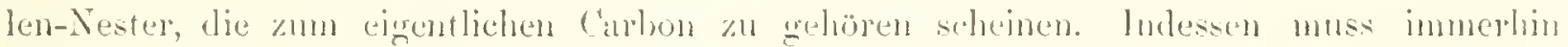
der Kohlensthiufer an allen Stellen, wo er unter dem Bergkalk liegrt, efwas älter sein als dieser mol darf ron domselleen untersehieden weselen, da er mancle devonische Arten enthailt, welehe nicht bis in den liergkalk linanfledelent.

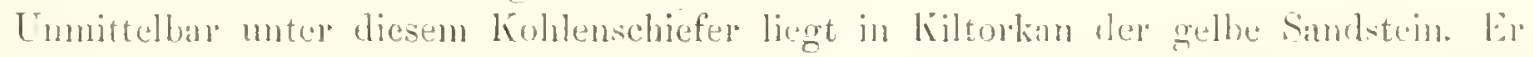
ist wenigg mähtig und bestelit ans vier Lagern, die zmm Theil in Platten sich spalten

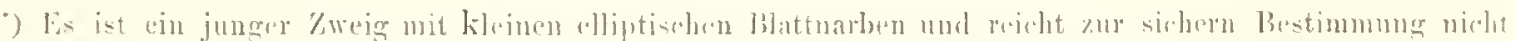

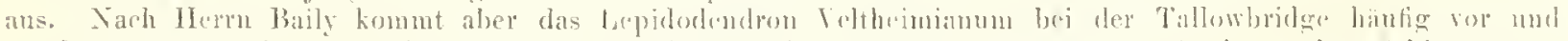

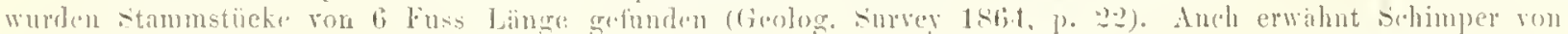

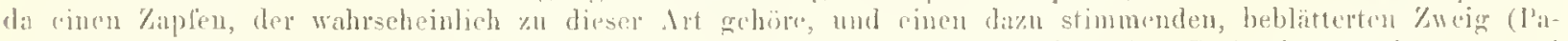
leontol. Teget. Il, p. bif). Prol'. Haughton lihit von der Tallowbridge stigmaria, Cyclostigma minutmu und

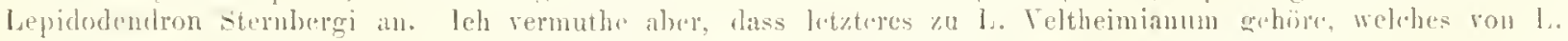
stembergi schwer mol in schlecht erbaltenen lixamplaren kamm $\%$ nuterscheiden int.

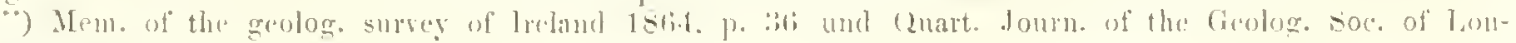

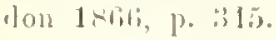


lassen. Es sind bis jetzt von dieser Stelle folgende Pflumen-Arten uns bekannt geworden $*$ :

1. Culamites raliutus Brgn. Die grossen Stannmstücke gelnören theils zur gewöhnlichen Form nit ochmalen Furchen, theils aher zom C. laticostatus Ett. Anch die Form mit erweiterten furchen kommt vor.

2. Cyclustigma Filtorliense Hatught. Es ist diess eine der häufigsten Arten, von welcher zahlreiche nud grosse Stanmstücke mir zukanen. Die äussere linde ist von zalılreichen, dicht stehenden Rumzehn durchzogen; die imnere Rinde dagregen ist glatt (C. Griftithi $\operatorname{Hght} t$ ).

3. Cyclostigme mimutum IIanght. Ist ebenfalls häufig.

4. Lepidostrobus Bailyunus Schinp. Ist wohl der Fruclitzapfen von Cyclostigma.

5. Lepidmendron Teltheimiamun Sternb. Ich erhelt einen jumgen Zweig.

6. Stigmaria ficrides Sternb., die Form nit den grosenen, zientich diclit beisammen stelienden Karben; daneben die breiten, grossen Zasem.

7. Palneopteris hilhernica Ford). sp. Ist häufig und tritt in prachtiollen Wedeln anf, die his 2 Fuss Breite halyen. Baily hat einen Wectel von vier Fuss Länge aufgefinde:ı.

8. Symenopteris Houleri Baily. Diese Art kenne num ans der von Baily *) gregebenen Abbildung. Sie ist nit spll. Schinperi nahe verwandt und gehört in dieselbe Gruppe der grosseil Gattung.

9. Sphenopteris Humphiesiunu biaily.

In denselben gelben Sandstein ron Kiltorkan wurden anch Thierverstcinerungen gefunden, nemlich eine grosse T'uichnuschel (Anodonta Jukesii Forb.) und mehrere Kruster, nemlieh Pterygotus hibernicus, Belinnrus? Kiltorken-is und Proricaris Hae Henrici, von welchen die zwei ersten carbonischen, der Proricuris aber silurischen Formen am ahnlichsten sind. Dazu kommen Schuppen von Fischen, von denen die Gattung Coccostens erkannt wurde****); aber anch die Gattungen Asterolepis, Bothriolepis und Pterichthys sind, nach Baily, wahrscheinlich repracsentirt, Gattungen die im Old lied Schottlands zu Hanse sind.

Diese gellen Suntsteine sind wahrscheinlich eine Süsswasserbildmag, wofür schon die grossen, dunnschaligen Anodonten sprechen; ihr Vorkonmen nud Verbreitung ist daher melır local als das der Kohlenschiefer, der mancherorts mmittelbar ant dem Old Red

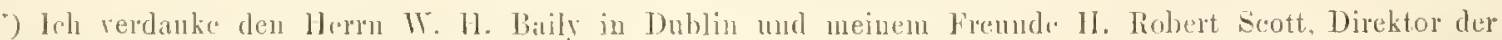
meteorologieal oftice in London, dic Zusendung einer sehr werthollen Sannlung von Kiltorkan-Pfianzen, anf welche ich obige" Holsammenstellung griunden konute.

*) Vgl. Explanations to alcompany shects 147 and 1.56 of the maps of the Geolog. Survey of treland Dublin 1861, p. 15. Die Spluenopteris sp. (Baily: memoires of the Geolog. Survey of Jreland 186t, p. 19, F. 1)

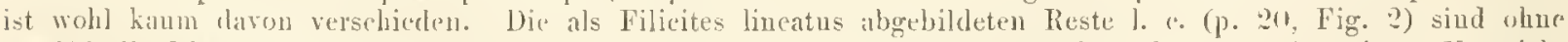
Zweitel die Blattspind.lu vou Faln und gehören wohl zu Sphenopteris. Ethgeridge führt in seinem Ver\%eichniss (Cuart. Jomrn. 1867, p. 616i) den Triehomanites adnascens Lind. sp. aus dem Ober-Deron auf. Es ist hiel wohl auch del gelbr sinndstein lrlands gemeint. Doch wäre zu Wünschen grewesen, dass el die Quelle, woraut el diese Angabe stiit\%, genannt hätte. Es ist dieser Farn bis jetzt nur aus dem Mittel-Carbon vou Whitehaven bekannt (cl. Liud. Tos\%. Flora II, t. 100). J)er Filicites rultranensis Haught. (Jouru, geol. soc.

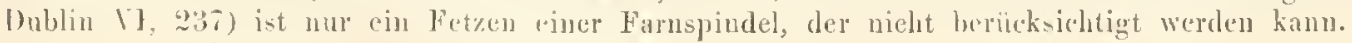

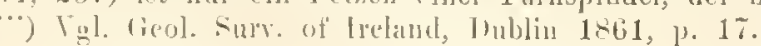




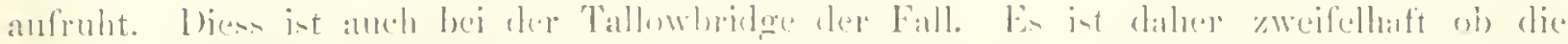

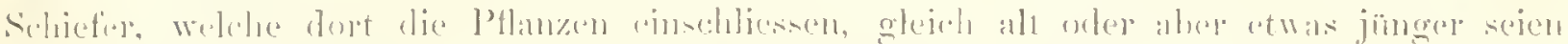

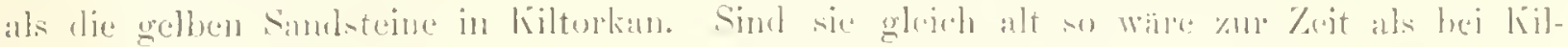

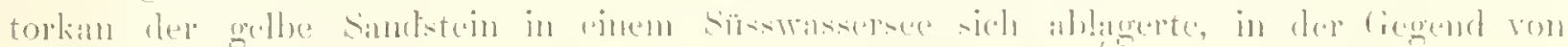

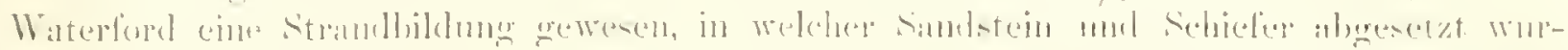

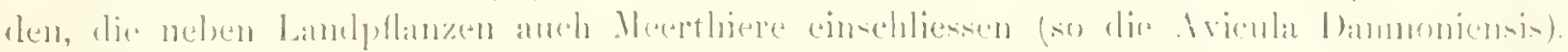

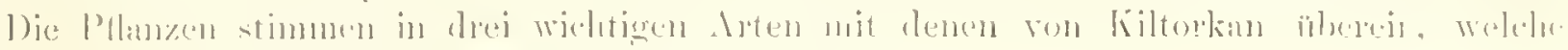

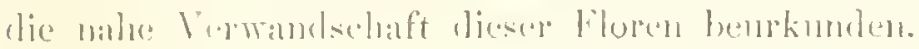

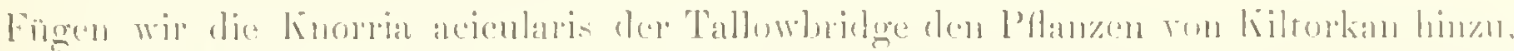

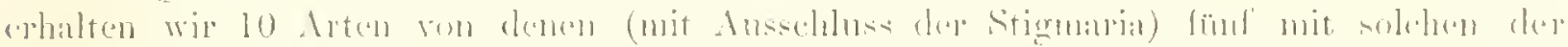

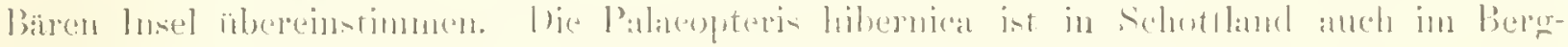

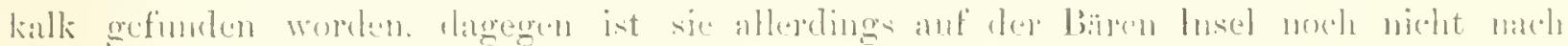

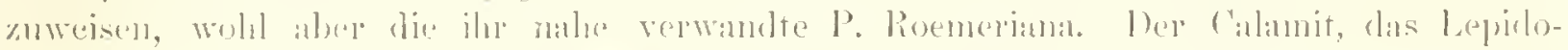

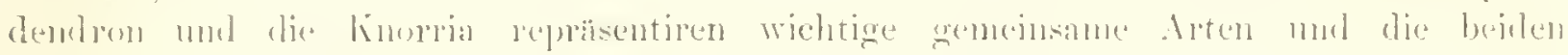

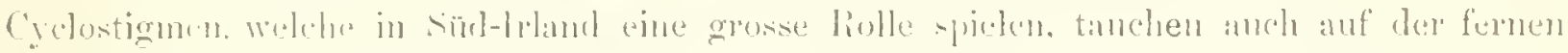

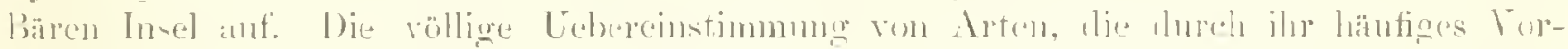

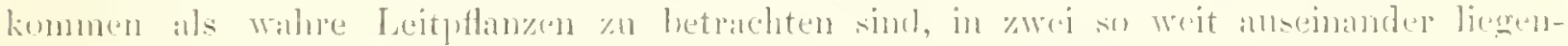

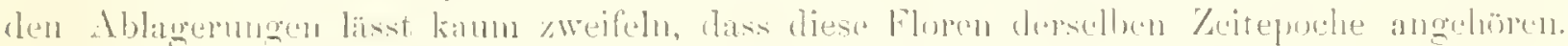

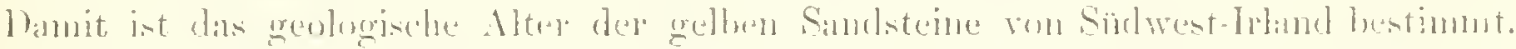

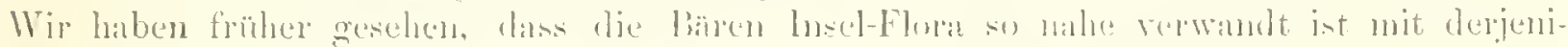

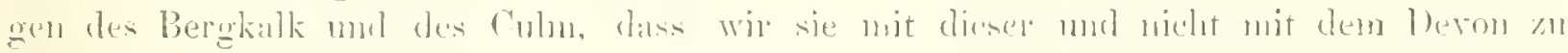

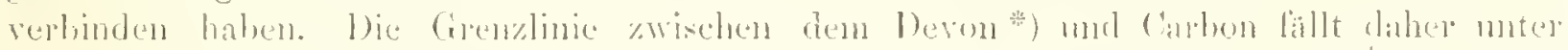

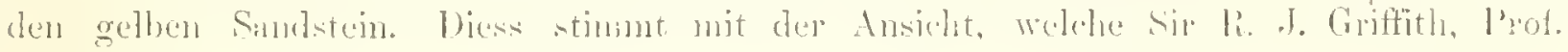

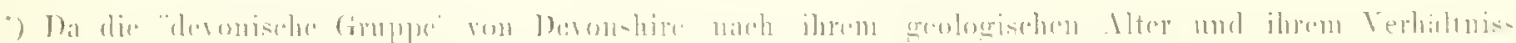

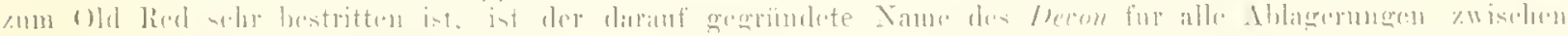

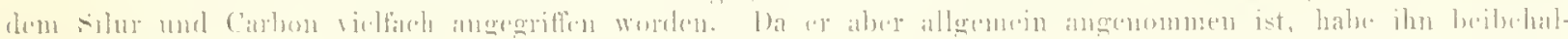

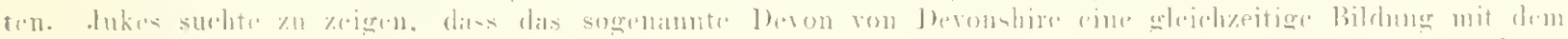

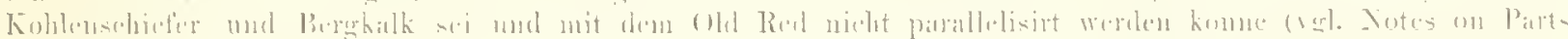

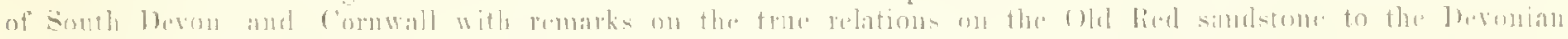

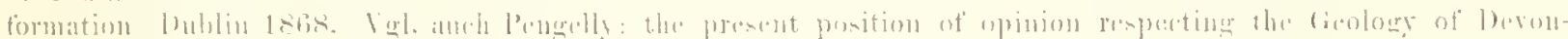

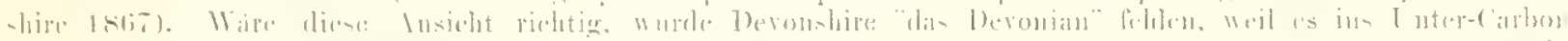

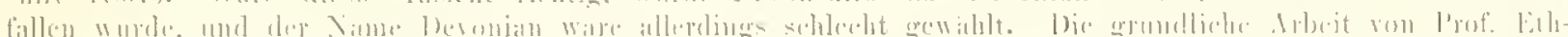

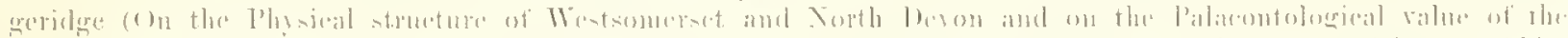

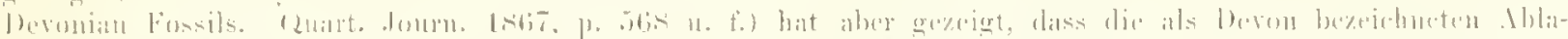

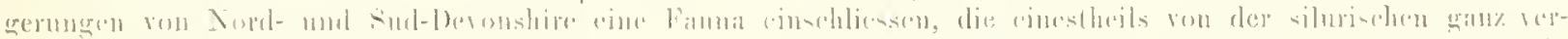

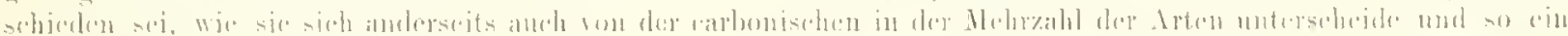

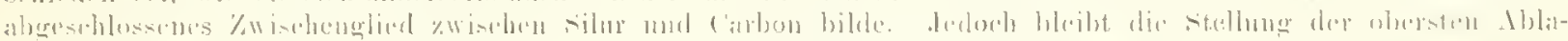

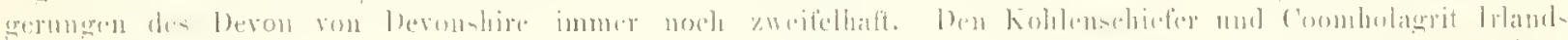

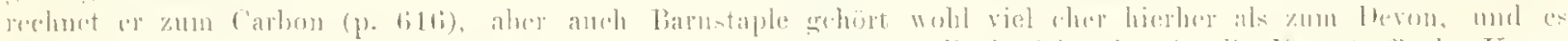

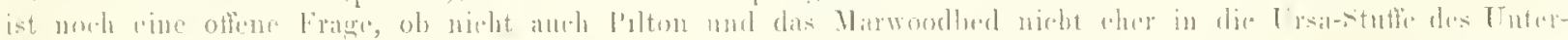

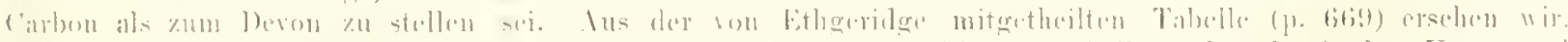

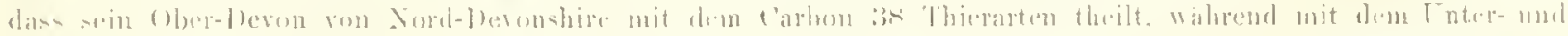

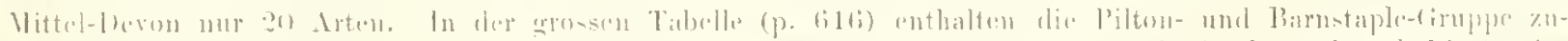

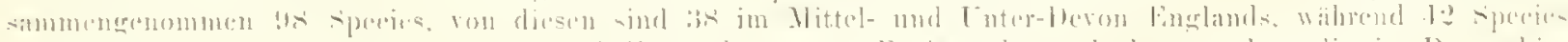

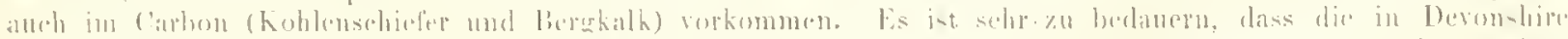

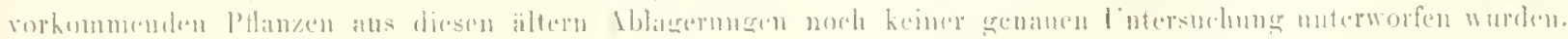

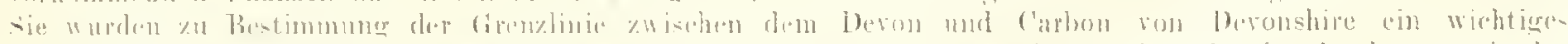

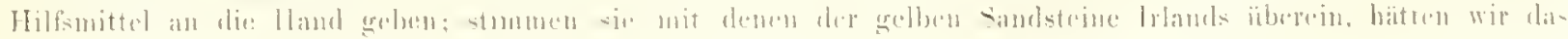

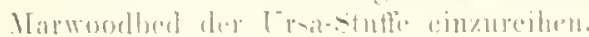




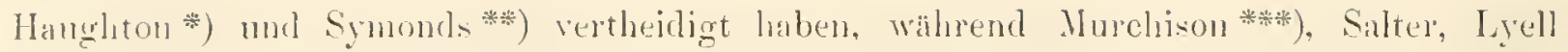
und äberhant die meisten englischen Geologen den gelben Sandstein lrands zmun Oberbevon stellen und die Grenzline zwischen renselben und den liohlenschiefer oder gar zwischen den liolnlenschiefer und den lierokalk legen. Dal der. Old lied Irlands keinerlei I'ersteinermugen enthält, herubt die Amnahme, dass der gelbe Sandstein zum Old lied gehöre, nur anf lithologischen lleskmalen und anf der Angahe dass die lische ron Kiltorkan denen des OHd Red ron Schottland ahnlich selsen. Diese Fischreste Irlands bestehen aber nur aus einzelnen Schuppen und einigen Zailnen, und so lange keine Arten als mit denen des Old lied von Schottland sieher übereinstimmend nacherewiesen sind, kömen diese Fisehreste keineswegs geren die Stellung sprechen, wekhe die Pflanmen den gelben Sundstein ron Kiltorkan anweisen. Sie sagen uns nur, dass manche Fischenttungen, die man bislang als dem Old hed ausschliesslich angehörend betrachtet hat, bis in die Urar-Stuffe des Lnter-Carbon hinanfeichen, hier aber wahrecheinlich in andern Arten nuftreten, als im (1)d Red Schottlands. Dasselbe hahen wir ja bei den Pflanzen, und von den niedern Thieren reichen nicht mur viele Gattungen sondern sellst zahlreiche Arten vom Devon bis in den lierokalk hinauf. - Aber, sagt Salter, es sei nicht möglich den gelben Sandstein rom Old Red zu tremen, weil en die obue l'arthie dieser formation selbst sej, die hier ihre Farbe geändert habe $\dagger$ ). Also soll hier die ähnliche Gesteinsbeschaffenheit. entscheiden, ein Merkmal anf das in der That kejn Werth zu lecren, wo so gewichtige palaeontolowisehe Crinule dagegen sprechen. Im Uebrigen ist es wahrscheinlich, dass ein Theil des rothen Sandsteines noch zur Ursa-Stuffe gehört und die Grenzlinie zwischen Carbon mel Jevon an manchen Orten im Old Red zu stichen ist. Symonds giebt die Old Red Conglomerate für Süd-Irland als eine vortreffliche Grenzlinie an und sagt, dass das, was man in England so nemne, die Basis des Carbon bilden müsse t†).

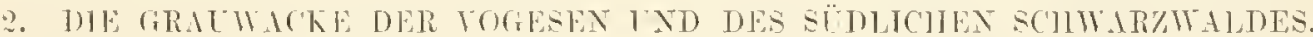

Da die Lagepungsterlä̈tnisse über das Mlter der Granwake der Vogesen keinen Anfschtuss gehen, sind dis Pflanzen, welche sie einschliessen, allein massgebend. Es konmen dieselben ans den Steinbrüchen von Thann, Bitschwiller und Bourbach. Die von Herm Prof. Schimper vortefflich beschrebenen und abgebildeten Arten sind fft): Cala-

-) Tgl. On the evidenee afforded by Fissil Plants, ats to the Boundary Line between the Devonian and

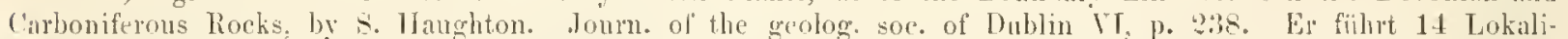
täten Sird-Jrlands anf, an denen der gelbe Sandstein rorkommt; an neht derselben giebt er die Cyclostignu'u (nls Sigillaria dichotoma) an. An mehrerm kommen in demselben aneh marine Thiere ror, so dass er hier und da eine strandbildung zu sein seheint. Bui Roughtes Bridge sei di“ Fenestella antiqua bei dem Cyclostigma, bei Cnltra die Ilachola Maeadami, Kellia gregaria und lloloptrchius l'ortloki. Die Stembergia approximata. welche er anlïhrt, diurfte wohl zum Calamites radiatus gehören ( $r g l$. unsere Taf. I Fig. 8).

*) On the hase of Carbonif. Deposit. Ldiuburgh new philosophie Journ. New Series 7, p. '2:2.

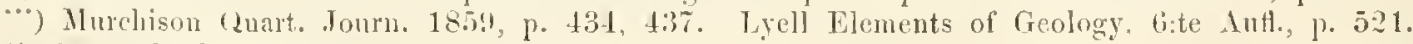

f) (2uaterly Jomm. 186:3, p. 487.

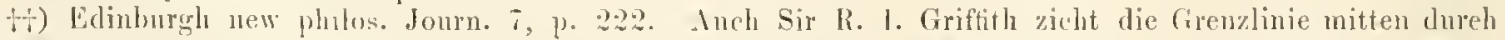
den ohol Red, weleher stellenwre cine mugehenre Michtigkeit hat. Wie trïgerisch die lithologischen Merkmale: sind \%cigen die Reptilien dinschliessenden Gesteine ron Elgin, die man linge Keit zum Old Red rechuetc. währenct es sich jutzt heransstellt, dass sic viel eler zmm Trias gehören.

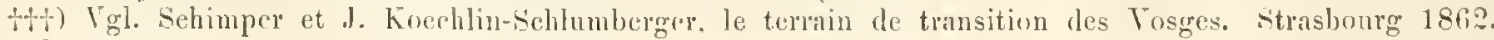
Das Lepidodendron acuminatum gehört \% 1. Teltheinianum. Das Ancistrophylhum stigmariaeforme Goepp. 
mites radiatus Br., Cardiopteris polymorpha, C. fromlosa, Triphyllopteris collombiama,

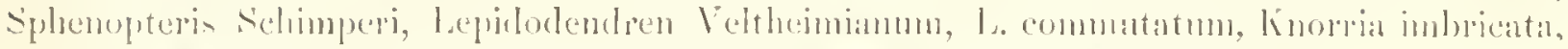

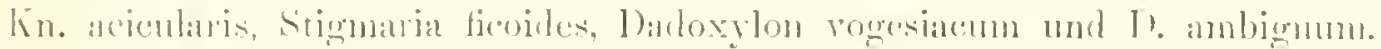

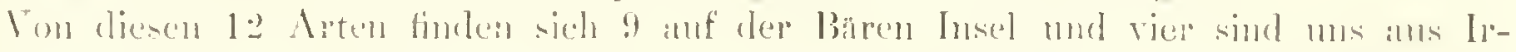

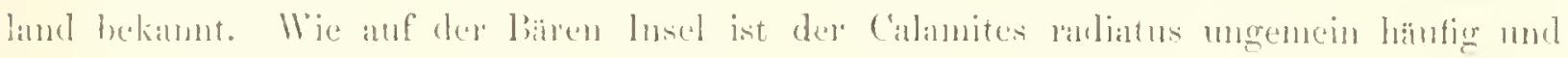

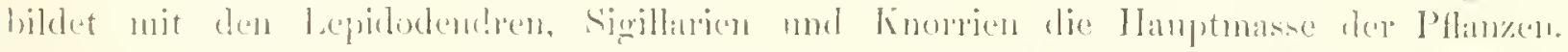

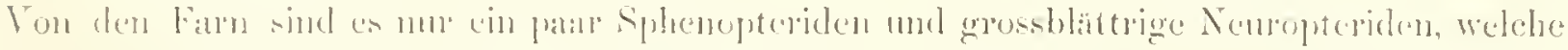

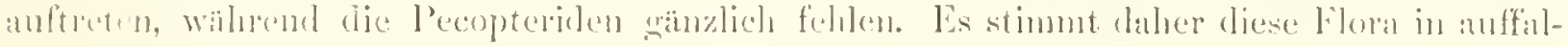

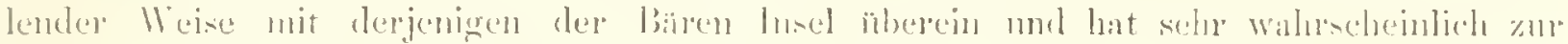

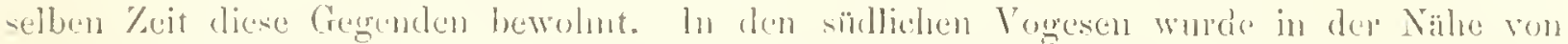

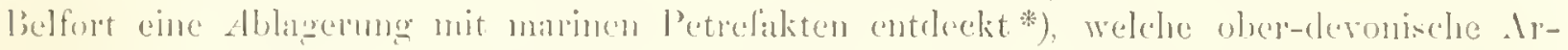

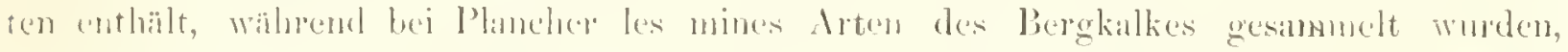

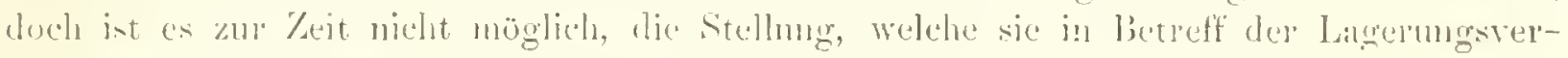

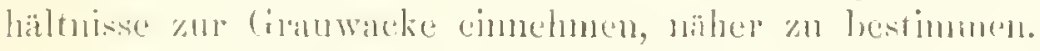

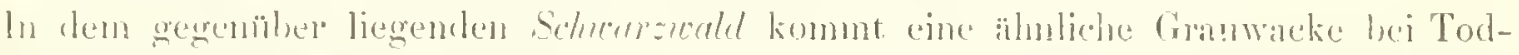

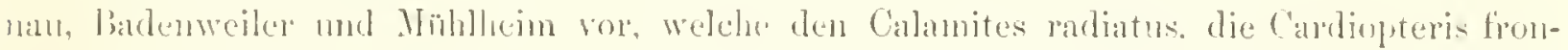

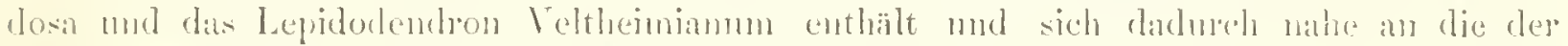
Vogesen anschliesent, wogegen dice Granwake des linzigthales (mit Calamites Voltzii, Hymenophyllites dissectus, ('yclopteris flabellata und Pecopteris anpera) zum obersten (ulm

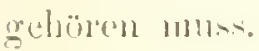

\section{$\therefore$ NIETER-BOH LUNAIIS.}

In östlichen Frankreich tritt die Ursi-Stuffe wahrscheinlich in Nieder-bonlonmais anf. Dort ersedeinen mach Godwin Austen unter den liergkalk eine Reile von Seliefer- und Sindsteinschichten, welche viele Calamiten und Fan'n cuthalten, manche aber anch viele marine Thiese geliefert haben, unter denen wir den Spinfer disjunctus nucl lihynchonella pleurodon erblicken. Nach Salter findet sich nichts in der ganzen Section,

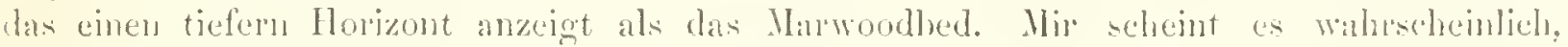

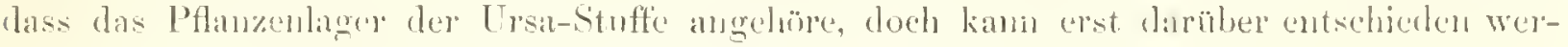
den, wemn die Pflanzen eine genamere bestimnumg erhalten haben.

\section{DIE TERAETLH SOHEFER TON AACHEX.}

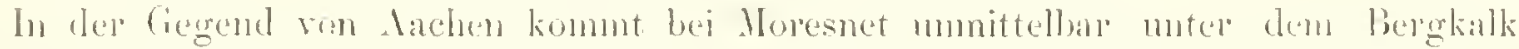
(in Scliefer vor, welcher anf dem Eifelkalk anfuht. Derselhe lieferte die Palacopteris Roeneriana und Spirifer disjunctus Sow. (S. Ternenlii Mnreh.) und wurde von Iterm von

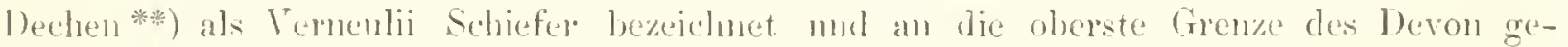
stellt. Ha aber dieser Spirifer in Irland anch in Kohlenseliefer rorkommt, somit ans dem

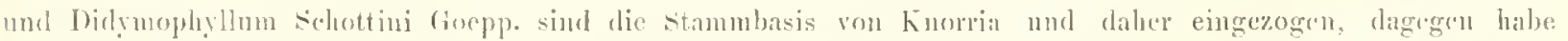

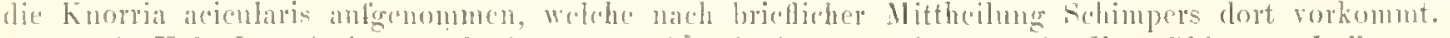

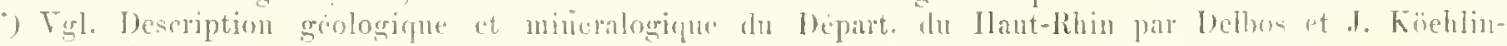
sorlilumherget. Mulhouse. I, p. 41, II, Mis.

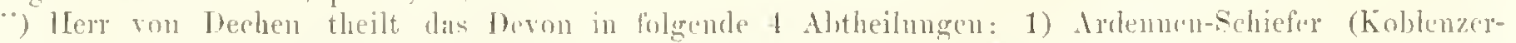

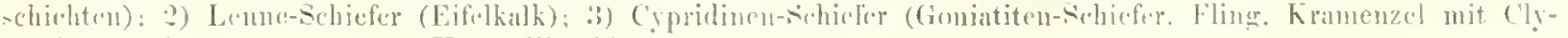

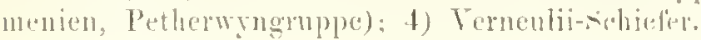


Devon ins Unter-farbon hinaufrejcht und das Farnkraut unter den Pflanzen der Baren Insel uns begegnet, dïrfen wir wohl diesen Vernenlii-Schiefer Aachons der Lrsa-Stuffe einreihen und die Grenzlinie nm so mehr unter denselben legen, da er mit dem darunter liegenden Eifelkalk eine discordante Lagernng zeigt.

\section{MILRKL.}

In Amerika begegnet uns die Bären lnsel-Stuffe in St. John in Nu Brannschweig (Canada). Da Dawson, der grïndlichste Kemer der canadisehen fossilen Flora, dicse wichtige Lokalitat zom Ober-Devon rechnet, habe ich neeine Ansicht naher zu begrinnden.

Nach Dawson liegen die Pflanzen in dunkdfarbigen Schiefer und grauem Sandstein. welche eine grosse lithologische Achnliehkeit mit denen des Carbon haben. Sic bilden seine Little River-Gruppe, welche stellenweise eine Ilächtigkeit von 5150 Fuss hat. Sie ist in Niu Braunschweig bedeckt von dunkelpothen mol grünlichen Sehefern mud Sandsteinen ron 1850 Fnss Mächtigkeit, auf welche dis Kohlensystem folge. Unter der die Pffänzen enthaltenden Little liver-Gruppe liegen röthliche Conglomerate und rerschiedenfarbige Schiefer mol Sandsteine. Sie Jilden Dawsons Bloombury-Gmper von 2500 Fuss Mächtigkejt, welche dem Sihnr auflagert.

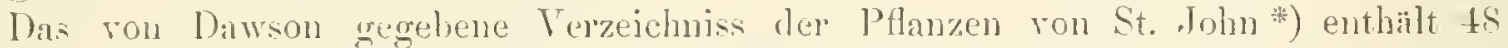
Arten. Vou diesen sind 37 Arten nicht anderwärts gefunden worden, nem sind alls dem Carbon und rleei ans dem Devon ${ }^{*}$ ) hekamnt.

!)je M[ell'zahl der mit andern Lokalitaten gemeinsamen Arten komnt also dem Carbon und nicht dem bevon zu und es ist seh. beachtungswerth, dass zwei dieser DevonArten nur in eingen wenigen Blattfetzen gefunden wurden, deren Dentung noch angezweifelt werden kann, während unter den Carbon-Arten dic Calaniten häufiz sind.

1)ie Carbon-Aiten ron St. John sind:

Calanites radiatus Br., C. camnaeformis Br., Asterophyllites longifolius Bro? Palaeopteris Boeksehii Goepp. sp., Sphenopteris Hoenninghansii Br., Hymenophyllites obtusilobus Goepp), H. Gersdorfii Coepps, Pecopteris obsema Lesq.? und Sigillaria ficoides Stlo. (dieselbe Forn wie in Carbon).

lassen wir die zwei Arten, deren Bestimmung noch nicht ganz gevichert ist, bej Seite, erhalten wir sieben Arten, die im Unter-Carbon Enropas nachgewiesen sind und unter diesen eine eigentliche Leitpflanze des Lnter-Cirbon, den Calamites radiatus, der in

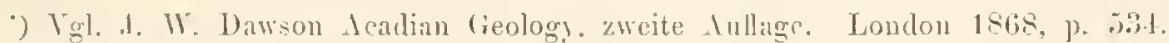

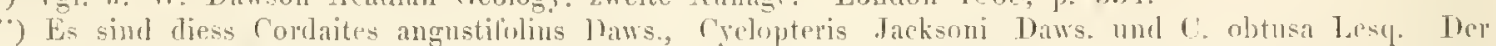

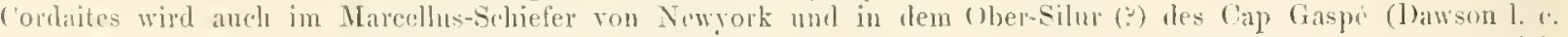

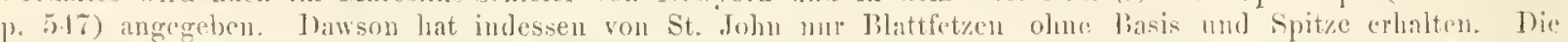

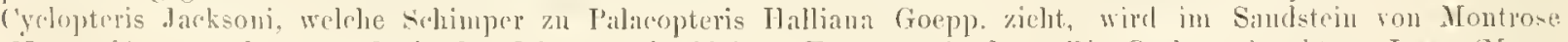
(Xewrork) angegaben, wurde in St. John nur in kleinen Fetzen gelunden. Die Cyelopteris obtusa Lesq. (Nocergremathia) wirl con schimper (Palcontolog. viget. 1, p. 476) \%u Palaropteris liberuica ge\%ngen, dorh scheint sis:

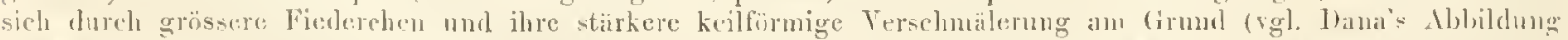

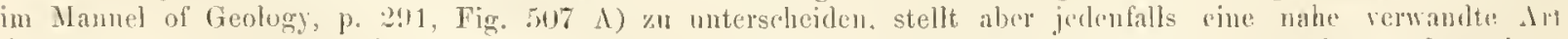

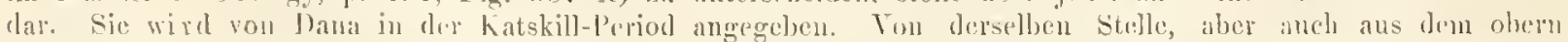
Theil der Ilamilton-Gruppe mal som Cap Gaspe wird das Lepidodendron Gaspianum 1)aw, angefïlurt. Fïr dir

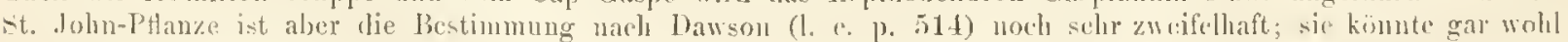

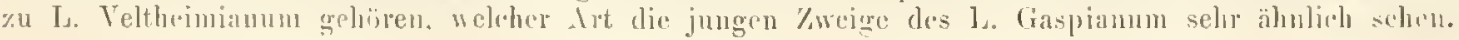




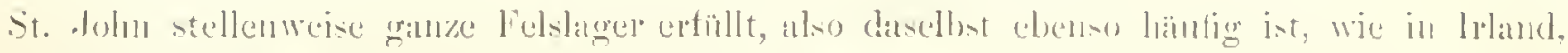

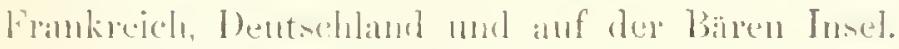

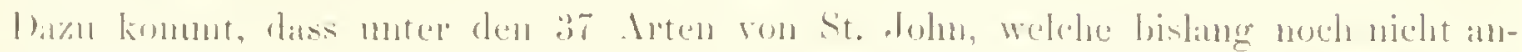

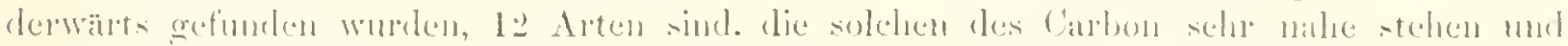

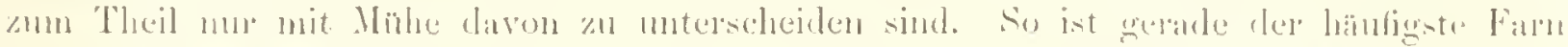

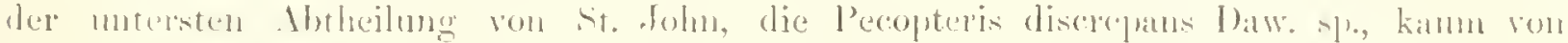

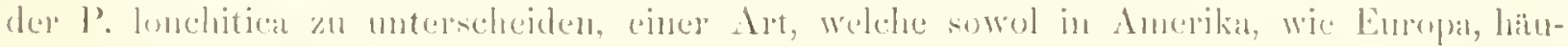

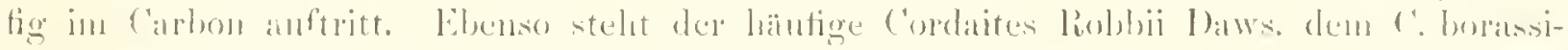

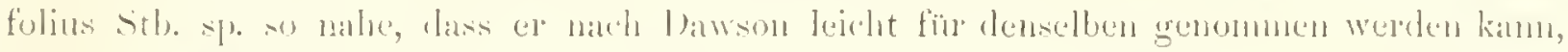

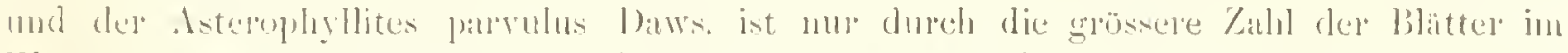

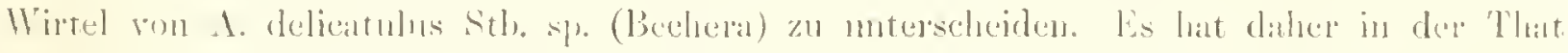

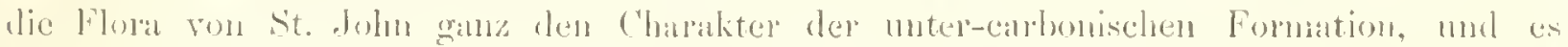
kamm sich sogar fragen, ol, sie nieht der ( sie mit ihn fünf Arten theilt und die Pecopteriden hier wie im C'un aluftreten. Ihr nii-

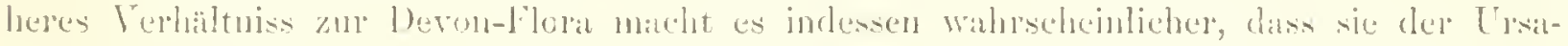

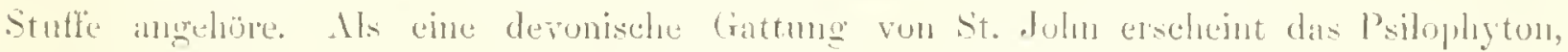
welehes indessen hies in zwei cigenthïmlichen Arten auftritt, die mus sagen, dass diese (rattung, welele bislang noch nicht in Europrat leobachtet wurde, in Anerika ron InterDeron bis in die nuterste Stuffe des Unter-Carbon hinanfreiche.

Dice Lagermugsverhältuisse der St. John-Sehichten sind nicht genen die Stellung,

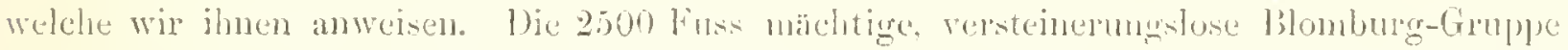

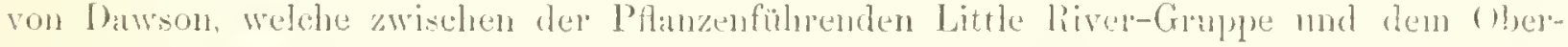

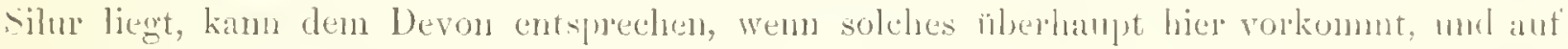
die versteinemngslose Mispeek-Gruppe, wetehe die Litte River-Gruple deckt, folgt in sit. Iohn de lerift.

Die wenigen Thierversteinenungen, die bis jetzt in sto fohn entdeckt wuden. getern keinen entecheidenden Anfschluss, sprechen aber eher für das Canbon als beren. Eine

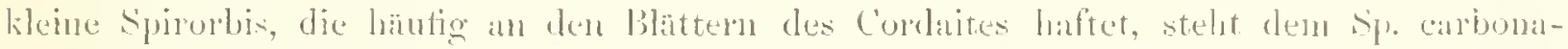

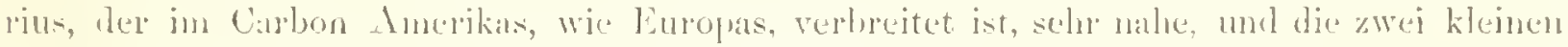
Krebse (Eurypterus pulicaris Salt. nud Amphipeltio paladoxus Salt.) gehören zn Gattmaen, von denen die erstere im ('arbon, wie l)evon vorkommt. Ton besonderenn futeresoe sind die Flüged ron vier. Insekten-Arten (P'latephemera antiqua Seud., Ilomothetur fosilis Send., Lithentomm 1lartii Semd. nnd Xenonemat antiquorum Semd.), welehe nach sender zu den Neurepteren gehören und nit den Epheneriden mul Sialiden verwandt sind. Sie

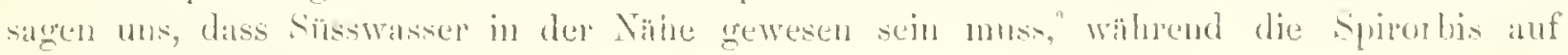
eine brackwisserbildung weirt.

\section{b. I)E PIRRI INSELN.}

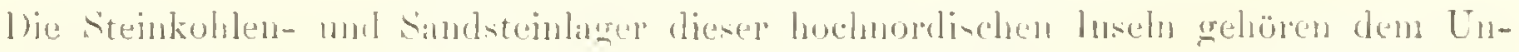

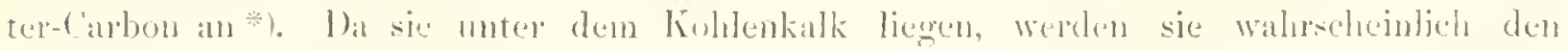

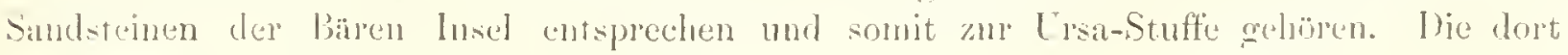


gesanmelten fossilen Pflanzen sind leider grossentleils verloren gegangen mud habe nur wenige und molentliche Reste, welche M'Clintock nach Dublin gebracht hat, zm. Untersuchung erhalten können. Unter denselben ist die Ĺnorria acicularis Gp. von der ItelvilleInsel, welche wenigstens einen Anknüpfungspunkt an die Flora der Bären Insel bildet. Die Schizopteris Melvillensis gehört zo den Cyelopteris-artigen Farn nnd ist vielleicht ein Blattfetzen einer Palacopteris oder Cardiopteris, da sie ähnliche zarte und dicht stehende Langrnerven besitzt. Die nuter Noeggerathia beschriebenen nud mit Cordaites angustifolius Dars. verwandten Blattreste sehejnen der Melville Insel eigenthümlich zu sein, und auch von den beiden Naldhölzern (Pinus Bathursti und Thnites Parryuns) ist anf der Bären Insel noch keine Spur gefunden worden.

Ans dem arctischen Asien fellen uns noch alle Nachrichten über das Vorkommen der Stcinkohlenbildung. Da indessen an der Lena, nur sechs Breitengrade vom aretischen Ḱreis entfernt, Kohlenlager mit dem Calamites cilmmeformis entdeckt wurden, lïsst diess hoffen, dass anch dort eine ähnliche unter-carbonische Flora zun Vorschein kommen werde, wenn ihr die nöthige Sorgfalt zugewendet wird.

Stellen wir sämmtliche bis jetzt in der Ursa-Stuffe des Unter-Carbon gefundenen Pflanzen zusammen erhalten wir das folgende Verzeichniss.

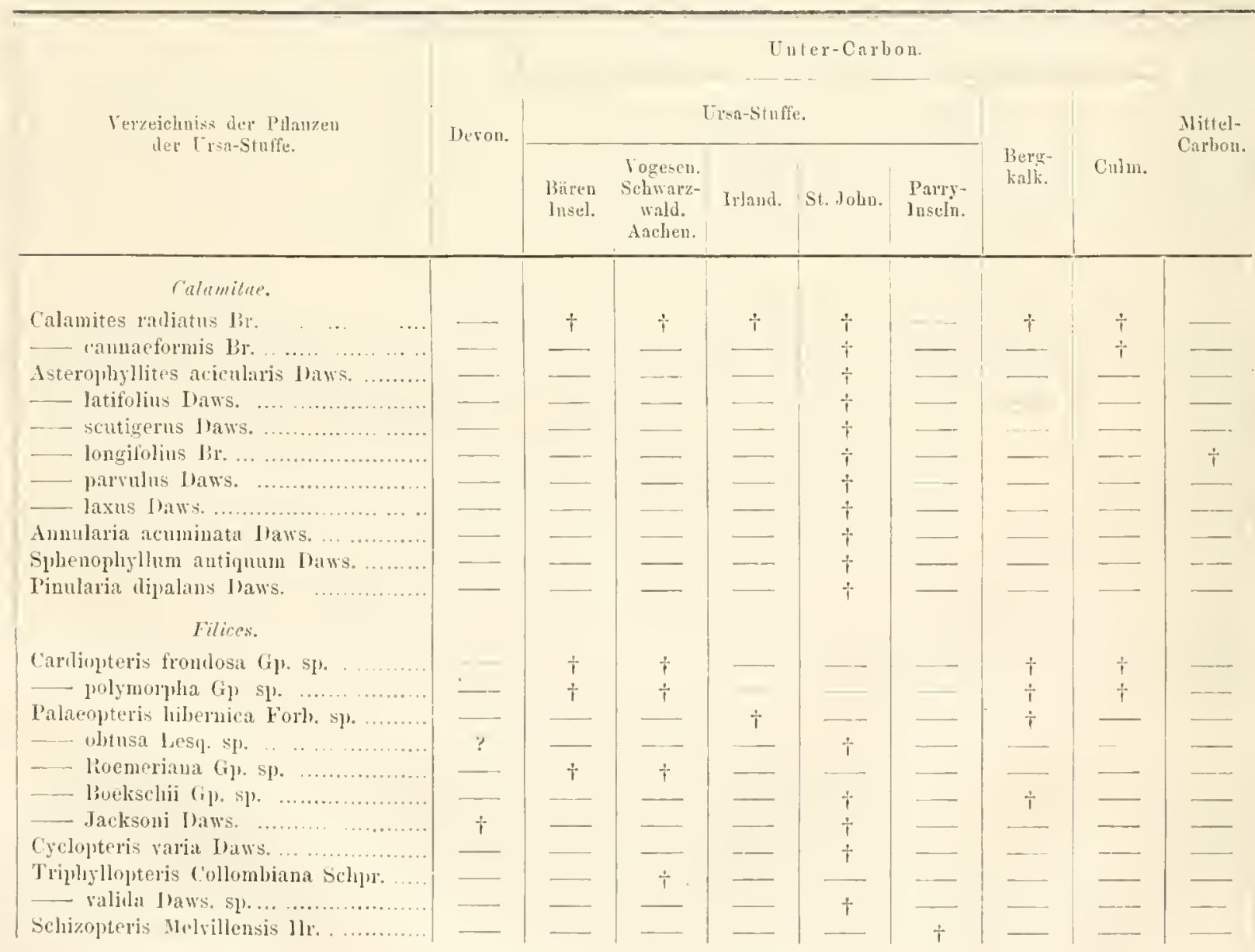


I neter-ition.

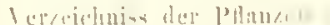

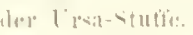

1)evoln.

\begin{tabular}{|c|c|c|c|c|c|c|}
\hline $\begin{array}{l}\text { Batren } \\
\text { lnsel. }\end{array}$ & $\begin{array}{l}\text { Vogesen. } \\
\text { Schwar\%- } \\
\text { walk, } \\
\text { Aathen. }\end{array}$ & Irland. & Sit. Johnt. & 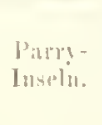 & $\begin{array}{l}\text { bereg- } \\
\text { kallk. }\end{array}$ & Culm. \\
\hline
\end{tabular}

Nenropteris polymorphat liaws.

1) iwsoni llart.

(1)illaial [

splienopteris knomperi (ip.

IJokkeri Baily

Jlorninghalusii lil.

maryuatala Itaws.

- Halttii liaws.

jilasi lbans:

ohtusilulat (romelu.

routilobal laus.

Hymenonglyllitus firmlertio (ip. sulifinatus Jans.

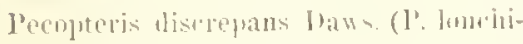
tica lir. :)

inerens baws.

obscular leempl.?

sploulata Taw,

pretiosa Hartt.

- Perleri Jaws.

\section{Sirleyints.}

Tycopolites Matthewi Ilans.

Lepidodenhon Teltheimianum sthes.

commutatum sichpr.

Wiikianum $\mathrm{Hl}^{\circ}$

farmegqamm Hr.

Lepinoplysllum lioeneri $\mathrm{Hr}$.

... ubtusin llr.

('yclostiema Kiltorkencis lloht

—_ minutun ]lught

Kunpria imbricata itlog. acionlatic Gip.

Halonia tuluroulosa lir:?

Sigillaria palpetal laws.

Stigmaria ticouble sither.

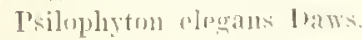
- glaturn liaws. .

Cordates lobloii lows.

_- angustilinius Jaws.

$$
\text { rimelente." }
$$

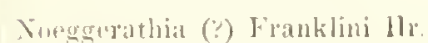
M'Tlintuki $11 \mathrm{r}$. julitis $11 \mathrm{r}$.

\section{romierents}

l'inus batlursti Ilr.

Thuites l'arramus ile

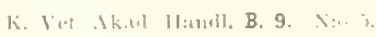


I' nter-Carbon.

Perzeichniss der Planten der. lisin-Stutio.

\begin{tabular}{|c|c|c|c|c|c|c|c|c|}
\hline Devou. & & ᄂ & 1'sa-Stufi & & & & & Mittel- \\
\hline & $\begin{array}{l}\text { Barreu } \\
\text { Insel. }\end{array}$ & $\begin{array}{c}\text { Vugesen. } \\
\text { Seliwarz- } \\
\text { wald. } \\
\text { Aachen. }\end{array}$ & Irland. & St. John. & $\begin{array}{l}\text { Parry- } \\
\text { Inseln. }\end{array}$ & $\begin{array}{l}\text { Berg- } \\
\text { kalk. }\end{array}$ & Culm. & \\
\hline
\end{tabular}

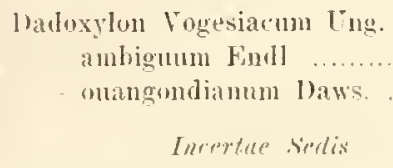

latoxylon Fogesiacum Ins. aubigunm Furl]

olangondianum l)aws.

$$
\text { Incrertue siedis }
$$

Carlincarjum punctulatrum Gij.

- $11 \sin 11 \mathrm{~m} 11 \mathrm{r}$

- Eirculare 111.

coxnutum Daws.

oblirgum lows.

('rimsii llatt.

bailevi Ilaws

Trigunocarpum lavemosun Iaw

Intholithes revonicus baws.

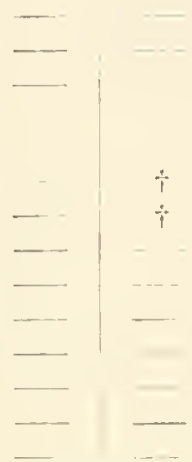

Die uns bis jetzt bekannte Flom der Crea-Stuffe umfasst demnach 76 Irten, von denen sie 3 mit dem levon theilt mul 7 mit dem llittel-Cabon; von erstem ist aber eine, von letztern sind drei Arten nach ihrer Bestimnung oder der geologischen Stellumg ihrer Fundorte noch zweifellaft. Hit dem (Iber-Carbon (dem Perm oder. Dyas) hat die UrsaStuffe kence einzige sicher bestimnte Irt geneinsan. Hit lem Bergkalk theilt sie 13 und mit dem Culm 12, mit beiden zusammen 18 . Irten. Dantunter sind gerade die hanfigsten Arten, welehe uils eigentliche Leitpflanzen zu betrachten sind. Als eine die Crsastuffe charakterisirende Gattung haben wir ('yclostigma zon nemen.

\section{HLOLA HES BERGKALKS.}

Der Bergkalk ist eine marine Bildmg mul scheint znm Theil ans Corallenriffen entstanden zu sein. Stellenweise simd aber anch Sandsteine und Schiefer, auch wohl wenig machtige Kohlenlager in deuselben gelagert, nnd in diesen kommen hier mud da Landp)thanzen vor, welche auf eine Strumlbildung hinweisen. Auch dise liohlenlager sind sehr wahrscheinlich nicht im Neer entstander, sonder's in an .leere gelegenen Niederingen. die zeitweise vom Aleer älerschwemmit worden.

Goeppert hat in seinen sehr verdienstlichen Werke über die Flon der silurischen. der devonischen und untern liohlenformation 32 Arten ans dem burgkalk und den zu diesem gezogenen Schiefern Schlesiens beschrichen; unter diesen erblicken wir 8 Arten der Bären Insel. Es zejehnet sich die schlesische bergkalkformation besonders durch seinen Rejehthum an feinblättrigen Firnkiäutern ans.

In Sachsen grehöpt das Kohlenbecken von Hainichen nud libersdorf nach den lagerungsverhälnissen einem ältern Horizont an. als die Zwickaner liohlenformation, wie diess 


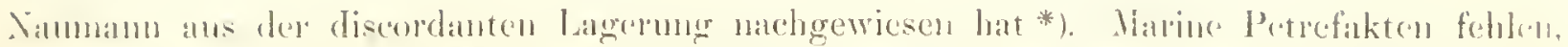

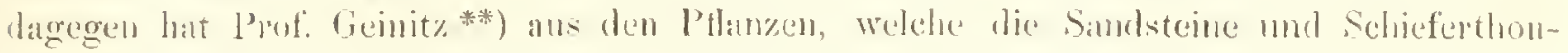

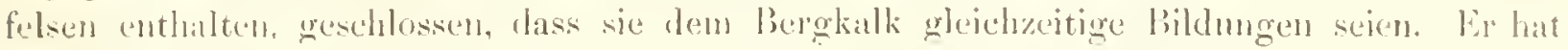

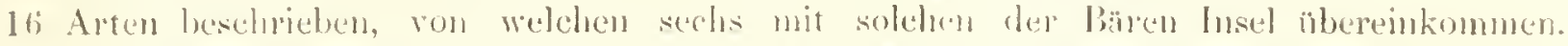

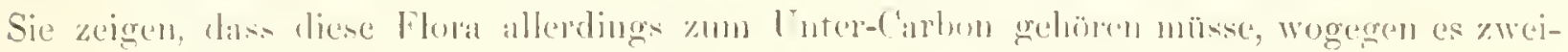

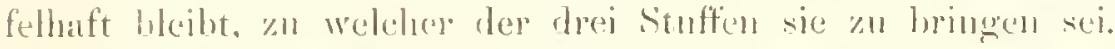

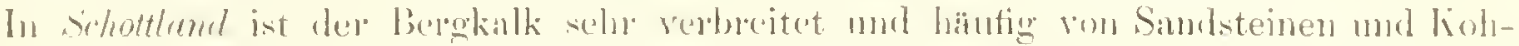

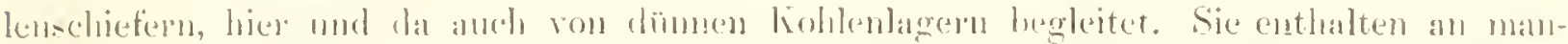

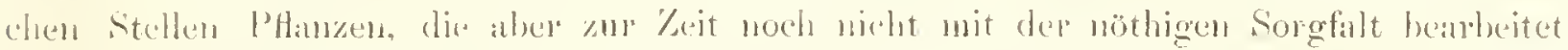

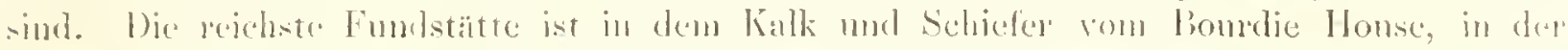

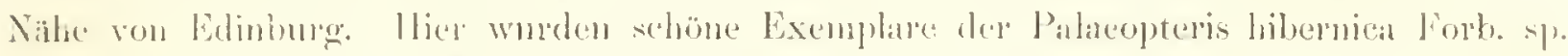

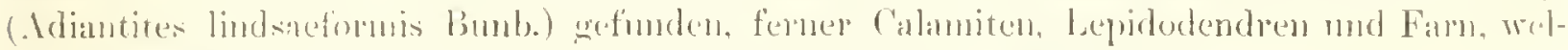

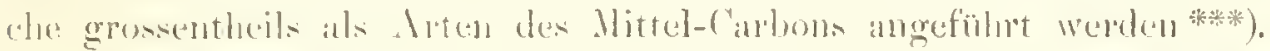

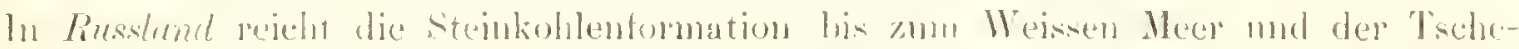

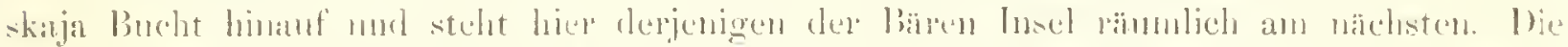

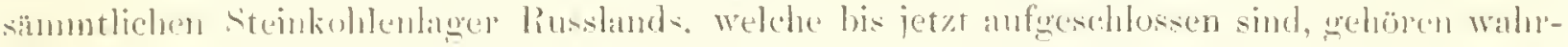

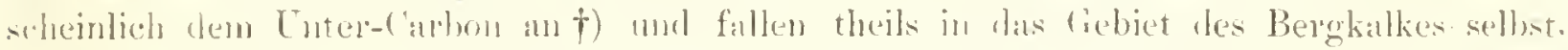

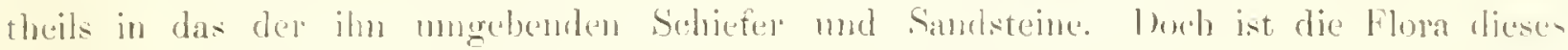

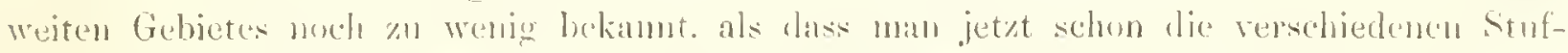

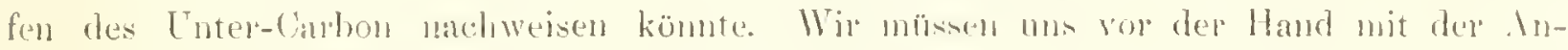

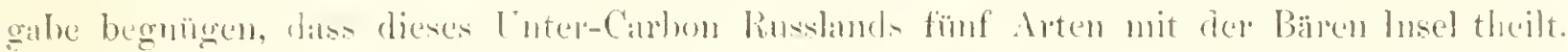

\section{HI. FLOHA DES ('TLII.}

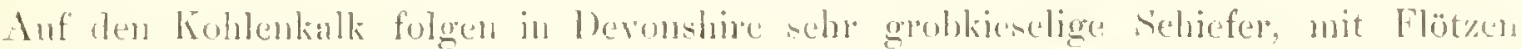
harter, magerer Kohle. die man mit dem Samen der Culm-sedinden (Cuhniferous beds) belegt hat: welchen man später anf die jüngere Granwacke des llapzes nond Sidulesion-

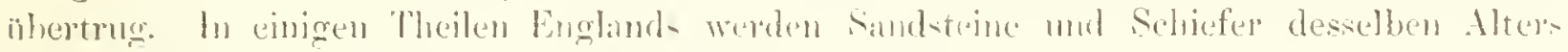

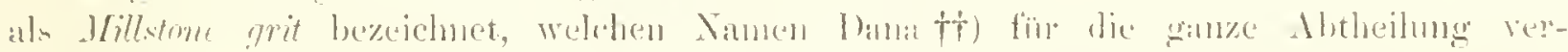

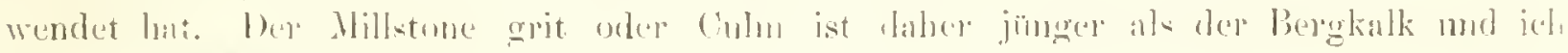

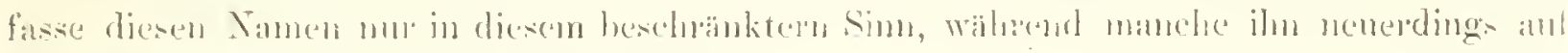

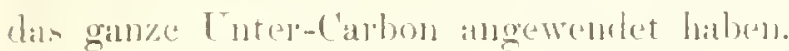

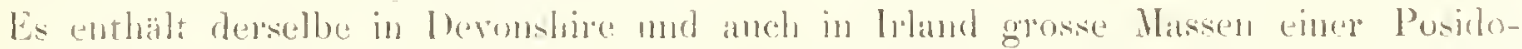

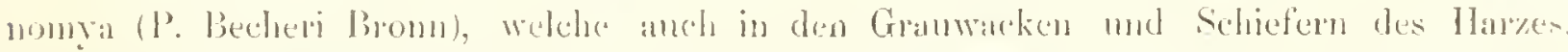
Schlesiens and Hährens anftritt, die davon den Namen der Posidonomyen-Schiefer crhice-

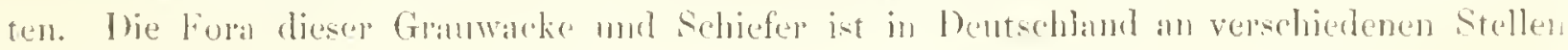
beobachitet worden.

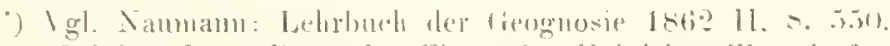

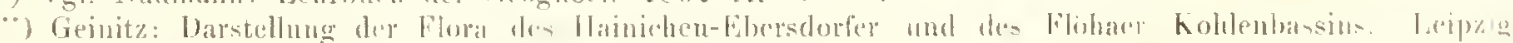

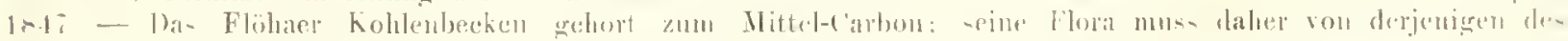

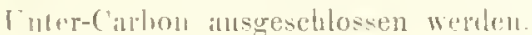

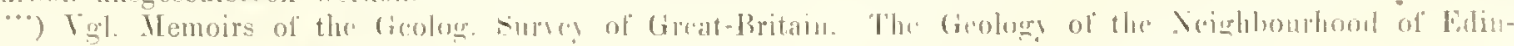
bureh. Lourton 1stil, p. It5.

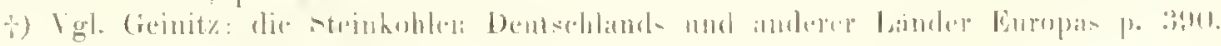

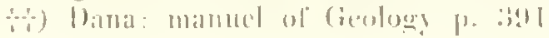


Im Hurz wurde sie ron Fr. A. Roemer sorgfaltig gesammelt und bearbeitet* $)$. Sie hat hier 29 Arten ergeben, unter welchen die Lepidodendren mit 12 Arten dominiren, von denen freilich mehrere auf zu kleine und unvollständige Bruchstïcke gegrändet wurden. Häufig sind die Knorrien und Calamiten. Es theilt diese Flora mit der Bären Insel fünf Arten.

Aus der jingern schlesischen Granuche hat Goeppert 31 Arten beschrieben **), von denen sieh fünf unter den Pfanzen der Bären Insel finden. Die Calaniten, Lepidodendren und Lnorrien sind die häufigsten Pflanzen. Sechs Arten rejehen bis ins Mlittel-Carbon hinauf.

An die sehlesisehe Grauwacke schliessen sich die Thonsehiefer und (irauwackengebirge von Oestreichiseh-Schlesien und Mähren an. Man bringt sie zu den Posidonomyensehiefern, da sie mehrere für diese bezeichnende Thierversteinerungen geliefert haben (die Posidonomya Becheri, Goniatites mixolobus Phil., G. erenistria, Orthoceras striolatum H. v. 11. und Pecten grandaevus). Die Pflanzen, welehe sie umschliessen, bestätigen diese Altersbestimmung. Es lat K. von littingshausen 33 Arten besehrieben $\left.{ }^{*}{ }^{*}{ }^{*}\right)$. Die Lepidodendren sind sehr selten, häufig dagegen der Calanites radiatus in seinen verschiedenen Formen, und die Farrn. Lunter diesen erbjicken wir zahlreiche feinblättrige Sphenopteriden. aber anch die beiden Cardiopteris-Arten der Bären lnsel, wogegen die Pecopteriden fehlen. Nit der Bären Insel theilt diese Flora fünf Arten, nit dem Nittel-Carbon aber 12.

Stellen wir die Pflanzen der verschiedenen Fundstatten des Cuhn zusammen, finden wir in jeder eine '/ahl eigenthümlicher Formen, wohl aber nur weil uns die Flora desselben noeh seh" urvollstïndig bekannt ist, dancben aber doch nanche gemeinsane Arten, welehe durchschnittlich zu den häufigsten und daher wichtigsten Pflanzen der Lokalităt gehören. Es sind diess grossentheits Arten, welehe zugleich anch in Bergkalk und des' Crsa-Stuffe vorkommen, somit als Leit-P'flanzen für das Unter-Carbon bezeichnet werden können. Es sind diess der Calamites radiatus, die beiden Cardiopteris-Arten, Lepidodendron Veltheimianum und Kuorria inbricata. Was die Culm-Flora gegenüber derjenigen der Ursa-Stuffe auszeichnet, ist dass in derselben die Zahl der mit den Mittel-Carbon gemeinsamen Arten grösser geworden ist und darunter Arten erscheinen, welche in dieser Formation eine sehr grosse Terbreitung haben, so die Neuropteris Loslui und Calamites

) Vgl. lioener in ren Palarontographieis $111, I X$, KIlI,

*) Novat acta aead. Leop. (Girol. 1852 und 1860 ).

“.) Vgl. K. ron Fttingshansen: die fossile Flora des mährisch-schlesischen Dardischiefers. Denkschritten ler Wiener Akademic 1865. Teh habe fïnf Arten abgezogen, der'n Artreehte mir sehr zweifelhaft scheinen, wie tirss im speeiellen Theil näher begrïudat ist. Teberhaupt bemreke ieh, dass die Zahlenangaben rer versehisdemen Floren sioh durchguhends anf Verzeirhnisse grinden, die ieh entworfen habe und bei welehen ich die niwthige Revision und Reduktion der Arten vorgmonmen habe, daher meine Zahlen keineswegs immer nit den \%aliken der betreffenden Autoren üboreinstimmen.

littingshansen hat mehrere Fann anf ]ebende Gattungen bezogen, doeh kanu ich ihm hierein nicht beistimmen. P'Hanzen mol 'Thicre, die einem so fermen Weltalter angehören, kimnen mu danu jetyt lebenden Gattungen eingereiht werden, wenn sehr wesentliehe äberrinstimmende Merkmale narhgewiesen werden können. Wie misshich hier die Fimrihung in lebende Gattungen ist, \%eigt die Palaropteris hiberniea, welche Ettingshansen (I. «. p. r) mit den rerwandten Arten zu Adiantun stellt; mu zeigen aber die Fruchtwedrl, welche schru Baily (geolog.

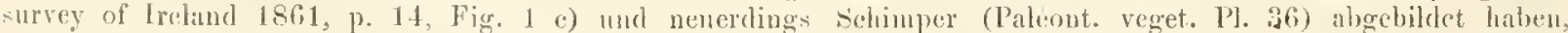

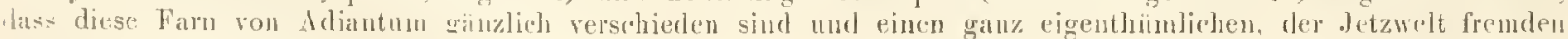
PAlallyentypus dillstellen. 


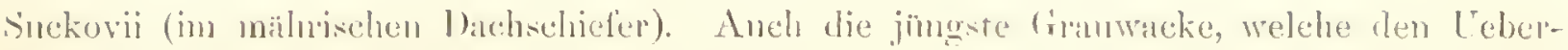

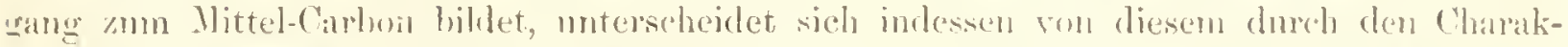

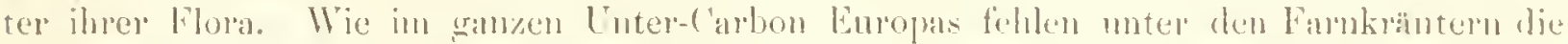
l'éepteriden. aler sind dorh sehr selten, dagegen treten Cycolopteris-atrtige Formen und femblätrige siblenopteriden häntig anf' und bezeichen die Fam-Flom dieser \%eit. Im Mittel-(arbon dagegen sind lie Gattungen Nemopteris umd Peropteris (nuit Linschluss vom

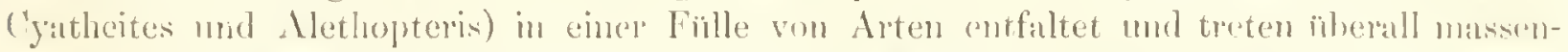
haft anf. Die Lepidodenden sind im Lnter- mol Wittel-Carbon verbeeted, doch in ersterem relativ noch läntiger, während die Sigillarien, welehe in llittel-Garbon cine so äusserst wichtige Rolle spielen, in linter-('arbon fast. ganz fehlen*). Es muss daher in dre

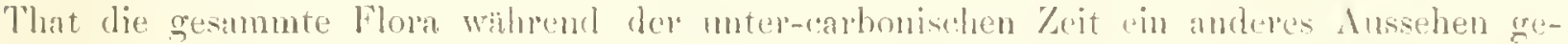
habt haben, olwol sie ans denselben familien und grossentheils anch ans denvellon (iattungen bentand, wie in Mlittel-('allon.

\section{R"“CKBILICK.}

['eberb]icken wir nochmals die unter-eabonischen Mb]agermgen der Bären lusel,

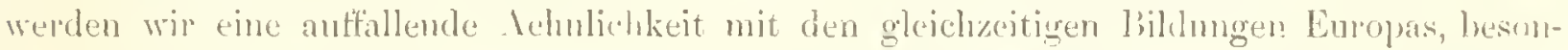
ders von Südwest-Irland, nicht verkemen kümen. Wir kömnen sie in folgender Weise znsammenstellen:

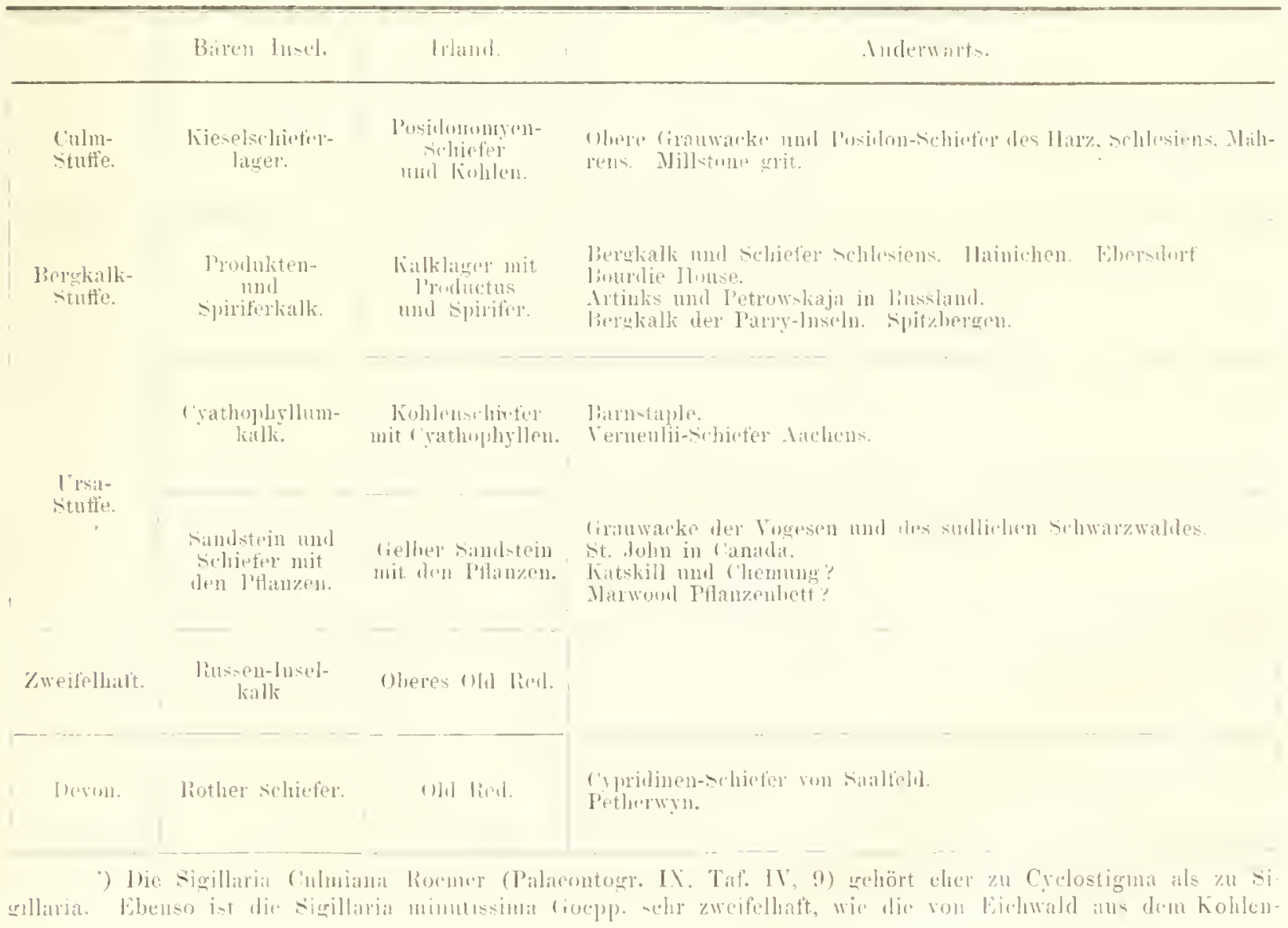


Auf der Bären Insel, wie in Spitzbergen, fehlt das Mittel-Carhon, es diürften abur dic Kiesekchiefer, welche in der obern Abtheilung des Bergkalkes sturk entwicke]t sint. dem Culm entsprechen, was freilich erst sicher festgestellt werden kam. wenn cimmal dic vielen marinen Versteinerungen, welche die schwerlischen Expeditionen aus dem Bergkalk nach Stockholn gebracht haben, genauer bestimmt sein werden. Dann wird sich auch herausstellen, ob meine Vermuthung richtig ist, dass der Cyathophyllum-kalk dem Kohlenschiefer Irlands entspreche, und es wird sich dann zeigen, ob dasselbe Verhältniss zwischen seinen Versteinerungen und denen Irlands stattinde, wie wir diess für das Pflanzenbett nachgewiesen haben. Wenn anch gegenwärtig noch manches zweifelhaft bleibt, so ersehen wir doch schon aus den jetzt sicher festgestellten Thatsachen, dass in Sïd-lrland, wie auf ảer weit entfernten Bären Insel, in hohen Norden und in Wittul-Luropa in der Bildung der Felsen, wie der Pflanzen und Thiere, welche sie einschliessen, eine anffallend gleichartige Entwicklung statt fand. Es ist daher die Flora der Urat-Stuffe für die Geschichte der Erde ron grosser Bedeutung, wie sich uns noch dentlicher ergeben wird. wenn wir einen Blick anf die Stellung werfen, welche sie im Entwicklnugsgang der Erde cimimut.

Aus den Silur und (Tnter-l)evon sind nur marine Thiere und Pflanzen bekant*). (ar-t in Mlittel- und Ober-Devon tanchen Landpflanzen anf, welche uns Festland rerkunden. Woch sind zur Zeit erst wenige Stellen bokanut, die als devonische lnsela bezeichnet werden kömmen. and nur die dem obersten bevon angelörende Gegend ron Salfeld in Thäringen hat eine ziemlich ansehnliche Zahb von Pflanzen geliefert, dic freilich meist 11u in kleinen Fetzen sich erhalten halsen, welche vielleicht in allzu viele Irten zerlegt worden sind. Gegen das Ende der devonischen Periode nimmit das Festland anf der nörd-

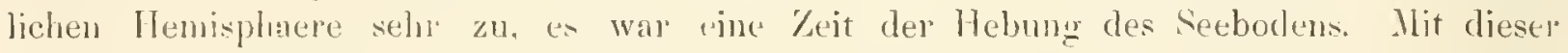
grössern Festlandbildung beginnt eine neue Zeitepoche, die der Stcinkohlen (des Carbon). Die arste Alytheilung derselben labben wir als Ursa-sinffe bezeichnet; nit ihr tritt die (arste rejedere Landflora auf, welche uns die Mittel an dic lland giebt, uns cin Bild von

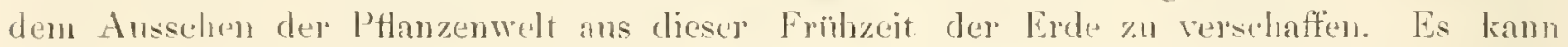
diese Flora anf der nörllichen Hemisplaere in der neuen und alten Welt vom $4 \overline{7}^{\circ}$ bis

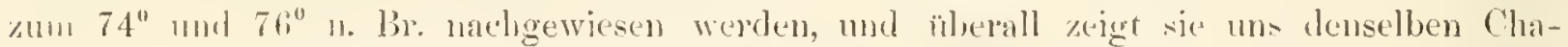
rakter"; ïberall tritt der Calanites radiatus anf, welcher wohl die morastigen Niedermagen mit scinen langen. sänlengleichen stämnen heklejdete, wähend seine grossen Rhizome die Torfgriunde durehzogen, überall dis gablig verzweigten mol dicht mit Blätem beschuputen Lepidodendron und die sonderbaren Knorrien. Alser auch die Cyclostignen, die wir aus Süd-lrland nud der bisren lusel kermen gelernt laben, fehltın kanm anf den dazwischen

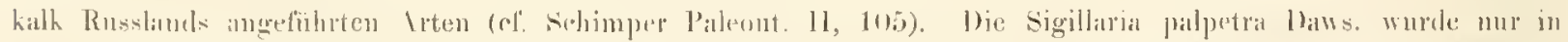

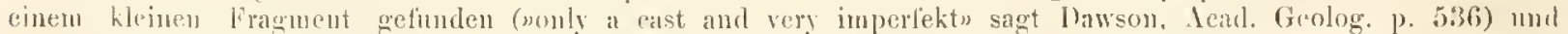
ist diaher now nicht gesiehert. Ti. Sigilandia llansmami Goepl. ans einem Quarzgestein zwiselien 1dre und

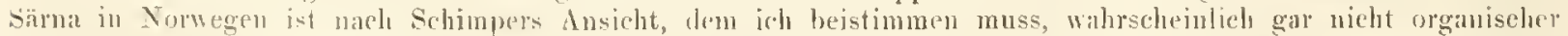

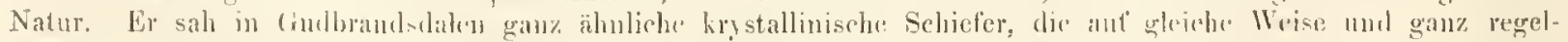
mä̀sig cancllirt waretr.

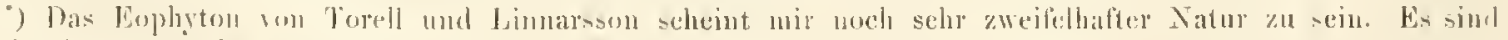

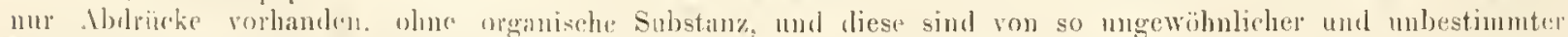

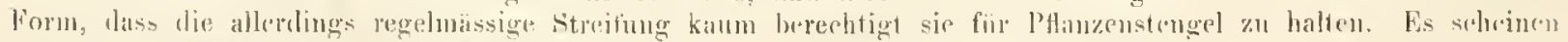

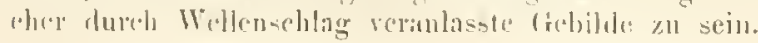




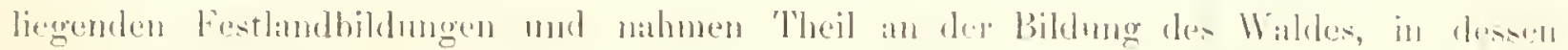
Schatten die Cardiopteris- mal Palaeopteris-Arten ibre mildatigen Wedel anshreiteten.

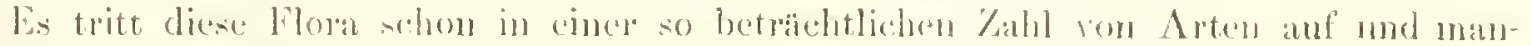

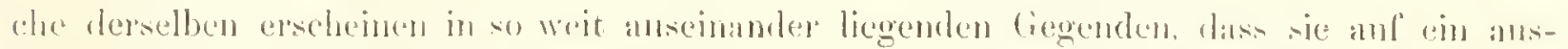

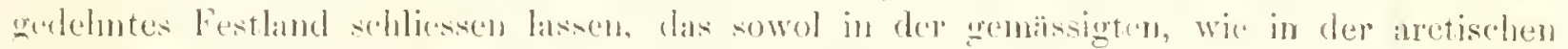

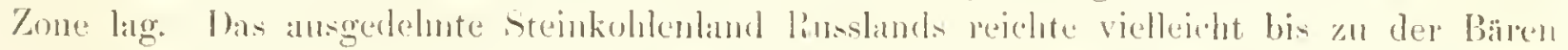

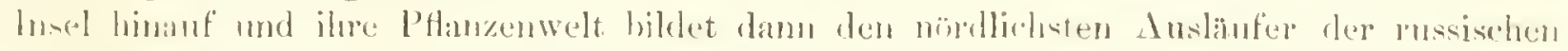

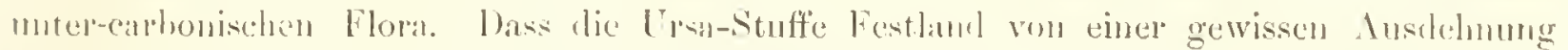

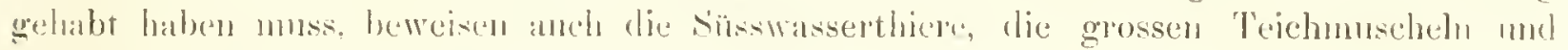

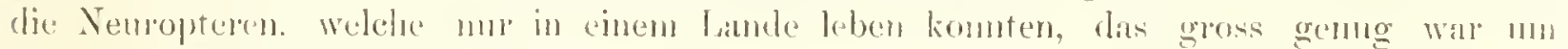

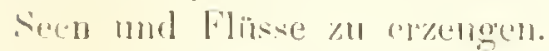

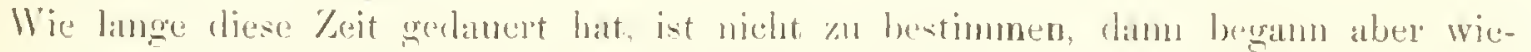
dur ein Sinken der Landex; es treten Brackwasserbildungen und später reine marine Ab-

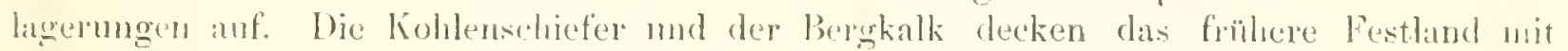

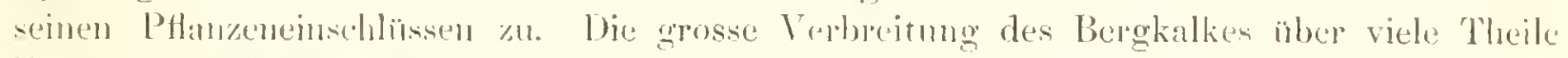

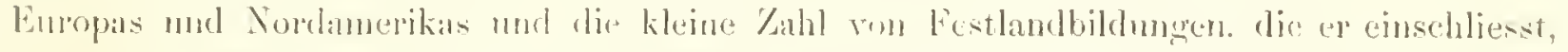
\%igt ms, dass diese senkung des landen eine allgemeine Erscheinmg gewesens sein muss. bie nördiche Hemicphaere hat daher sehr wahrohcinlich damals ein ganz anderes Ausoehen geluabt, als während der l'rsit-Stulfe.

Dann wederholt sich aber wieder dieselbe Erscheinnur wie hei beginn der carbonischen Periude. Wir arhalten in Folge eince weit verbreiteten Hebung die Festlanduldun-

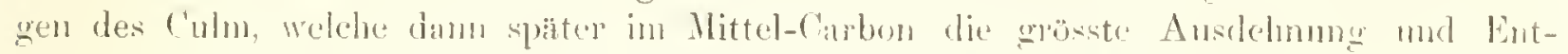

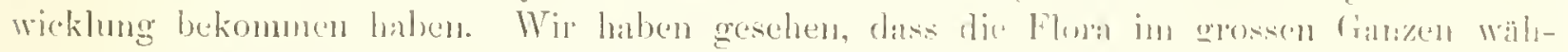
lend dieses as langen Zeitranues dieselle gehliebent ist. Wanche der lominirenden Arten

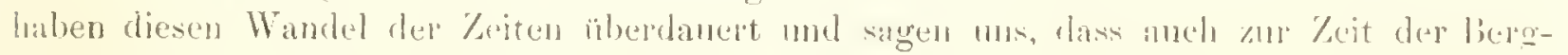

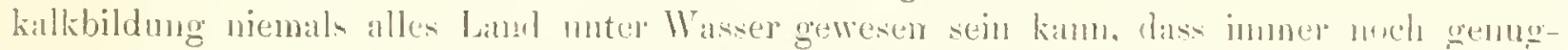

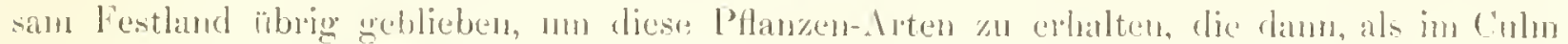

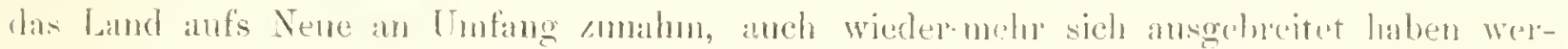

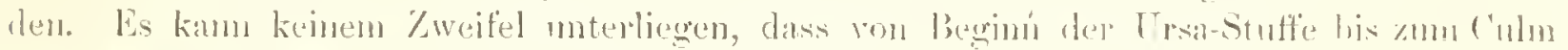
vine lange \%eit verstrichen ist, ebenso dass während diesen vielen Jahrtankenden die La-

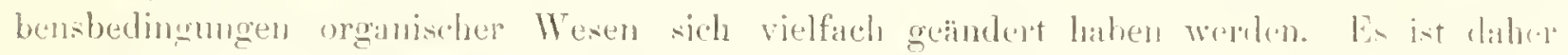

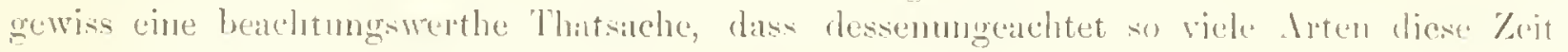

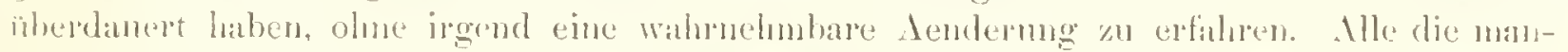
nigfaltigen formen, in welchen der Galamites radiatus anf der Bären Insel arscheint, fin-

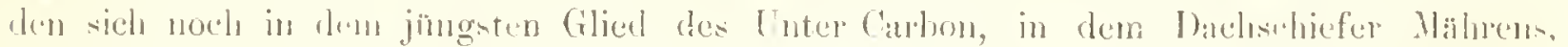

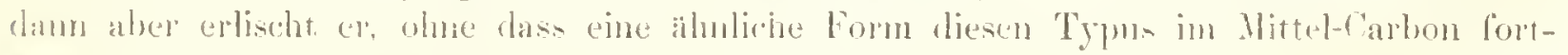
-

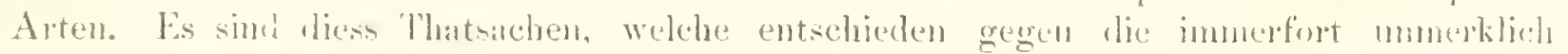

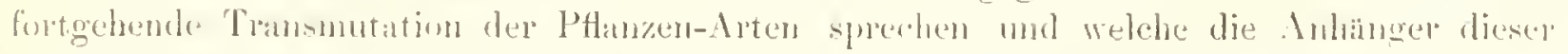
Labe nicht ignoniren sollten. Sie sind un so wiehtiger, da offenbar die l'flanzen auf der. Baren Insel moter anderen Lichtverhältnisen leloten als die der Vogesen oder Irlands, indum se cine lange Winternacht za bestehen hatten. Ws ist in dow' That anffalleme, dam

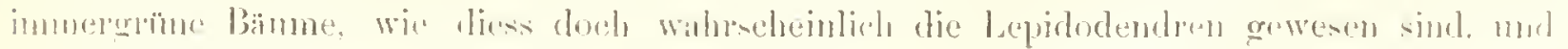


l'flunzen mit so grossen Blättern, wie die Cardiopteris frondosa, eine so lange Wintemacht ansgehalten haben, auch wenn wir dabei in Betracht ziehen, dass die Bären Insel-Flora finst ans lanter Gefuisskryptoganen bestand *), welche das Lichlt leichter und länger entbehren können, als die Phanerogamen. Im Uebrigen ist das Kilina auf der Baren Insel für den Pftanzenwuchs wohl ebenso gïnstig gewesen, wie in Irland und in den Vogesen, obwol jene Insel nm 26! hö̆er im Norden liegt, dem die entsprechenden Arten sind ebensr) gross und ehenso üppig entwickelt und haben sogar ein mächtigeres Steinkuhlenlager el'zeugt, als die gleichalterigen tieferen Breiten ***). Die Wiane war daher damals wohl noch gleichnässig äber die Erde vertheilt, während schou zur niocenen Zeit ein wesentlicher Untersehied bestand, der in der Jetzwelt noch viel grösser geworden ist.

Zu demselhen liesultat führt uns auch eine Vergleichng der Thiciwelt des Ifeeres, welches die bären Insel unspült hat. Der Productus gigantens, Pr. striatus, punctatus und hemisphaericus, die wir im Bergkalk der Büren Insel kemen gelernt haben, sind fast ïberall in Bergkalk gefunden worden und entsprechen in ihrer V'erbreitung ganz der Knorria imbricata, den Lepidodendron Veltheimianmu und Calamites radiatns. Ja zwei Mollusken aus dem Bergkallk Spitzbergens (Spirifer Keilhanii und Productns costatus) wurder sogar in Indien, eine Art aber' (Productus Humboldti) in Sindanerikir nachgewiesen, so dass arctische Arten bis in die Tropenwelt hineinreichen *****as). 1)ass aber das Kilima nicht allein ein gleichnnissiges, sondern zugleich ein warmes war, dürften die Korallenbänke beweisen, welche damals in Spitzbergen gebildet wurden, ebenso aluer auch die grossen hamuartigen Gefüsskryptogamen und die grossblittrigen Farnkränter, welehe die liaren Insel erzengt hat.

") Nur die beiden Carpolithı'n gehörn wahrschejulich zu den Phauerogamen.

“) In gelben Saudstein Irlands konnen nme ganz dïnne Kohjenlager ror, die aber in der unmittelbaren Nachbarschaft der Pllanzen auftreten (voj. (riffith in Journ. of the geol. soc. of Dublin VI. p. 241). Auch in den Vogesen, wie ïberhaupt im ganzen Lnter-Carbon finden sich nirgends mäehtige Steinkohlenlager. Diese beginnen erst im Mittel-Carbon, das daber als die Bildungszeit der produktiven Strinkohlen bezeichnet wird.

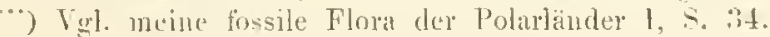




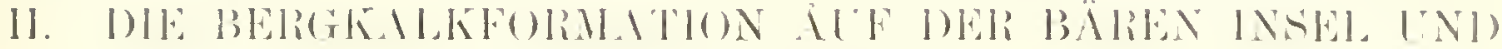

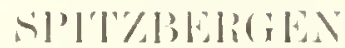

\author{
rou A. H. Sormemskiölıl.
}

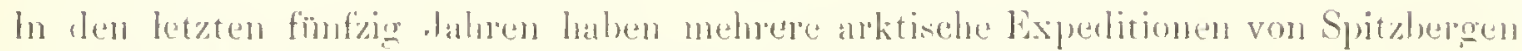

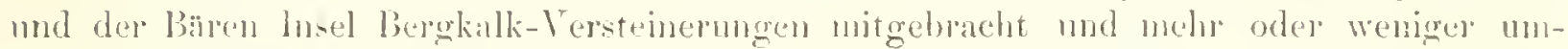
fassende beitrige an der kentniss der Formation geliefert, nümlicls:

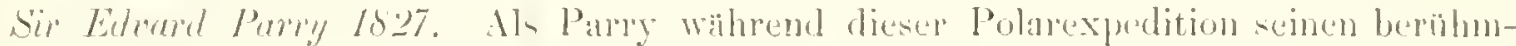

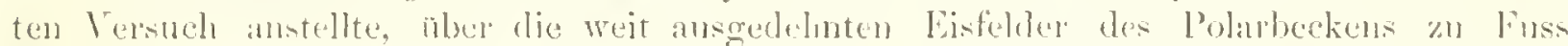
nach dem Pole vor'zudringen, nuterauche einer der Theilnehmer der bxpedition, lientemant Foster, in geographischer nud, so weit gerchelen konnte, in geognostischer IInsicht die nächsten Tugehmugen des Ankerplatzes des lahrzeuges, ein IIafen in der Treu-

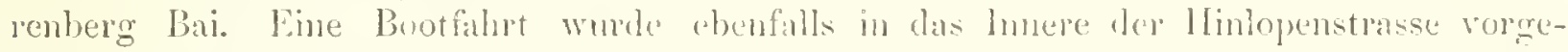
nommen, bei welcher vesschieclene fragmente von Tersteinermugen in den an (anp Fanshawe anstehenden nhtersten Lagern der lergkalkfopmation angetroffen wurden. Diese sind, wem auch nur ganz in Torbejgehen, in dem von Ross d. J. redigirten, wissenschaftichen duhange zo der Beschreibung der lieise*) erwähnt.

B. H. Keilhon 1827. In demselben . Jahre wirden die liaren Insel und Spitzbergen

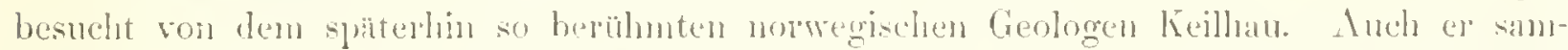

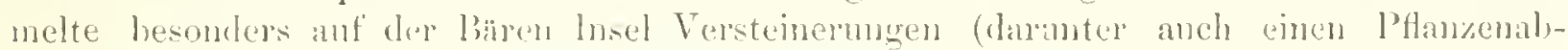

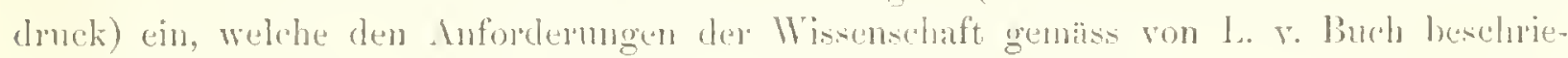
ben wurden :

Sien Lomin 18.37. Line bedeutend grüsere, jetzt an das Stockholmer licichsmm-

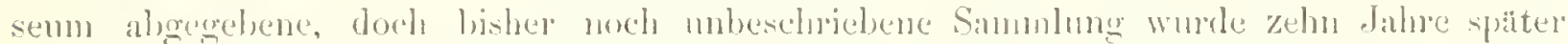

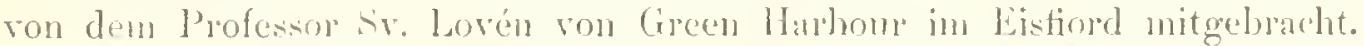

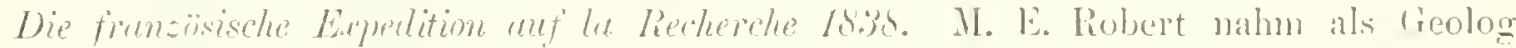
an dieser Expedition Theil und hachte von Bel Sound verschierlene Vursteinermingen mit.

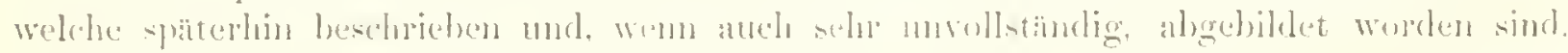

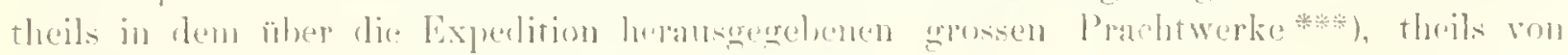

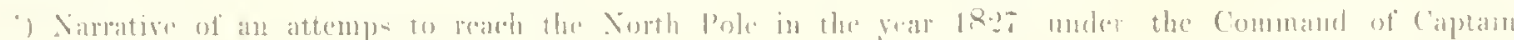
Willian Edsard laury. London Is:- Appondix.

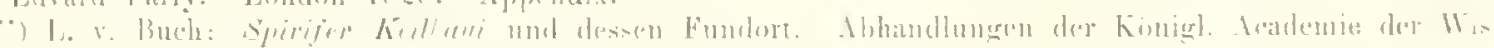

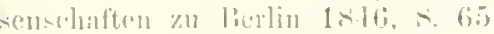

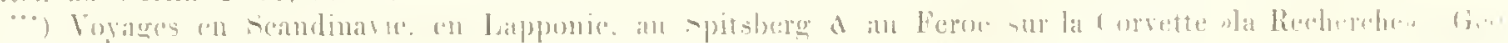

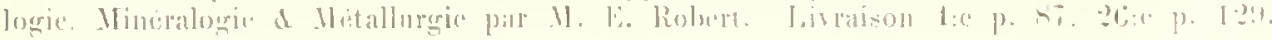

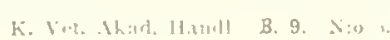


v. lioningk**). von welehem die Versteinerungen mit Unrecht zu der Permisehen Formation gerechnet wurden.

Lamont 18.58 und 185.9. James Lamont ***) besuchte in den tahren 1858 und 1859 $111 n$ Jagd und Fang anzustellen verschiedene Orte an den Kü̈sten von Spitzhergen und widmete sich während seiner zweiten Reise auch der Einsammlung geologischer Stufen und Tersteinerungen. Seine Sammlungen (besonders von Bel Sound), bedentend übertreffend was sowohl Robert, als auch Keithau und Parry eingesammelt hatten, sind von Salter Leschrieben worden.

Die schwedischen Expeditionen 1858, 1861, 1864 und 1868. Die sämmtlichen schwedischen Expeditionen heschäftigten sich mit der Erforschung der so ansserordentlich interessanten Geologie des Landes, und fast ausschliesslich auf ihre Untersuchungen $\dagger$ ) grünlet sich der nachfolgende Bericht über die in diesen Gegenden so mächtig auftretende Bergkalkformation. Leider ist gleichwohl das reiche IIaterial der von uns von einer Menge versehiedener Fundorte mitgebrachten Fossilien noch unbearbeitet, wodureb die Bestimmung des relativen Alters der verschiedenen Schichten sehr erschwert worden ist.

In den in Norden von Europa belegenen Theile des Polarländer tritt die Kohlenformation oder richtiger die unterste Abtheilung derselben, d. h. der Bergkalk, an vielen Orten mit ungeheuer mächtigen, gewöhnlieh marinen und an Versteinerungen reichen Lagern auf. Diese ruhen, wie die Profile, Fig. 1 Taf. XV, von der Ekman Bai und die frinher von mir publicirten Profile der KJaas Billen Bai in Eisfiord darlegen, auf rothen und grünen Schieferarten und Conglomeraten, in denen wir nur an emem einzigen Orte Spuren von T'ersteinerungen (Fischüberresten) gefunden haben tr), die zwar noch nicht vollständig untersucht sind, aber doch zu beweisen scheinen, dass auch die rothe Schieferformation Spitzbergens in der devonischen l'eriode abgelagert worden ist. In den Innern des Eisfiordes dagegen sind die productnsführenden Bergkalkschichten äberlagert theils von Schichten, die der Triasperiode angehören, thejls von den auf Spitzbergen in regelmässigen Schichten so häufig anftretenden eruptiv-sedinentären Hyperit.

In der liergkalkformation selbst lassen sich folgende Abtheihugen unterscheiden:

1. Ein graugelber Kalk oder richtiger Dolomit, der genäss einer in meinem Laboriltorium von G. Lindströn àsgeführter Analyse cnthält:

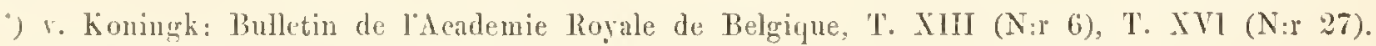

*) Scasons with the Seahor'ses, by James Lamont. London 1861. Appendix.

†) C. W. Blomstrand: Geognostiska iakttagelser under en resa till Spetsbergen âr 1861. Kongl. Svenska Vetenskaps-Akadeniens IIandlingar IV, N:0 6 .

A. E. Nordenskiöld: Geograflsk oeh geognostisk beskrifning öfver nordöstra delen af Spetshergen och 1linlopen-Strait. Kongl. Sv. Vet.-Akad. Handl. IV, N:o 7. Utkast till Spetsbergens Geologi. Ib. VI, N:o 7 ; auch besonders abgedruekt in engliseher Ubersetzung unter dem Titel: Sketeh of the Geology of Spitslergen, by A. E. Nordenskiöld, Stockholm 1867. troffen.

t+) Diese wurden willrend der Expedition des Jahres 18 bs von Malmgren in Licfde Bai ange- 


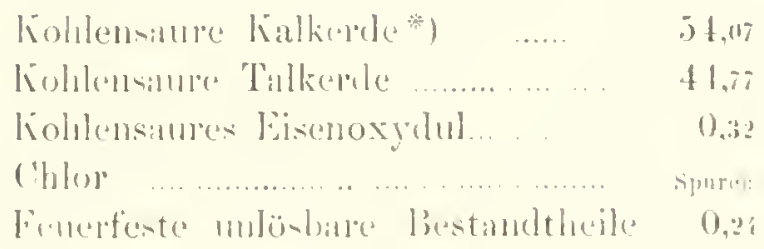

$9 !,: 10$.

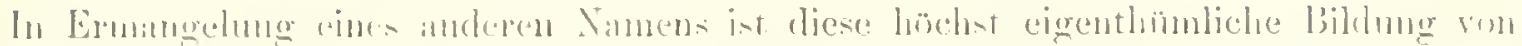

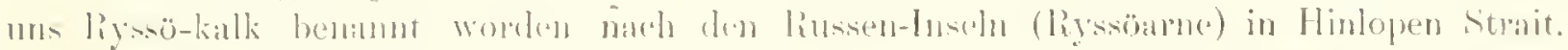

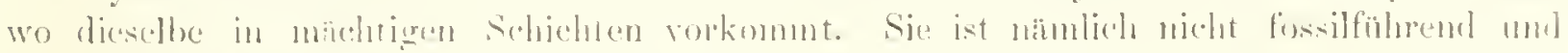

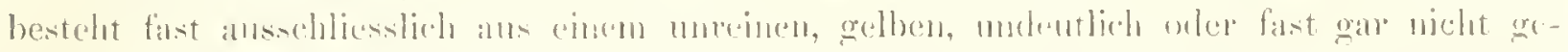

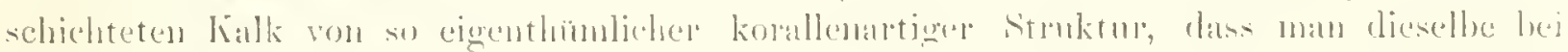

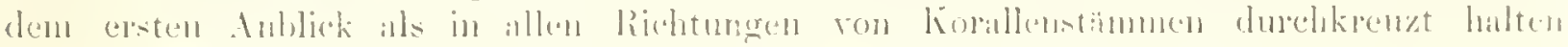

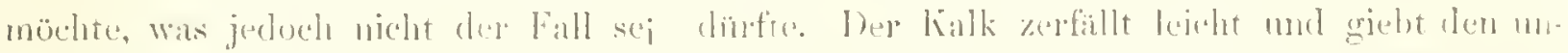

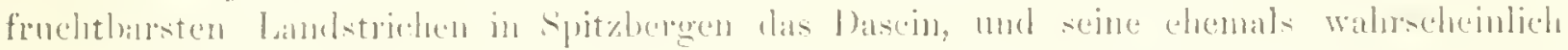

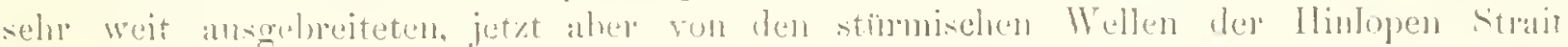

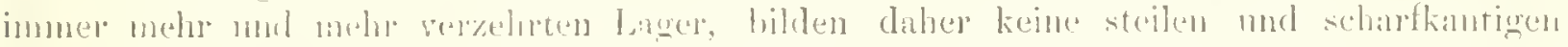

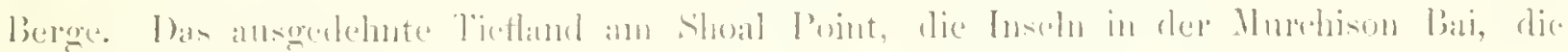

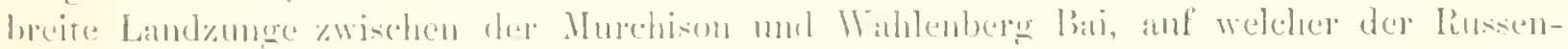

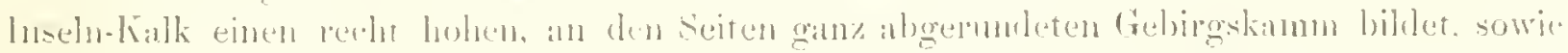

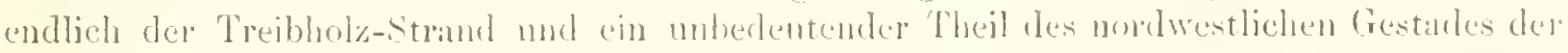

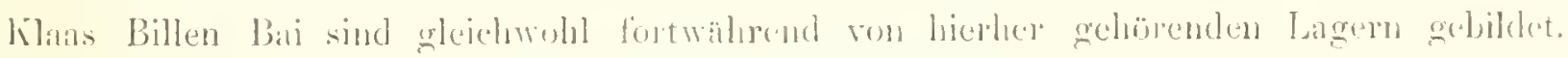

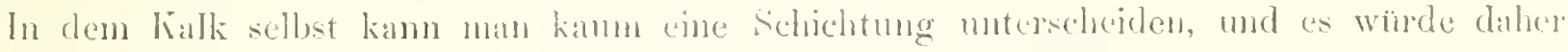
mit grossen Schwierigkeiten verbunden sein, die Lagerungroverhälnisse desselben zu be-

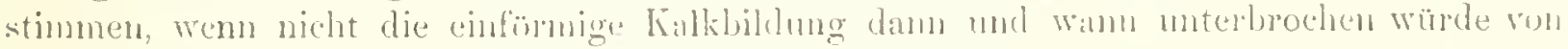

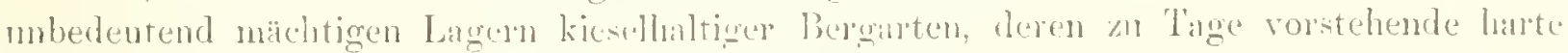

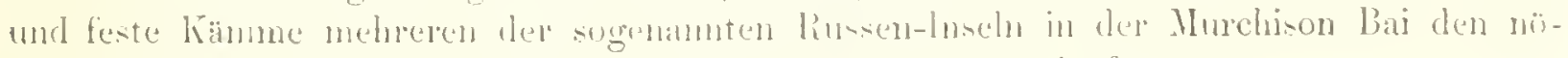
thigen Schut\% gegen das andmingente. Ireer gegeben haben diuffen.

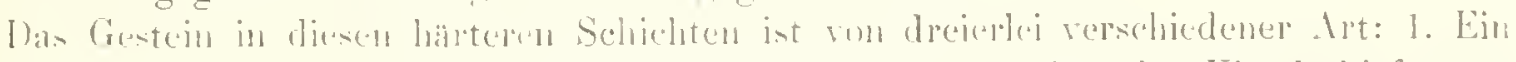

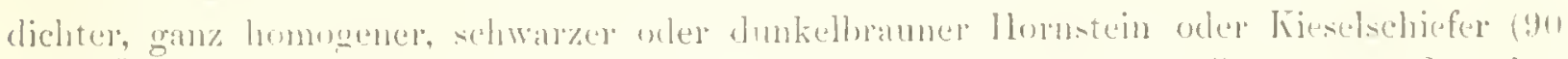

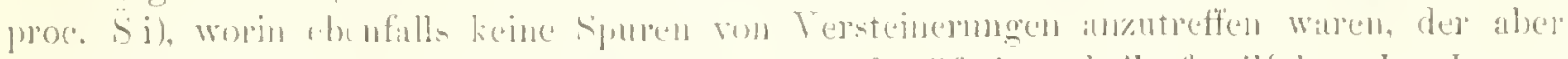

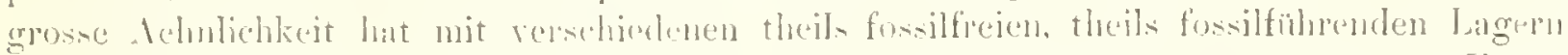

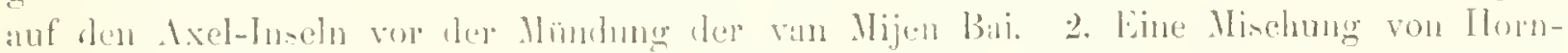

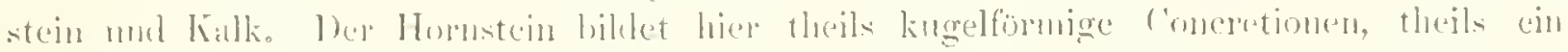

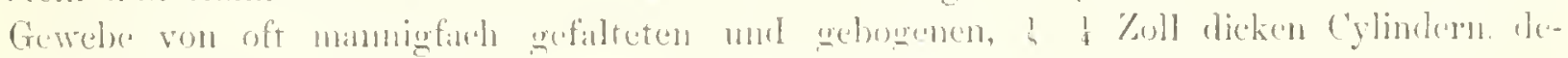

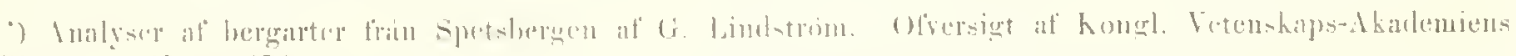

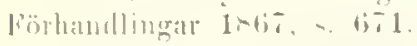

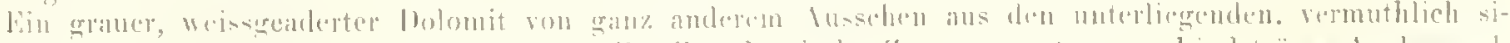

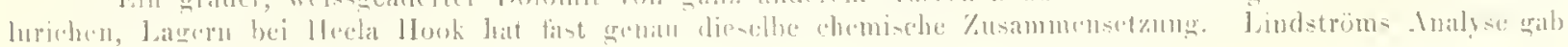

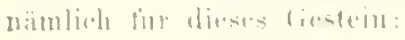

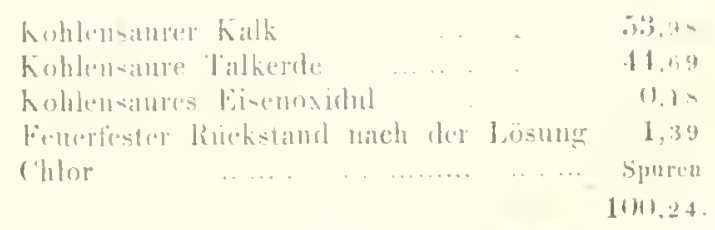

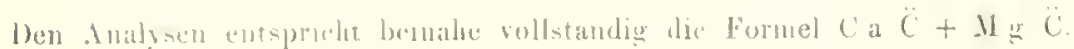


ren Zwischemäume mit granem kalk angefüllt sind, und in denen oft kleine mit Quarzkristallen bedeckte Drusenböhlen angetroffen werden. Diese Cylinder haben cine auffallende Aehnlichkeit init liosallenstämmen, und eine nähere microskopische Untersuchung dürfte vielleicht zeigren, dass diese Lager lteberreste von alten Koralienkolonien sind. 3. Ein weisser oder weissgelher Quarzit, ahmlich dem Quarzit rom Hecla Hook. Alle diese Sehichuen stehen bei den Russen-Inseln beinahe aufrecht nud streichen von Norden gegen Süden, am Treibholzstrande dagegen streichen sie, gleich den mterliegenden Hecla Hook-Lagern, von Nordnordwest gegen Südsüdost and fallen ungefibr 60" gegen Osten ab.

II. Win harter weisser buar:it ähnlicher Sandstein, zwischengelargert con Kohlen-Säumen

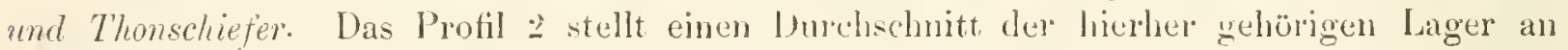
der Mündung des englischen Flusses ann nördlichen Gestade der Bären Insel dar. IIan hat hier:

1 (zu muters1). Sandstein mit ausserordentlich schönen Merkmalen von alten Wellenschlären. Die unterste Grenze dieser Schichte lag unter dem Niveau des Meeres, daher licss sich die vermuthlich sehr bedentende Mriehtigkeit derselben nicht bestimmen.

2. Eine dünne unregehmissige, hier und da geknotete Sandsteinsehichte nit Kolnensänmen; 8 bis $0,:$ Fuss.

3. Weissel, barter und dichter Sandstein ohne Pflanzenabdrücke, ungefälur 10 Fuss.

t. Graner, weniger harter Sandstein, mgefïh 4 Fuss.

$\therefore$ Sandstein mit Sehieferbänder'n, ungeführ 2 Fuss.

(i. Thonschiefer, ungeführ 4 Fuss, mit schönen Pflanzenıbdrücken und unregelınässigen Knollen von Thoneisenstein.

7. Kohlen mit Thonschieferbänden und einer Menge von Pflanzenabelrincken; ungefülur 12 Fuss.

8. Sandstein unit Calaniten, theilweise anfrecht stehend und von bedentender Grösse, 20 Fuss.

Die schichte 8 nimmt einen bedentenden Theil der Elene gleich in Westen ron dem Fusse des Mount Misery ein, wosellost man Gelegenheit hat alle möglichen Uebergänge zu sehen von eiuem thleichmässigen, hurten und spaltenfreien Sandsteinfels zn einem Sandsteinfels nit kleinen lissen und einem Sundsteinfels, unterbrochen ron fuss-, ellenoder klafterbreiten Spalten bis zu einer Sammlung ron kolossalen Felsenblöcken, welche unt ihren Fugen noch genan in einander prssen, und zuletzt zu ausgedehnten, ungeordneten und für den Fusagänger äusserst beschwerlichen Steinhaufen zerfallen, gebildet von kantigen Sandsteinstücken, den Moränen so ähnlich, dass ein moderner Glacialist kamm Anstand nelnnen wärde, dieselben für Ztengen der grossen Eisdecke zn erklinen, welche nach ihrer Anssitge cinst den ganzen Nordpol eingehïllt hat.

Rin ahnlicher Sandstein, anf gleiche Weise in moränenartige Steinhanfen übergehend, kommt auch nuf Charles Foreland vor. Diese Abtheilung der Steinkohlenformation scheint daher anch dort vorznkommen, wenn anch vermuthlich nicht kohlenführend. Ansserdem dürften der sog. Sandsteinkamm an dem Cap Staratschin und die anfrechtstehen-

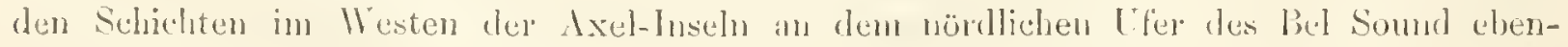
falls hieher gehören *). Aneh hier seheint die Sehichte nicht kohlenfïhreud zn sein. \%an

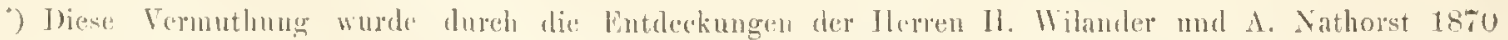

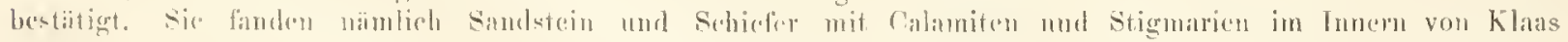




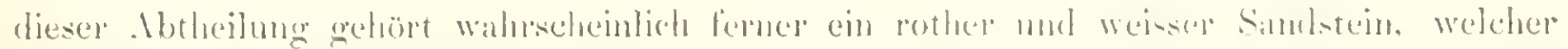

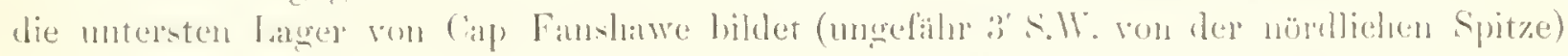

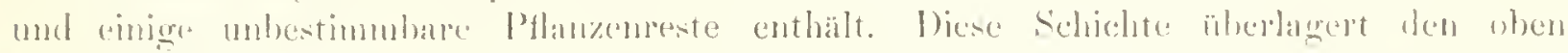

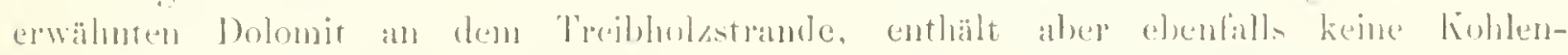

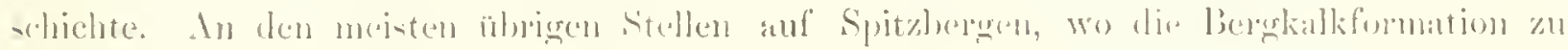

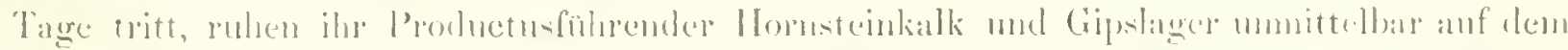

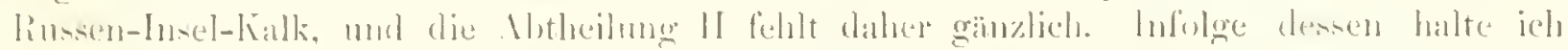

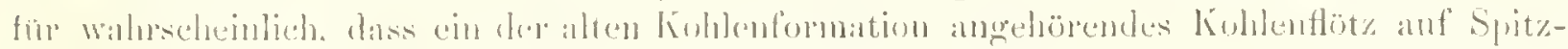

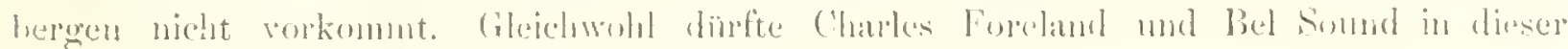

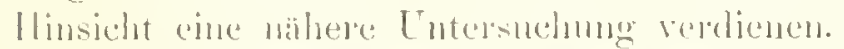

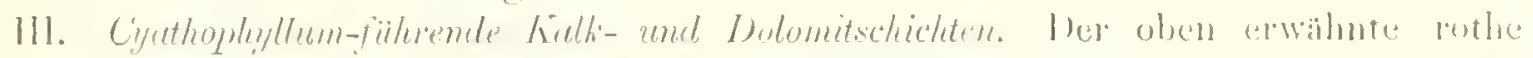

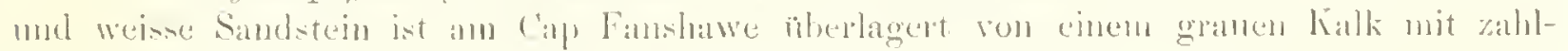
reichen, foch nicht gut crhaltenen Versteinernugen, klcinen diten ron Terebratula, ('ri-

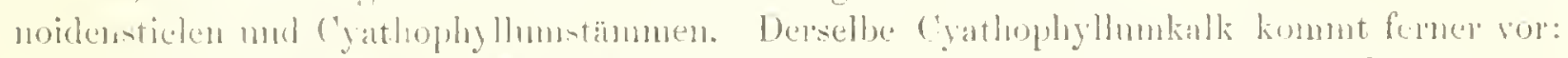

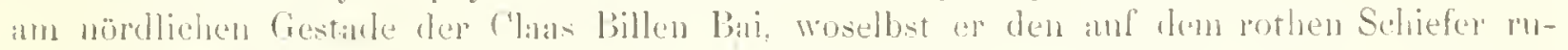

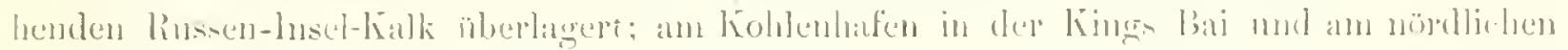
I'fer der vill lijen Bai.

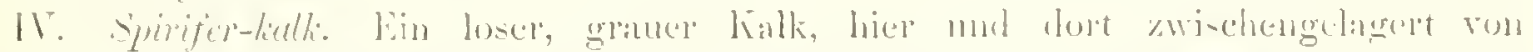

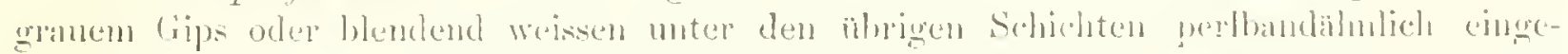

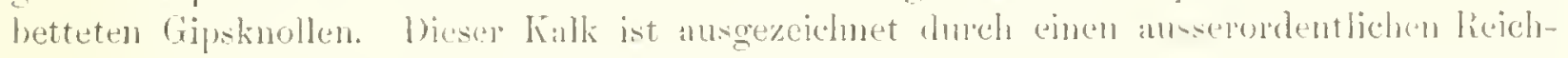
thum an Spiriferartigen V'ersteinerungen (das Genns Productus ist hier woniger reprasen-

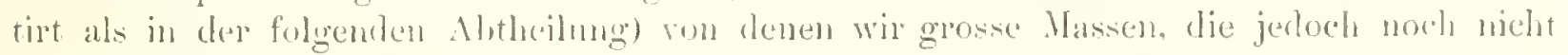

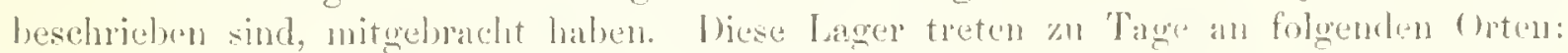

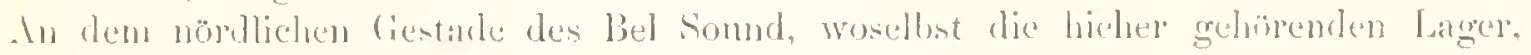

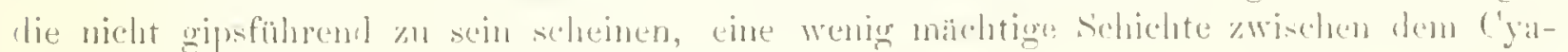
thophylhm-kalk mo dem Hornstein hilden.

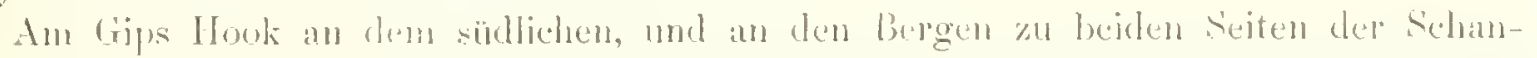

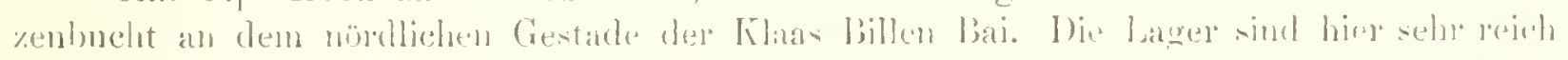

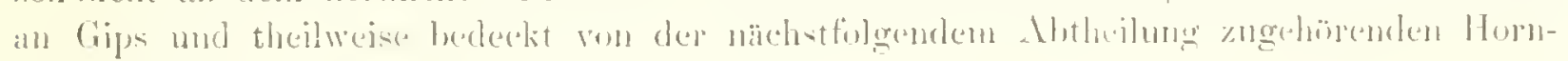
-teinschichiterl.

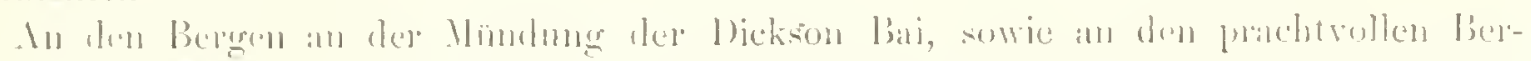

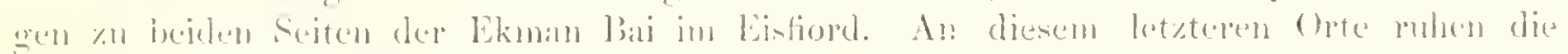

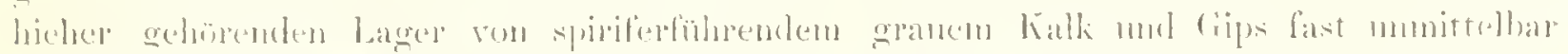

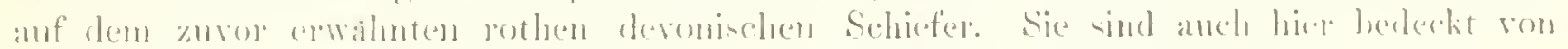

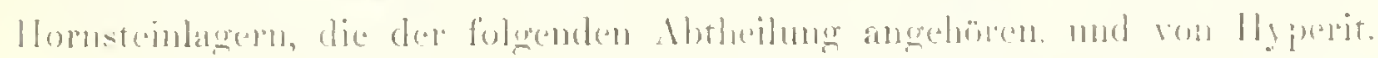

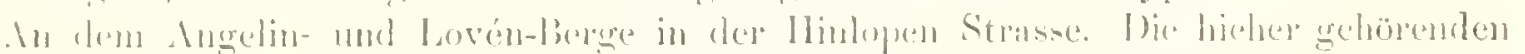

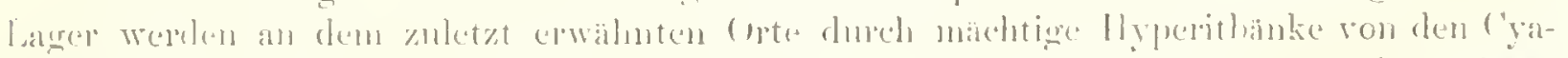

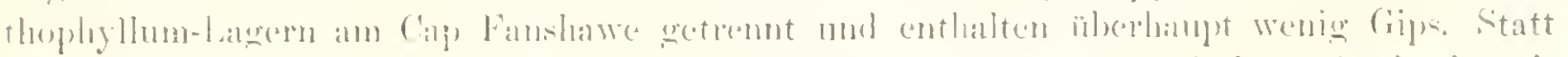

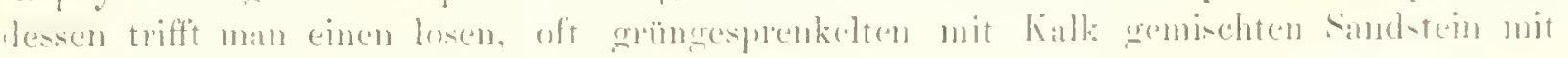

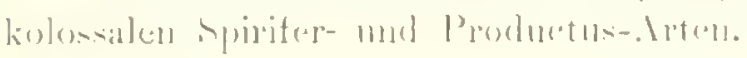

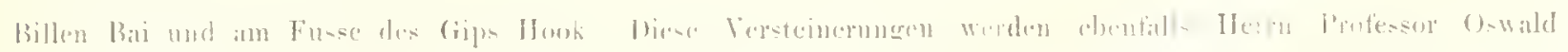

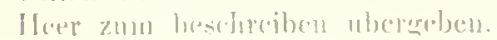


Auf der bären Insel (Fig. 3 und 4). Lose Stücke von einem grauem Sandsteinlager. werden hier ind dort zerstreut auf der Ebene der Baren lusel angetroffen. Vermuthlich ist dieses Lager, in welchem unter andern V'erstenerongen auch der ursprungliche Spirifor Keilhaui vorkommt, anstehend auf der hohen Bergen an der Südspitze der Tnsel. Anstehende, an Tersteinerungen reiche Kalklages kommen dagegen gleich bei Tobiesens Hämschen am Nord-Hafen vor und ganz besonders an Hount Misery, weleher grösstentheils ans lauter an Versteinerungen reichen, theils dieser und theils der folgenden Abtheilung angehörenden Lagern besteht.

V. Productus-fülrender Kalk- und Kieselschiefer. Eine wirkliche paliontologische Grenze zwischen dieser und ler vorhergetuenden Al,theilung ist nicht vorlanden. An mehren Orten auf Spitzbergen kommt diese Productus-Schicfer jedoch su schurf ansgebildet vor, dass ich gemeint labe dieselbe als eine besondere Unterabtheihng anfnehmen 211 nüssen, welche hesonders ausgezeichnet ist fluch Reichthum an kiesel und darlurch, dass, wälrend Spirifer orler nahestehende Geschlechter den äberwiegenden Theil der in IV gefundenen Thierformen bilden. hier dagegen grosse, grolschalige Producti gewöhnlich, wo nicht inmer, den ersten Platz eimehmen. Einen schönen vertikalen Durchschnitt dieser Schichten trifte man anf den Axel-lnseln an der Mündung der van IIjen Bai, woselbet die Lager ganz anfechtstehend sind und meistens ans cinen beinahe reinen, dunkelfarbigen Hornstin :ihnlichen Kieselschiefer bestehen, der theils fossilfrei theils mehr oder weniger mit dickschaligen Productus- und Spirifer-Arten von mitterer Grösse, sowic anch mit äusserst manschnlichen Cephalopoden erfüllt ist. Ähnliche productusführende Largere treten zn Tage zu bejelen Seiten der Mündung des Eistiordes, in den oberen Schichten des Lovén- und Angelin-Bergen in Hinlopen Strait, sowie in den höler belegenen Schichten des Mount Misery anf der Baren Insel - hier jedoch weniger Kieselreich, ein L'mstand, der viellejeht danit in Zusimmenhang steht, dass es kein wirkliches Hyperithager auf der Bären Insel giebt. Der Rejehthm an Kiesel in der oberen Abtheilumg der Berogkalkformation Spitzbergens ist un so merkwärdiger, als die Kieselschieferbänke angenscheinlich nicht durch eine Vetamolphose des Sandsteines entstanden sind. Sie zeigen nïmlich niemals eine sandstemartige Natur und gehen niemals in diese Bergart äber: wihrend man dagegen unzihlige Ueberginge zwischen kieselfpeiem kalkstein, Kalkstein mit Kieselkemen, mit kalk gemischten Hornstein und reinem, dem mbewaftheten Auge kalkfreien Kiesel findet.

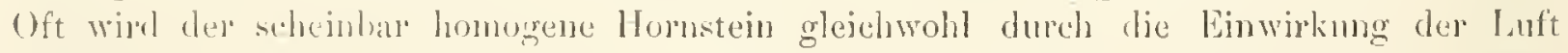
lustig und zackig, Welclues andentet, dase anch hier lejchter auflösbare Stoffe in die bergant cingesplengt vorhanden sind.

I'. Hyperit. Ehe ich diese Notizen über die Ausheitung des Bergkalkformation

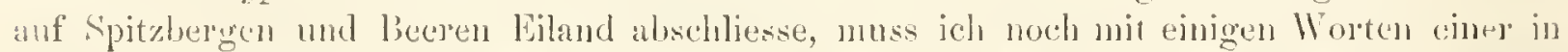
diesen Gegenden höchst charakteristischen Bergat erwahnen, die gleichsan das oberste Gilied der Formation lifldet.

Sowohl in den inneren Armen des Eisfiordes als anch in der Hinlopen Strasse sind die kalk-, Gips- und Hornsteinbanke der Bergkalkformation von mächtigen sehwarzen, nit bassaltähnlichen Süulen in jühen Absätzen zersprengten Lagern gekrönt, welehe, wie verschiedene Ninnen anf mesere Karte andeuten, den Beroen dats Ausschen kolossaler, bir 2000 Fuss hoher Rumen ertheilen. Nit den gewöhlich spiegelhlanken, mit Eis bestrenten Fiord an ilrem Fusse und dur hendent weissen Sclmedecke anf ihrem Scheitel, ger- 


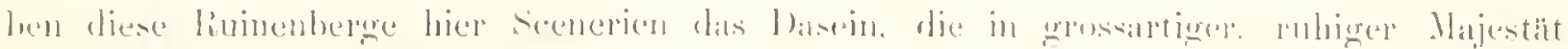
kamm ihres Giteichen hahen dïrften.

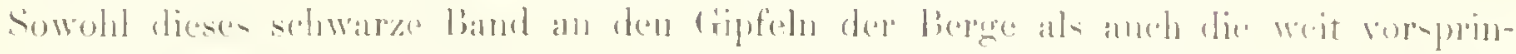

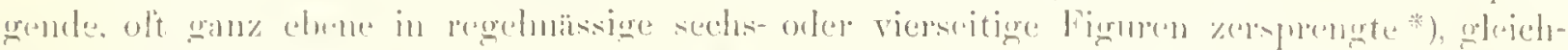

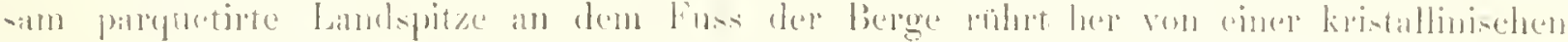

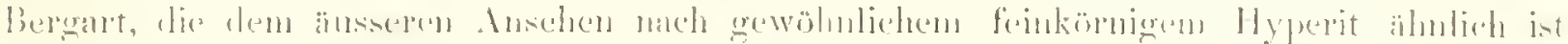

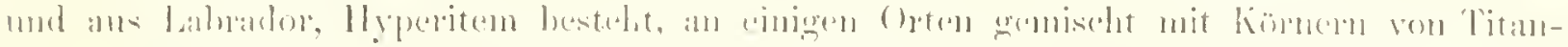

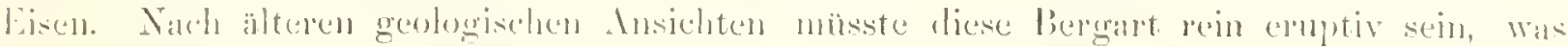

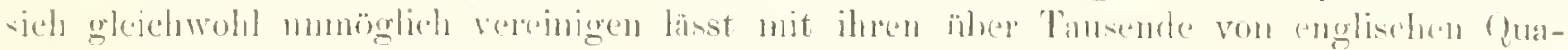

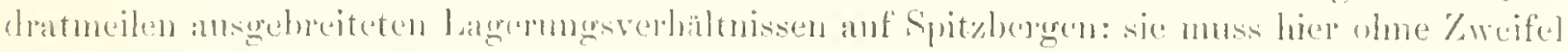

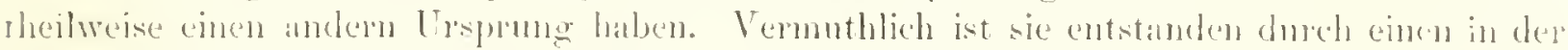

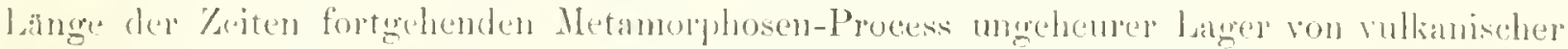

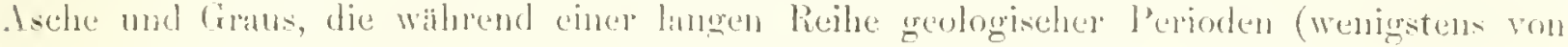

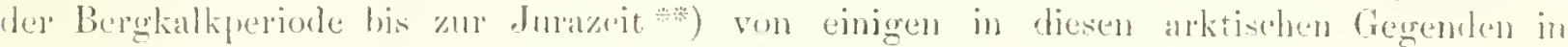
früheren Tagen befindlichen Vulkinen ansgeworfen worden sind.

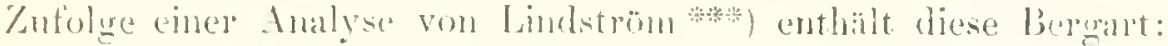

\begin{tabular}{|c|c|}
\hline 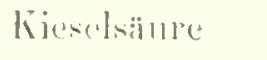 & \\
\hline lialkerete & \\
\hline Tallierde & \\
\hline 'Thoneder. & \\
\hline Eiscnoxid & \\
\hline Titansämre & \\
\hline Mang̣unoxidul & \\
\hline Alkulicn & \\
\hline Glöhrerlust & \\
\hline
\end{tabular}

$10(0,011$.

Die obere Abtheilung der Steinkohlenfornatimn scheint in den Gexenten, von denem hier die liede ist, gänzlich zu fehlen, ma aller Wabreheinlichkeit nach and die Permivelue Formation, obglejeh die Bergkalkverstemermangen spitzbergens anf gewisec dpt ein

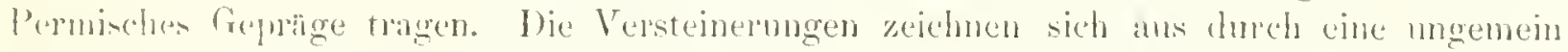

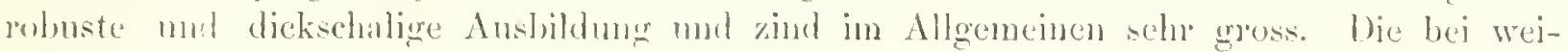
tem iöherwiegende Anzahl besteht in gewaltigen Brachiopoden, demuächst kommen Koral-

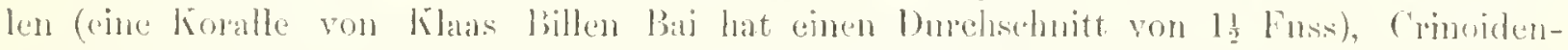
stengehn, Enkiniten, eingen wenigen ibuserst unansehnlichen Cephalopoden (bon den Hopn-

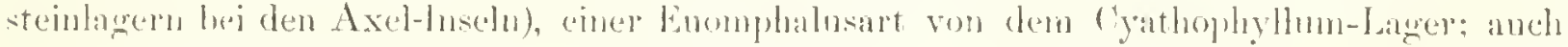
rin Tribobit-Fragment. int muter dem Spirifer-Kalk von den loven berge von Angelin erkannt worden.

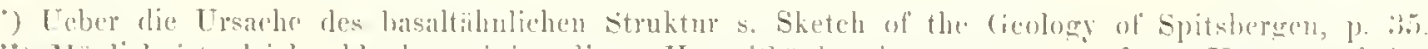

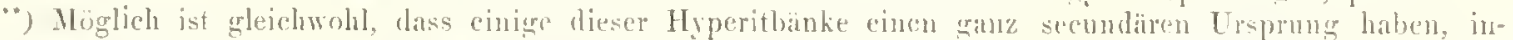
dem sie nichts anderes sind als verhärtotop I!peritsand, gleich domjenigen. der noeh houtigra Tages an dem

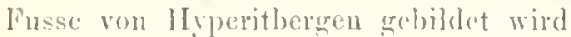

․) Siehe die oben angrefülnte Ablamdlungr. 


\section{BESCHREIBUNG DER AR'TEN.}

\section{Calamiteae Brign.}

1. Calamites radiatus Brgn. Taf. I bis VI.

C. caule cylindrico, articulis vix contractis, distantibus, sulcis in canle corticato parum conspicuis, in caule decorticato profunde notatis, parallelis, continuis, supra articulos transeuntibus, costis subplanis, tenuissime striatis; foliis liberis, linearibus; rinomate magno, cylindrico, ramoso, tenuissime striato, radicis fibrillis verticillatis, elongatis anguste linearibus, ramosis.

A. Brongniart hist. des régét. foss. I, p. 122, pl. 26. Schimper, le terrain de transition des Tosges de Köchlin p 321 , pl. I.

Equisetites radiatus, Sternb. Vers. p. 45.

Bornia radiata, Schimper Paléontologie végétal pag. 335, Taf. XXIV.

Calamites transitionis, Goepp. Flora des Uebergangsgebirges, nova acta Acad. Leop. carol. 1852, p. 116, Taf. III, IV, und 1860 p. 465 . Geinitz Flora von Hainichen-Eber:dorf p. 30, Taf. l. Ettingshausen die fossile Flora des schlesisch-maehrischen Hachschiefers, p. 10, Taf. I, 4, II, III und IV. Dawson Acadian geology p. 537. Eichwald Lethate rossica I, p. 166. Taf. XIII, 1-3. Richter der Kulm in 'Thturingen. Keitschrift der deutschen geolog. Gesellsch. XVI, p. 166.

Bornia transitionis, Roemer in Dunker und Meyer Palacontograph. III, 1, Taf. VII. Calamites scrobiculatus, Sehlottheim Petrefalktenkunde p. 402, Taf. 20, Fig. 4 *).

Bornia scrobiculata, Sternb. Vers. I, p. XXVIII. Goeppert nov. act. 1852 p. 131. Roemer in Palaeontograph. p. 4, T'if. I, Fig. 4.

Bornia Jordani, Goeppert l. c.

Calamites laticostatus, Ettingshausen 1. c. p. 12 Taf. III, 1.

Equisetites Goepperti, Ettingsh. l. c. Taf. IV, Fig. 2 (ein Wirtel Wurzelzasern).

Equisetites gradatus, Eichw. Lethaea rossica 1, p. 181, Taf. XIII, Fig. 3, 4?.

Calannites Sternbergi, Eichw. 1. c. 1. 172. Taf. XIV, 3?.

Calimites variolatus, Goepp. Flora des Tebergangsgebirges nov. act. 1852, p. 124, 262 , Taf. V.

Calamites obliquus, Goepp. 1. c. p. 121, Taf. VI, Fig. 9, 10.

Sphenophyllum dissectum, Gutb. in. Gaea von Sachsen p. 72.

") Sehlottheim gicbt als Fundort das Dachgestein des Steinkollenlagers bei Zürich an. lis ist schwer qu sagen wie Schlottheim zu dieser irrigen Angabe gekommen ist, den bekanntlich haben wir leider das Steinkoltlengebirge weder bei Zürich, noch ïberhaupt in unserer Gegend. - Da Sehlottheim die l'Hanze schon im Jalur: 1820 als Cal. serobionlatus beselrieben hat, bätte dieser Name das Prioritätsrecht, da er alser mur für eine Var. passt, hahe Brongniarts Bezejehuung vorgezogen. 


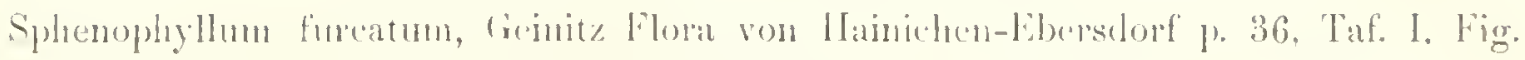

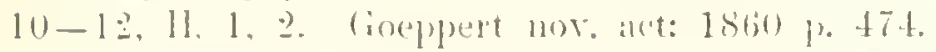

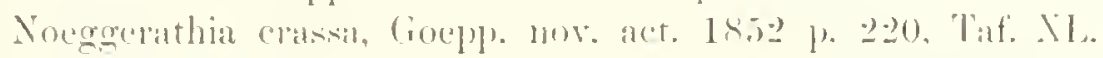

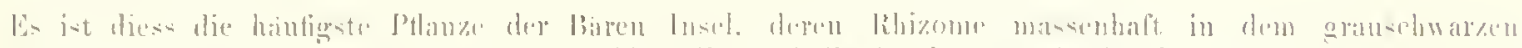

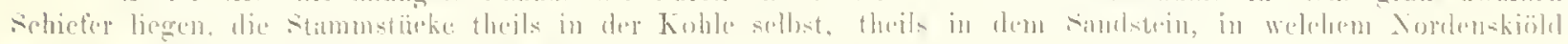

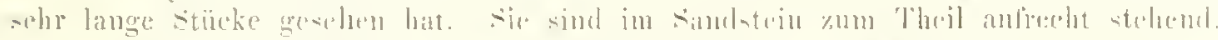

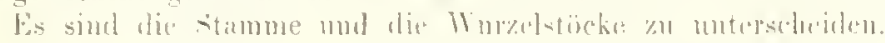

\section{SThMns'iéche.}

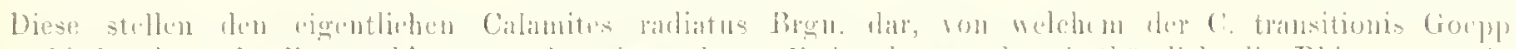

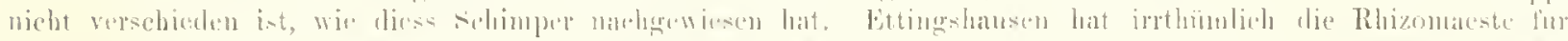

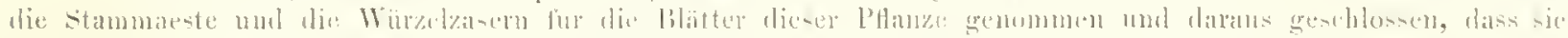

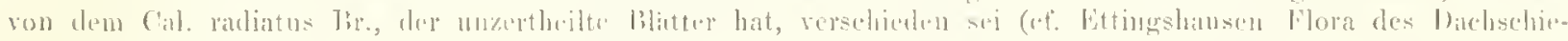

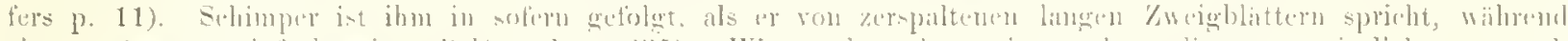

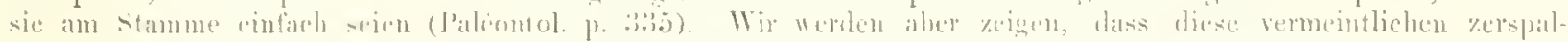

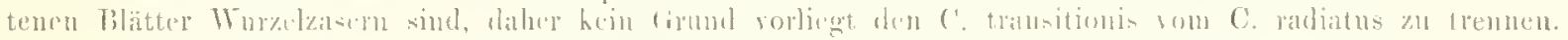

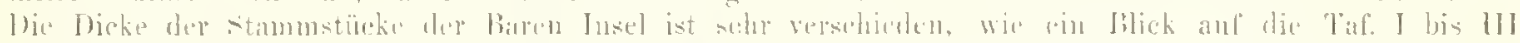

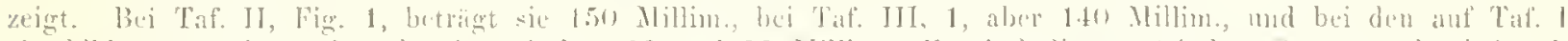

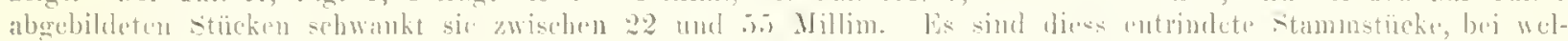

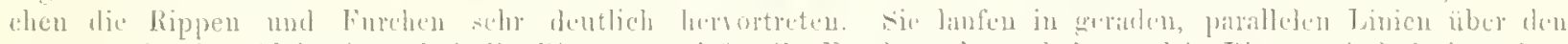

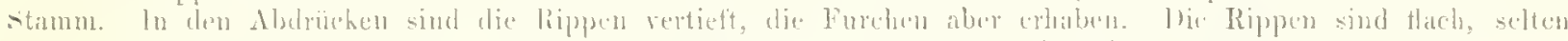

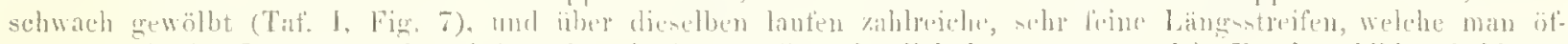

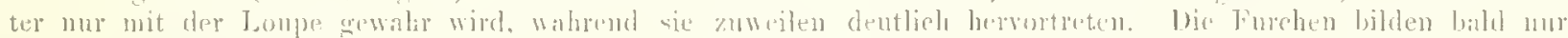

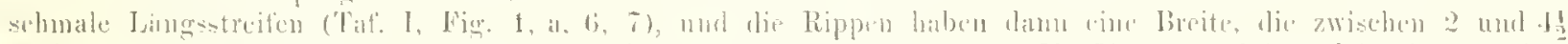

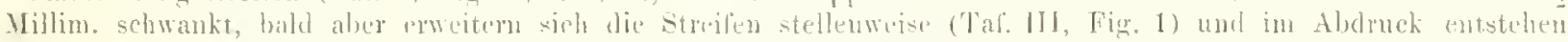

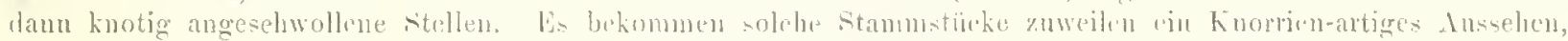

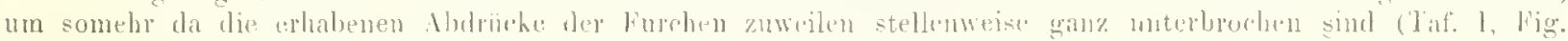

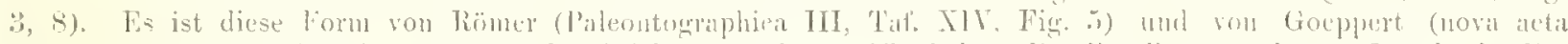

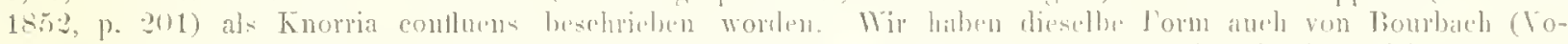

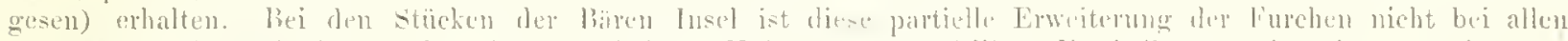

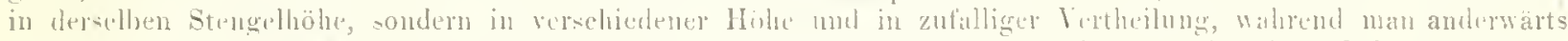

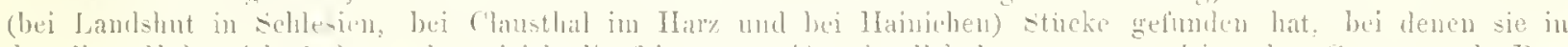

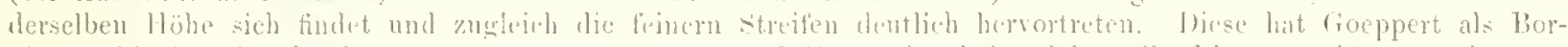

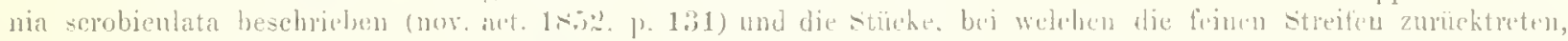

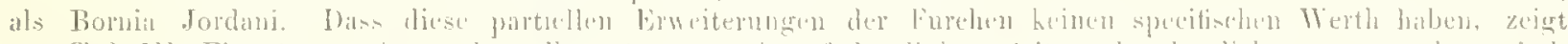

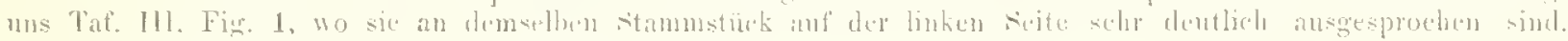

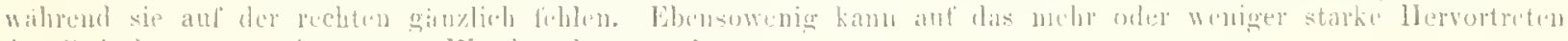

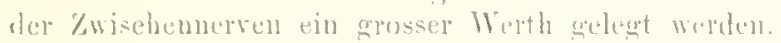

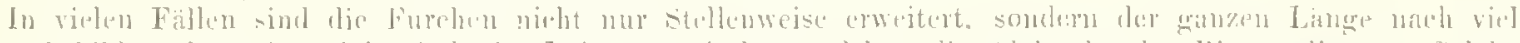

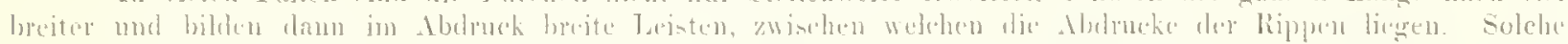

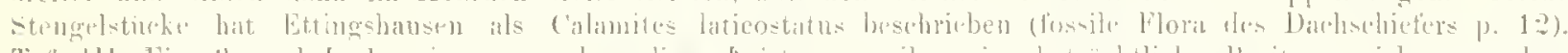

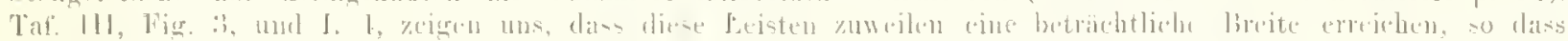

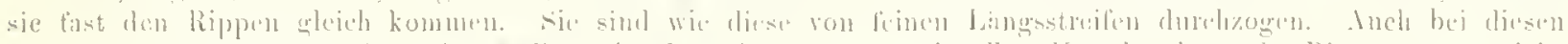

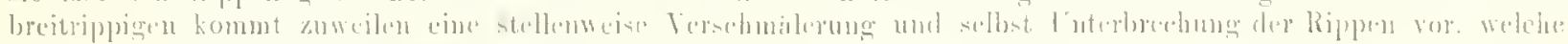

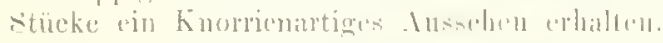

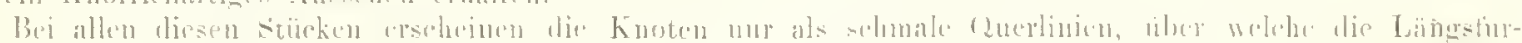

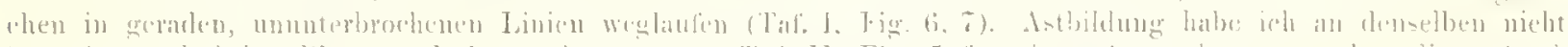

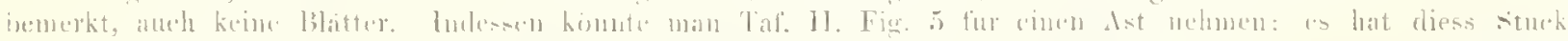

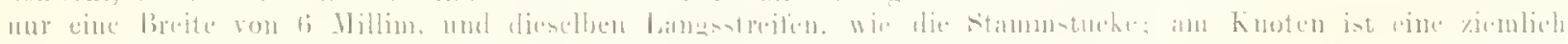

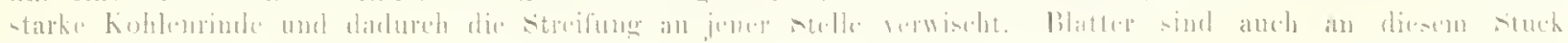
nicht trhlailtun.

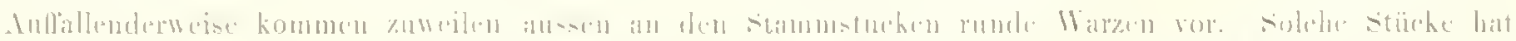

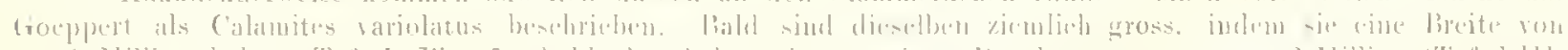

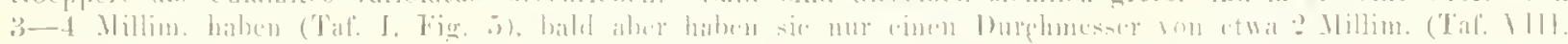

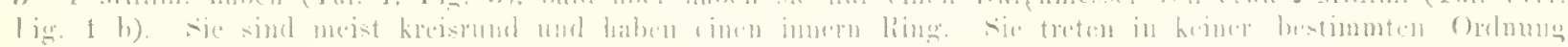

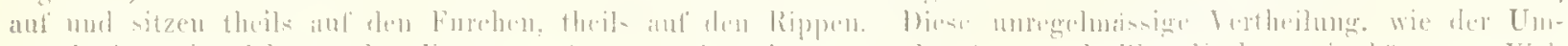

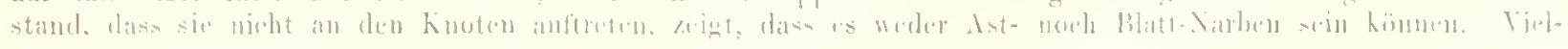


leicht rïlnen sie ron I'ilzen oder Flechten her, die anssen am Stamme anfaissen oder aber es sind Abdrück. von Rinden anderer. Pflanzen-diten, welche anl die Calamitenstämme gedrückt wurden, wofïr namentlich Taf. IA. Fig. 2 b, angefiilnt werden kam, wo ein Rindenstïck der stigmaria minnta neben einem C'alitmiten liegt mit solchen runden Eindrïcken, welche deuen der Stigmaria sehr älnlich sehen, nur wird die rogelmässige Stellung drerselben vermisst, wouluch die Dentung zweifelhalt wird.

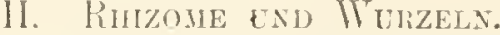

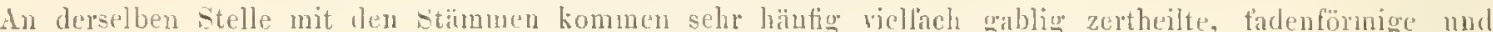
urist in allen Richtungen durcheinander gewirte Gebilde ror, welehe ohne Zweifel die Wirzelzasern unserer" l'tanze darstelten. Sie bedecken zuweilen ganze Platten und sind selten so guagert, dass man iluren Furlauf rerfolgen kann. Diess ist indessen ler Fall bei Tat. IT, Fig. 2, .9, und Tar. II, Fig. (i. In einzelnen Fällen sieht man, dass zahleciche soleher Wurzclzasern wirtelig um einen Knoten herumstehen (Tat. 11, Fig., 2 b). Ls ist diess eine Bildung, mie wir sie genan so bei den Rhizomen der lebenden und fossilen Fquiseten haben (cf. miocene Flor spitzbergens Tal. I, Fig. 2, 10, 14, II, 1, 2, :, 6) Man hat aber irrthümlich bisher diese Murzclzasern fïr Blätter genommen, was Geinitz veranlasst hat, diese Rbizome zu sphenoplyyllum zu stellen. Ettiugshausen hat zwar die Zusammengelörigkint derselbun mit unserem Calamiten erkinnt, aber setzt sie als beblätterte Aestu in den Stamm, whirend sie als bewurzelte Rhizome in die Erde gehörell. Ueber die Grösse, Form mul Veraestelung der Rhizome geben die Taf. II, lig. 2-t, Taf. IV, T und VI genügenden dufsrhluss. Die Grösse derselhen ist sehr betrïchtlich, indem sie eine Breite vou 11 Decin. erreichen, und sie milissen sehr lang gewesen sein, wie das Taf. VI ahgebildete, immerlin ganz frngnentarische Stück beweist. Dic Knotcn sind bald mur schwach angedentet (Tal. V), balıl aber suhr deutlich ansgesprochen (Taf. IV) und dann zuweilen etwas angeschwollen (1'if. IT, Fig. A, VII, Fig. 1 a). Bei Taf. IV, Fig. 5, bildet die Querlinie drei Bogen. An dem Knoten sehen wir nicht selten mudlichc Narben (Tal. IV, Fig. 4, 5, II, 4), welche uns die wirtelständige Stellung der" Aeste anzeigen. Einzelne solelie Aeste sehen wir noch am Rhizom befestigt (Tal". IV, Fig. 1) oder sie liegen neben demselben (Taf. II, Fig. 2, V). Sie sind rie die Rhizomstämme cylindrisch und stellenweise mit Knoten versetleu und an diesen mit den Wurzelzasern besetzt. Wis diese Rhizomacste und Rhizomstämme vor den oberirdischen Stiumen voraus anszeichnet ist, lass die Längstreifen und Rippen viel weniger hervortreten und zwar noeh weniger als bei den berindeten Stimmen, wogegen die feineren Zwischenstrifen cbenso dentlich sind. Stellenweise treten diese ebenso deutlich bervor ats die hauptstreifen, und dano haben wir sehr zahlreiche und momein dieht stehene parallele Streifen (Tar. Y), oder von den Hauptstreifen, dic ein Stük weit deutlich sind, rerlieren sich einzelne unter den feinern, oder a's sind alle Längsstreifen verwischt und die Riuden crscheinen als glinzend ghatte lä̈nder, bei denen man nu mit der Loupe die zalhlreichen und dicht stehenden Lingsstreifen sehen kann. Dahurch bekommen diese Rhizone und ihre Acste ein etwis anderes Ausschen, als die oberidischen Stämme"), zeigen abel so viele Uebergünge zu denselben, dass ilıc Zusamnengeliörigkeit nielıt bezweifelt werden kann. Anlänglieh hahe ich vermuthet, es könnten diess die äussern Rindenparthien der Stämme unseres Calamiten sein, da bei diesen die Streifen und Rippen ancl weniger stark liervortreten. Das Zerspalten zahlreicher Schieferstiicke, welche mit denselben erfiillt waren, ergab aber, dass unter diesen Rinden niemals solr.lıe lagen mit stärkern Streifen und Rippen.

lici mehreren Stïcken sicht man anf den Rinden cigentlü̈nliehe Eindrücke, welche wahrseheinlico von

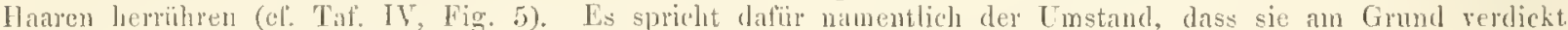
sind, vorn aber in cine feine liorste auslanfen. Sic müssen stellenweise dicht beisammen gestanden haben und verbalten sich wohl iibnlich, wie die Rhizombare maneher Nasserpflamzen, so der Nymphaecn.

Zn Calamites radiatus rechme anch das Tal. $\mathrm{X}$, lig. 8 abgebildete Stiuck. Es ist ansgezeiehnet durch die kurzen Intemodien und die dicht beisammen stehenden Knoten. die in Abdruck Querfurchen bilden. Das sehr unvollständig erhaltene, in grauschwarzem Kohlenschiefer liegende stitek ist 27 Millin. ling. Die Knoten sind 4 Millim. von einander entfemt. 1)ie feinen hängsstreifen stehen dielt boisanmen und sind von gleicher Stärke. Ist sehr äbulich cinem Stïck, das C. Riehter als Rhizom des Calamites radiatus abgebildet bat (ef. \%oitschrift der dentschen geolog. Gesellsch. XVT, 1864, 'T'af. T, lig. 8 and Schinper Paleont. 'Tat. XVIV. Fig. 7). Nach

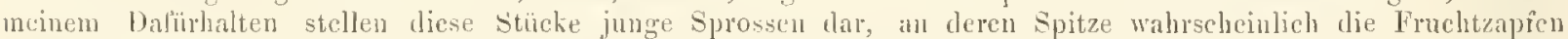
sich gebildet haben. Sie erinnern in mancher bezichnng auch an die sonderbaren Gehilde, dis: Brongniart als

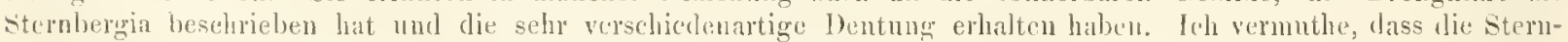
hergian, welche aus den Culn Engtands angegeben werden, bicrlier gehören.

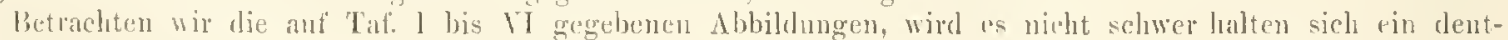

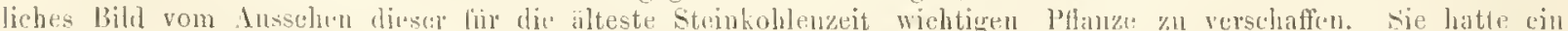
scheukelsdickes grosses Rhizom, das wohl von schwammiger, weicher struetur war, denu auch dic ganz grossen

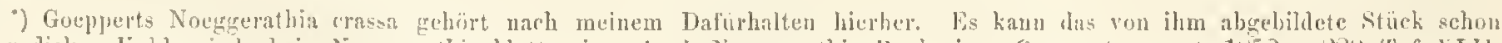

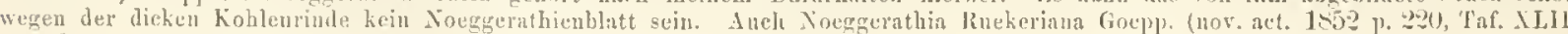

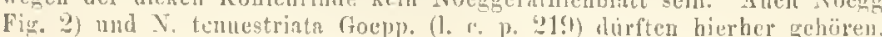




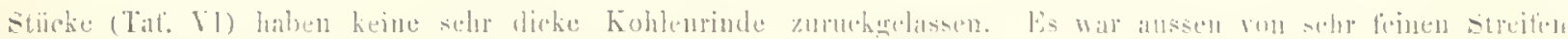

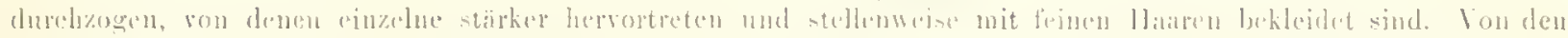

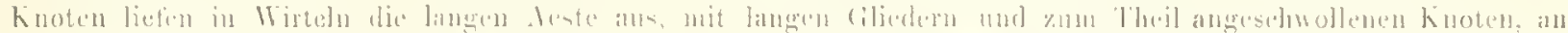

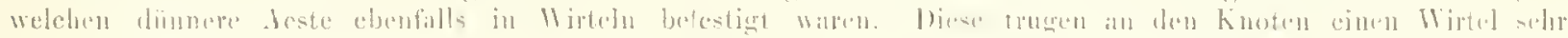

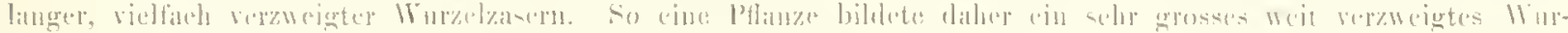

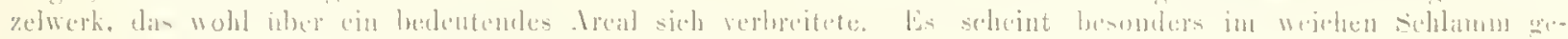

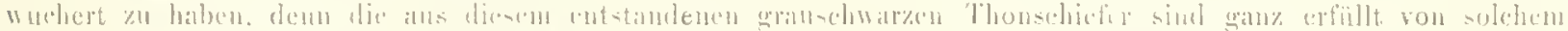

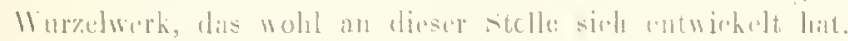

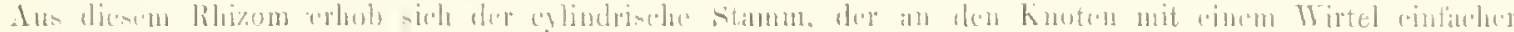

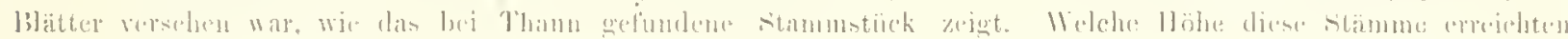

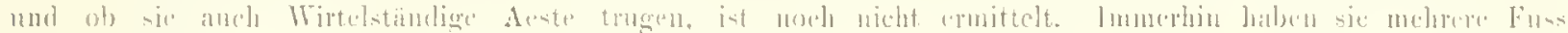

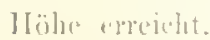

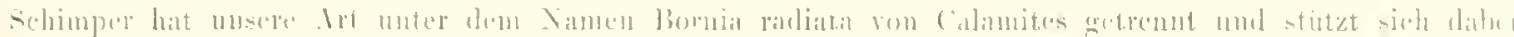

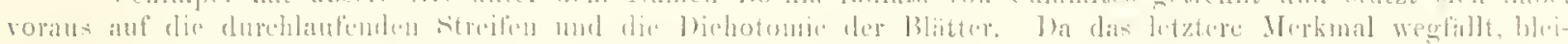

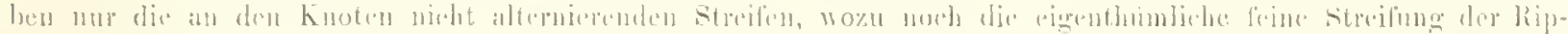

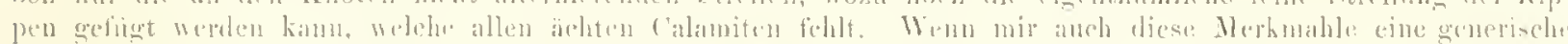

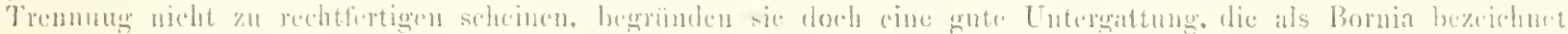

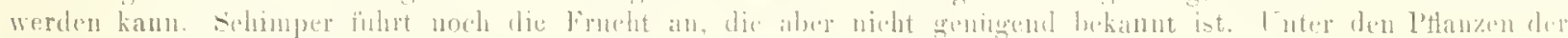

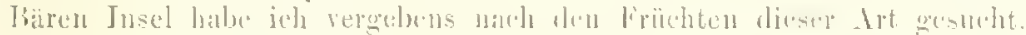

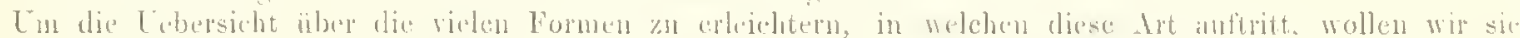

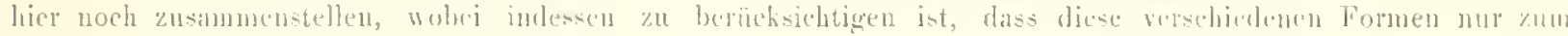

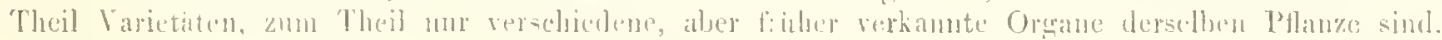

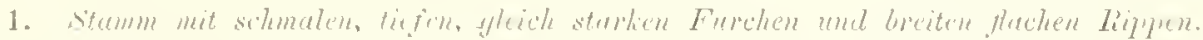

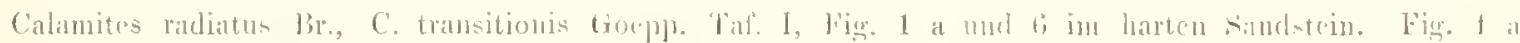

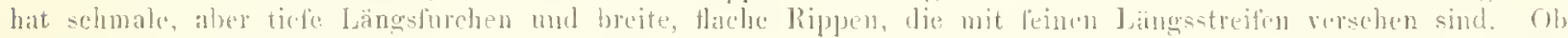

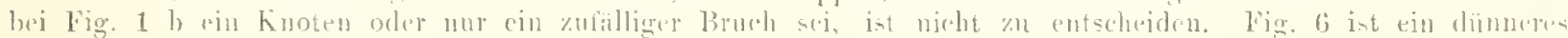

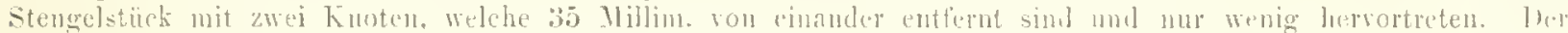

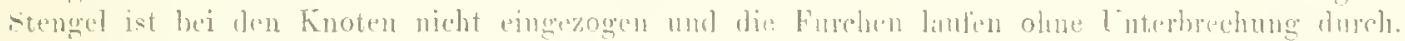

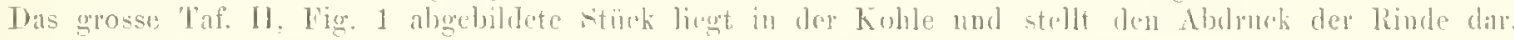

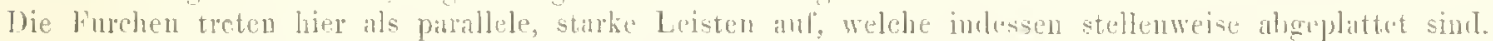

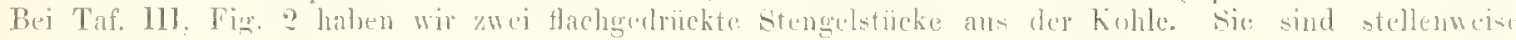

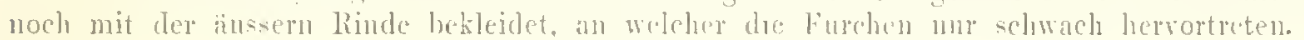

\section{?. Furehne stellenueise verbreitent. Tar. III, Fig. 1.}

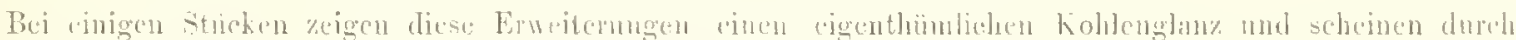

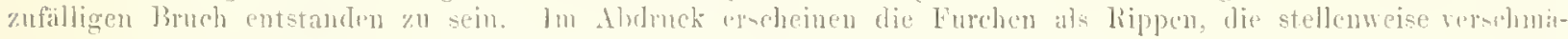

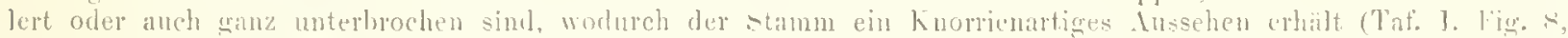

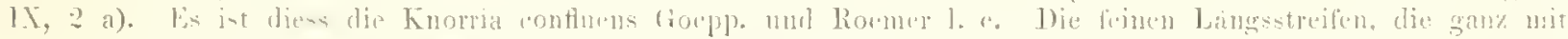

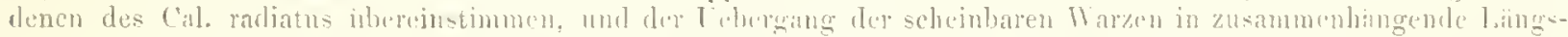

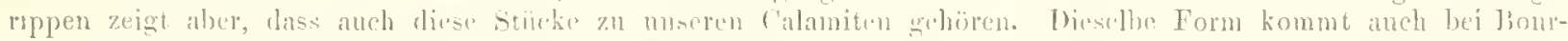

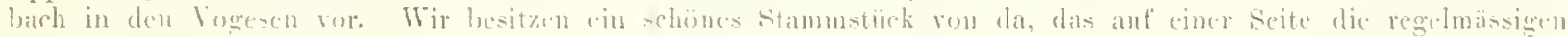

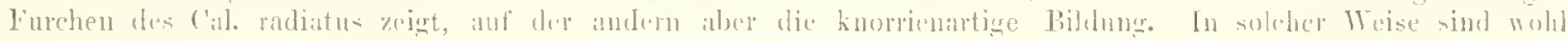

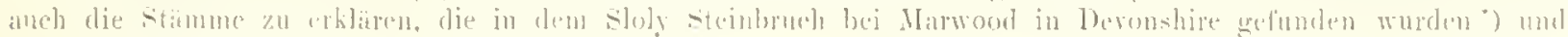
wahrseheinlich zur rorliegenden .irt gechiorm.

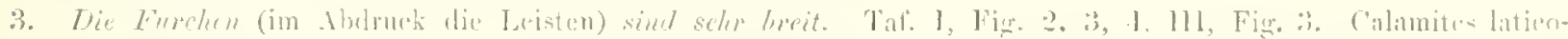
status litingsh. 1. P.

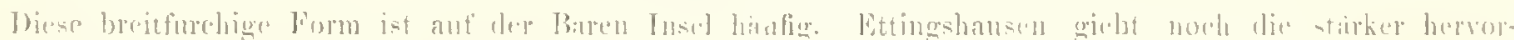

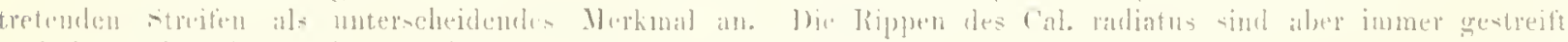

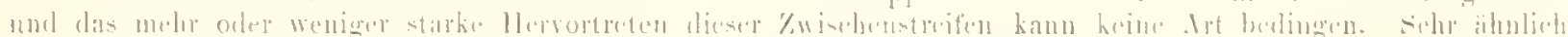

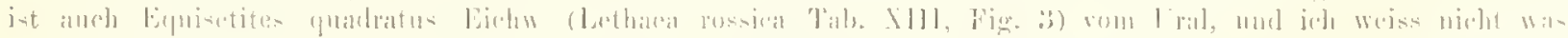

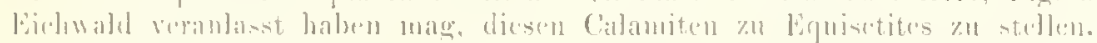

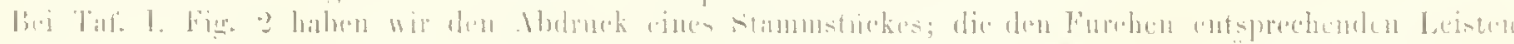

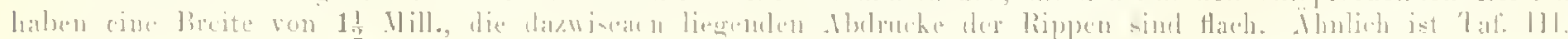

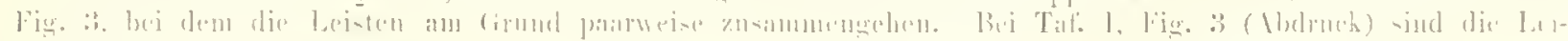


sten stellenweise versehmälert und sich abthaehend, so dass aueh bei dieser breitfurehigen Form dieselbe Bildnng wiederkehrt, die wir rorhin hesehrieben haben. Taf. 1, Fig. 4 stellt ein diunnes Stengelstïek dar mit viel enger" stchenden l'urelien und Rippen.

\title{
4. Die Rippen sind etwer gewolbt. Taf. 1, Fig. 7.
}

Der Knoten ist anf der rechten Seite zerdrïekt und diess wohl der Grund, dass dort die Rippen etwas versehober: sind, so dass die Furchen hier alternieren.

5. Der Stengel stelleneeise mit muden Hursen besetzt. Taf. 1, Fig. 5, 'Taf. 1X, Fig. \& b. - Calamites rariolatus Goep.

\author{
6. Stengel mit sehr hurien Internodion. 'f'af. X, Fig. 8.
}

7. Rhizome mit Aesten und Wurzelsasern. Sphenophyllum tureatum Gein. Taf. 11, Fig. 2-6, Ill, Fig. 1, Tat. IT, Y, Y'.

Taf. V, Fig. 1 ist ein grosses Rhizom mit 10-15 Millim. von einander abstelunden, etwas tiefern Streifen und zahlreichen äusserst zarten Zwisehenstreifen. Velor die Mitte läuft ein Knoten. Zahlreiehe, parallele, sehief stehende Streifen sind wahrseheinlich die Abdrïcke ron Stengeln, die in anderer Riclitung verliefen. An dem breiten Stengelstiiek Fig. Z verlieren sich die tiefem Streifen, nud is ist ron zallheiehen, fast gleichstarken Streifen durehzogen. An dem rahlreichen Aesten (Fig. 3) sind dagegen wieder stärkere und feinere Streifen zu unterseheiden. Ton einem sehr grossen lihizom, hei welehen die stärkcm Streilen stellenweise ansgohen, entspringt ein langer Ast, der zwci Knoten besit\%, welehe nieht angeschwollen sind, wälnend ein zweiter dabci liegender Ist eine starke Anschwellung an Knoten zeigt. Dasselbe ist der Fall bei Taf. V111, Fig. 1 a, bei dem aueh die Streifung schr deutlieh ist, nauchtlieh bei einem dünen, schr langen und doch dalsei ungegliederten Ast. Daneben liegen die langen, vielfach rerzweigten Wn'zelzasem. Noch grösser sind die Taf. YI abgebildeten Rhizome. Es liegen vier auf der Steinplatte, von welehen drei zusammenzugehörcn seheinen. Die Knoten sind nur dureh schwach hervortretende Querlinien angedentet; die stärkem und sehwächern Längsstreifcu stellenweise sieh verlierend.- Die Noeggerathia crassa Goepp. ist anf ein solches Rbizomstüek gegründet. Auf Tal: 11 zeigt nns lïg. 1 cin Rlizom mit dentliehen Längsstreifen, cinem Kuoten und einem ziemlich langen 1 st, der beim Knoten entspringt. Ton dem Knoten des Astes gehen zarte Wurzelzasern ans. Fig.? ist ein Stengelstiiek mit dentlichen, zum Theil aber etwas verworrenen Streifen und daneben gablig getlieilten ITurzelzasern, deren viele anf Fig. 3 sich anslyciten. Fig. 4 haben wir Rhizomstäcke mit sehr dentlichen, etwas angesehwollenen Knoten, ron denen der eine zwei grosse lunde Astnarben trägt. Fig. 5 ist ansgezeiehnet durch die bogenformige, den Knoten anzeigende Querlinie und die wohl von Hareu herrüluenden Eindrüeke, welehe uns auch Fig. 6 zeigt. Auf Taf. 11, lig. 2 licgen neben cinem Rlizomstiiek zwei mit Knoten versehene Leste, an denen die Wnzelzasern befestigt sind (lig. : b). Fig. $\$$ zuigt uns sehr schön die feine Streifung der Rhizomaeste, die Kuotın und die grossen rnnden . Istuaben and Fig. 6 die Wurzelzascm. Taf. 111, Fig. 4 einen kleinen Rhizomast, dr.r am Knoten weiter verzweigt ist.

Die Wurzelzasern sind meist sehr fein und lang (Taf. 1T, 3, VII, 1), znweilen aber aneh ziemlieh stark (Taf. IV, 1, 2), meist reraestelt, doch kommen auch rinfache vor. Der Asteropliyllites elegans Goepp. (nor. act. 1S5? Tal. VI, 11) aus den zum Kohlenkalk gehörenden Thonsehiefer von Haendorf (Glatz) dürfte daher hierher gehören.

\section{Filices.}

2. Carliopteris fromlosil, Goepp'sp. The. XIT, Fig. 3, 4.

C. fronde speciosissima, pinnata, pinuis basi subcordatis, apice obtusissimis, mediis imbricatis, 4-10 centim. longis; nervis e basi exorientibus numerosis, dichotomo-fureatis, ranis elongatis, tenuissinis, densissimis, mediis subrectis, lateralibus parum arenatis.

Schimper Paléntolng. végét. p. 453 T'af. XXXIV. Cyclopteris frondosal Goepp. nov. act. 1852 p. 16\%, Tab. XIY, Fig. 1, 2) und 1860 1. 502.

Cyclopteris Haidingeri, Ettingsh. Flora des Dachschiefurs p. 96, T'ab. V.

Cyelopteris Küchlini, Schimp. végét. foss. du terr. de transit. 1. 340, Taf. XXIIIII.

Von diesem prachtvollen Forn, von welehrom namentlieh Ettiugshausen cin sehr selönes Excmplar aus dem Dachschicfer ron Meltrls in Mähren abgebildet lat, sind in den Schiefern der Bären lnsel zwar nur ein- 


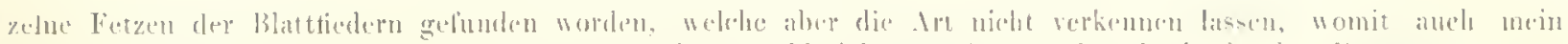

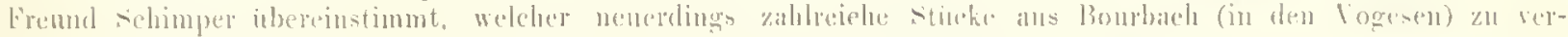

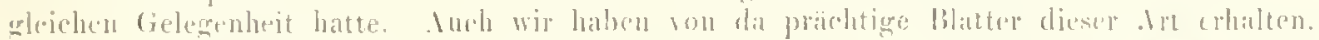

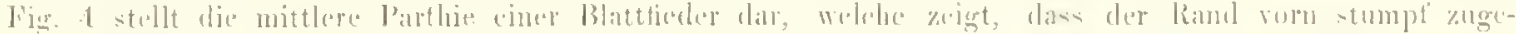

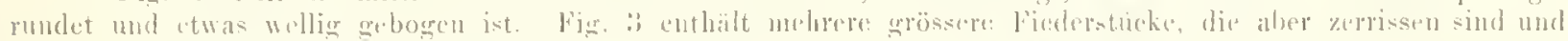

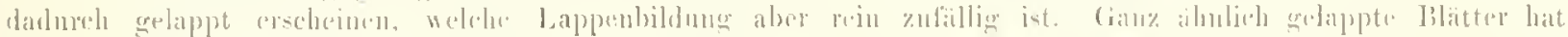

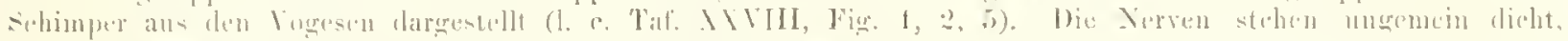

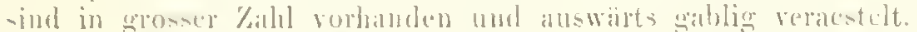

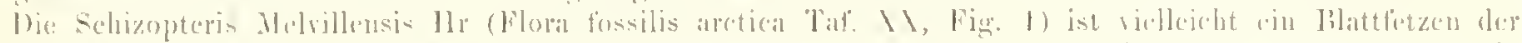

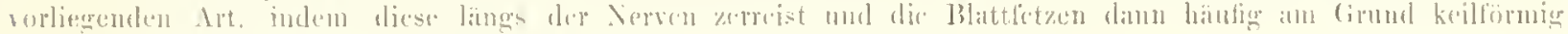

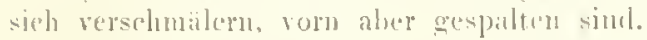

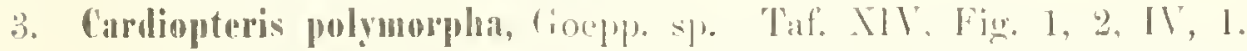

C. pinnis rotundatis, integerminis (sacpins fortuito laciniatis), obtusissinis, batituline 15-20 mill., longitudine 22-30 nill. metientibus, nervis e basi orientibus nuncrosis, dihotomo-fureatis.

Schimpte P'aleontul. viget. P. 452.

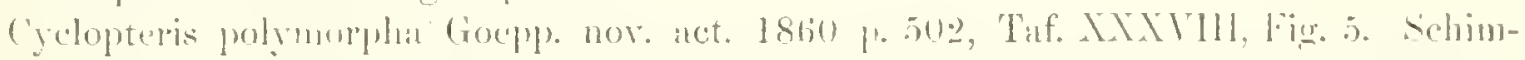

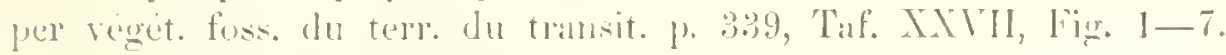

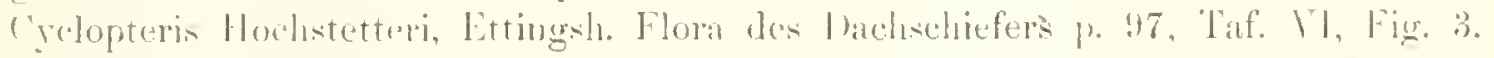

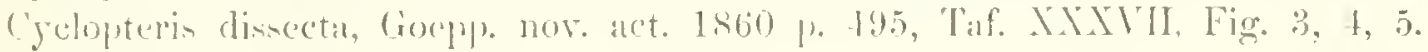

Ancimia Tachemakii, Ettingsh. l. c. p. 28.

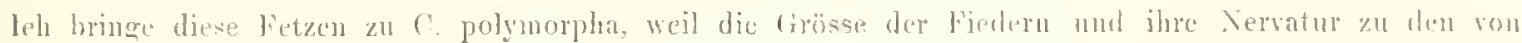

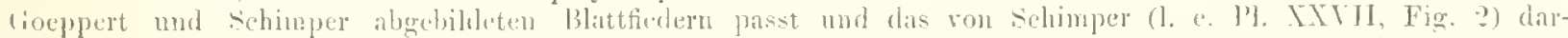

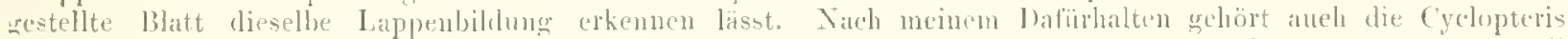

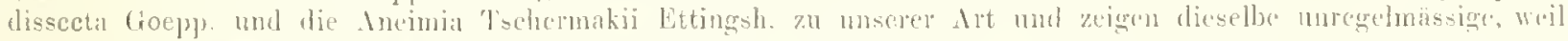
chen zul'ïlige, Lappenbildung.

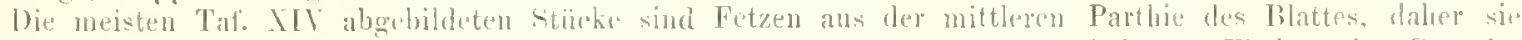

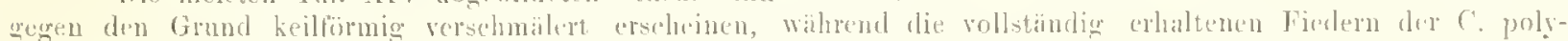

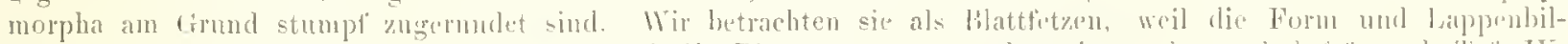

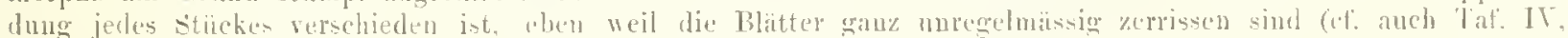

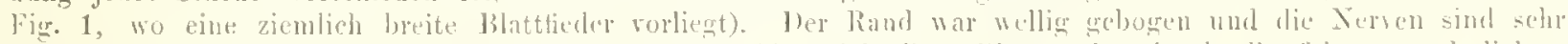

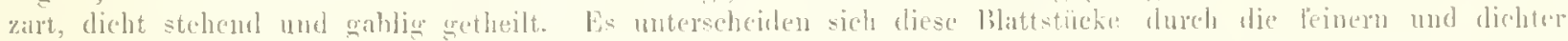
stehenden Jerven von Palacopteris hibernica l'orb. sp.

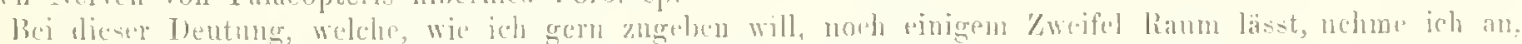

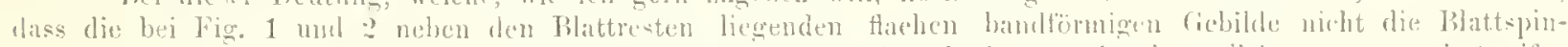

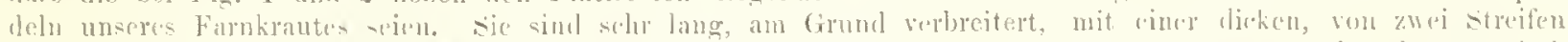

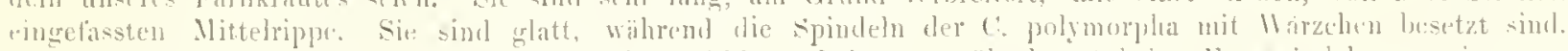

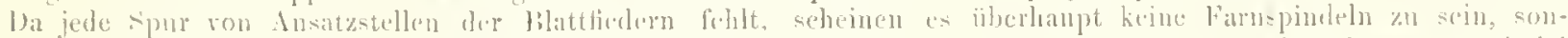

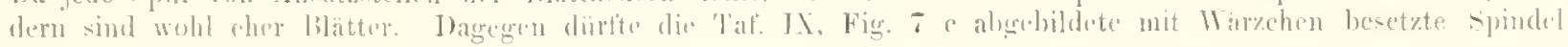
licerher gehörest.

4. Palaeopteria Roemeriana, Goepl. s]. Taf. XIV, Fien. 5.

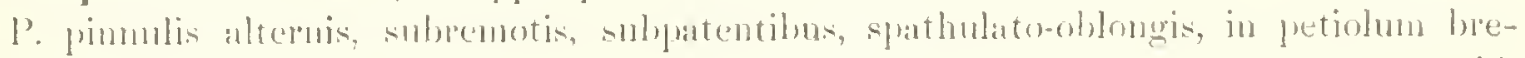

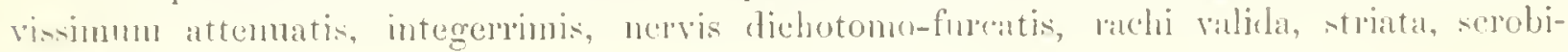
culat:i.

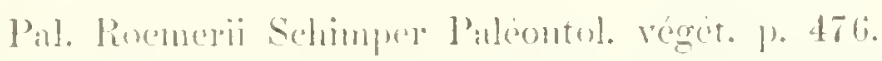

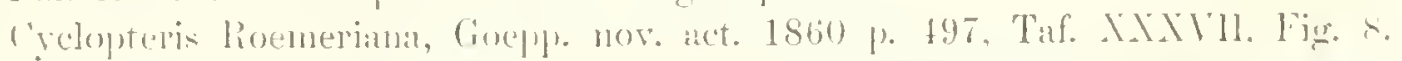

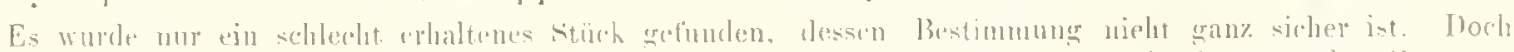

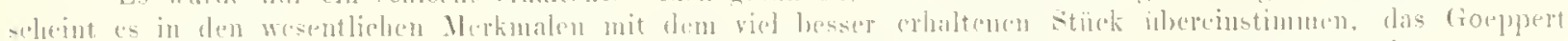

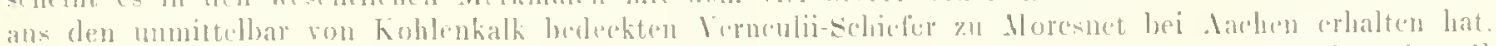

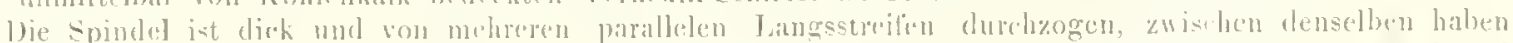

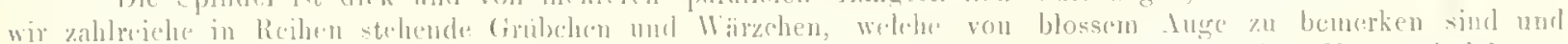

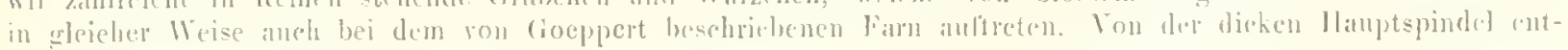


spriugen viel dümere; an einer derselben sind ganzrandige gegen den Grund versehmälerte und rom zugerundete lïederchen befestigt, die von feinen, gablig zertheilten Längsuerven dureluzogen sind,

Es liegt diess stück in einem liarten, grausehwarzen Sandstein uit vielen seln kleinen Glimuerblätehen. Zweifelhaft sind die zwei an einer dïunen spindel befestigten lilattfiederelocu, die anf Taf. IT, Fig. 1 abgebilds't sinc. Sie sind rom abgebroehen, die basis ist aber beilförmig verschmälert, wie bei der vorliegendn Art.

5. Splenopteris Schimperi, Goepp. Taf. XIII, Fig. 3-5.

Sph. fromle dichotoma, lachi primaria valida, semicylindrica, scrobiculata, pinmulis sessilibus, pimatisectis, lobulis mumerosis, erectis, anguste linearibus, subcuneiformibus.

Schinper terrain de transit. des Tosges p. 341, Taf. XXIX. Paléontolog. végét. p. 408 (S. Schimperiana).

Hymenophyllites Schimperi, Goepp. nov. act. 1860 p. 490, t. XXXiri, 2, a, b (die Figur ist aber ganz missrathen).

In einem risenhaltigen, an der Anssentläche rothbraunen, inwendig hıcll bräunlieh granen Thon liege• die Reste cines Farnkraut's, wrlehe durelı die starken, gablig getheilten und von zalılreiehen feinen Querrunzeln durehzogenen spindeln und die lein zertheilten Blattfiedem mit sph. Schimperi übereinstimmen. Jedoelı sind die Lappen ler Buäter etwas schmaler und rorn kanm merkliels rerbreitert, aber unvollständig erhalten.

Die aul' Fig. 4 a abgebildete Blattspindel ist zweimal gablig getheilt, naeh Art der Gleichenien. Zwei Streiten fassen eine mittlere lippe ein. Die Spindeln, Fig. 4 b, e, d, sind mit melneren lieilıen kleiner Grïbchen besetzt, mit welchen kleine Wärzehen wechseln. Die Blattfiedern sind grossentbeils zerstört, doel, ist bei Fig. 4 e eine dünue spindel crhalten, welehe von den Resten melnerer Blattfiederehen umgeben ist. Ein parr derselben sind handförmig gelappt, während andere fiedersehnittig, aber sehr zerdriiekt sind; die Lappen sind sehr sehmal und auswärts nur sehr sehwach verbreitert (Fig. 5 ein Stüek vergrössert).

Auf Fig. 3 sind kleine Reste einer sphenopteris, welehe cler Sph. refraeta Goepp. (nov, aet. 185? p. 141, 'Taf. XII) äbnlieh sehen, doch zur Bestimmung zn umrollständigg erhalten sind.

\section{Selacines.}

6. Lepidodendron (Sagenaria) Veltheimianmu, Sternb. Taf. VII], Fig. 1-7, IX, 2 a, 3, 4.

L. foliis scmipollicaribus, patentibus, leviter incurvis, foliorm pulvinis corticalibus ellipticis, utrinque angustato-acmminatis, basi incurvo-caudatis, linea media elevata acuta longitudinali aliarque transversali biancuata insignitis, cieatricula immersa subrhomboidea; ranorum junioreun rhombeis utrinque acmminatis; ciratricibus trunci decorticati oblongis rel elliptico-lanceolatis, utuingue acuminatis.

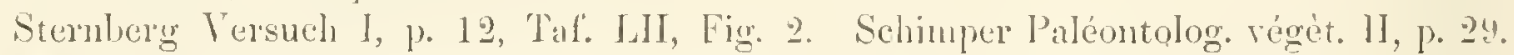

Sagenaria Velthemiana, Presl. in Sternb. Ters. III p. 180, Taf. LXIIII, Fig. 14. lioemer in Palacontogr. III, Taf. VII, 14. Goeppert nov. acta 1852 p. 180-184, Taf. AVII-XX; 1860 p. 520. Geinitz Flora von Hainichen p. 51, Taf. IV, 1-5. 11; II, 1, 3. Schimper teriain de transition des Voseres p. 336 (ex parte), 'laf. XXII, 1, XXII, XXIT, XXYI, $1-4$.

Sagenaria acmminata, Goepp. nor. act. 1860 p. 185 . Schmper l. c. Taf. XXY', l-4. Ist häufig unter den Kohlenpflanzen der Bären Inscl; die Stämue und Istreste liegen theils in der Kohle sclbst, theils in den schwarzen Eehichern. So hiafig alser entrindete heste sind, wurde doeh bein gutes

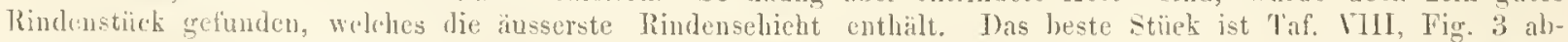
gebildet. lis ist granz platt gedriirkt und darum sind wohl die Blattwilste in nur selwaeh nul'steigenden Parastielh'rl. Sie sind elliptisch, oben und unten in cine schmale spitze ausgezogen, doch ist diese bei der Mehr-

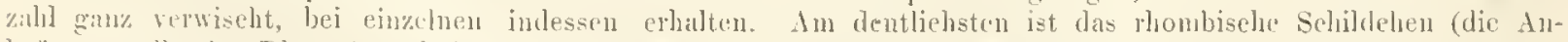
heltungsstell, des Blattes) und die Ruerlinie, weldoc etwas oberhalb der Mitte liegt und brim Selildelen in der.

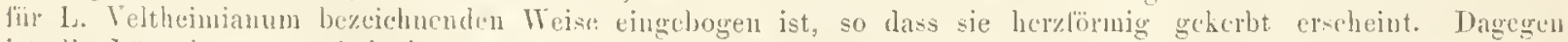
ist die Längskante nur bei vin par Blattwillsten schwach angedeutet, bei den meisten ganz rerwisclit. 


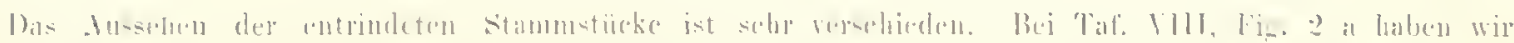

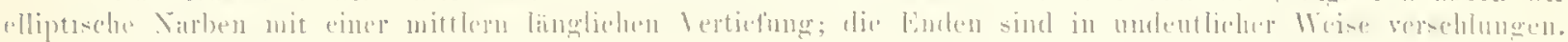

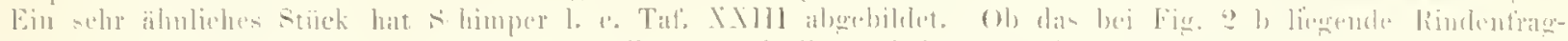

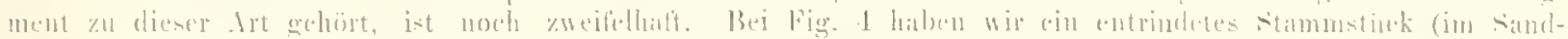

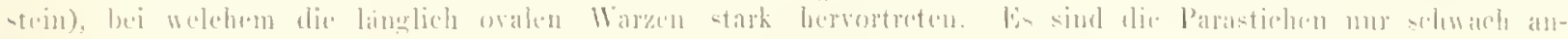

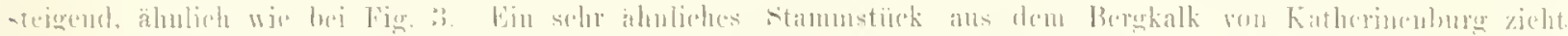

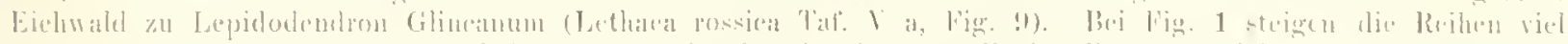

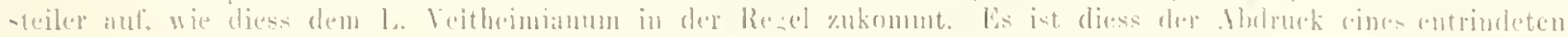

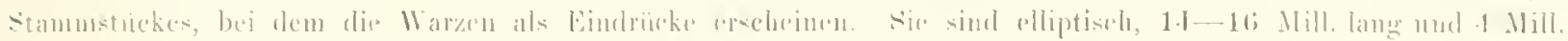

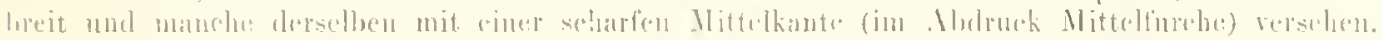

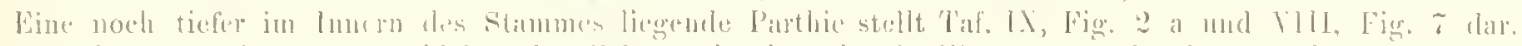

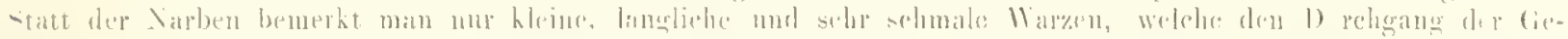

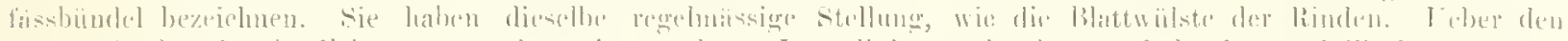

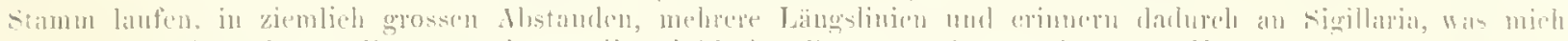

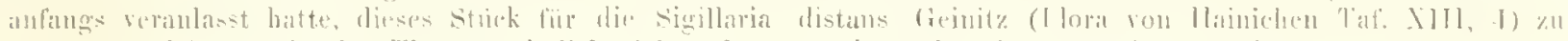

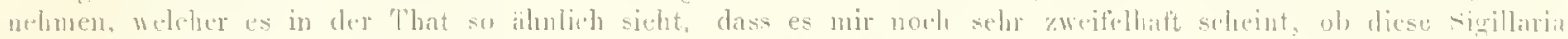

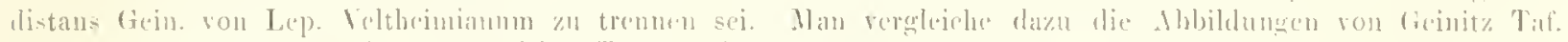

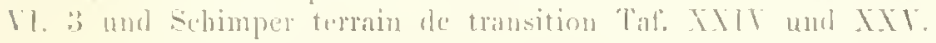

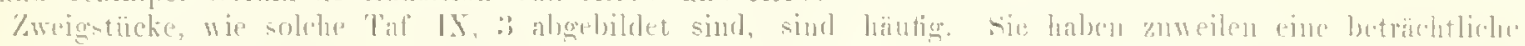

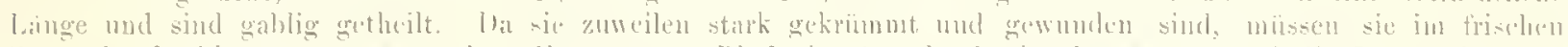

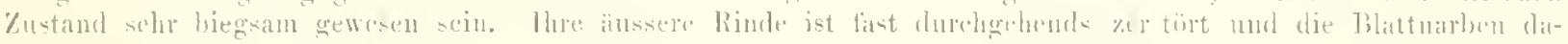

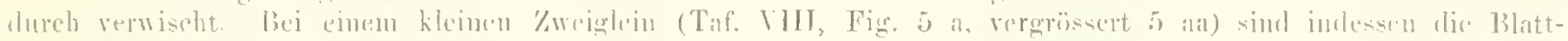

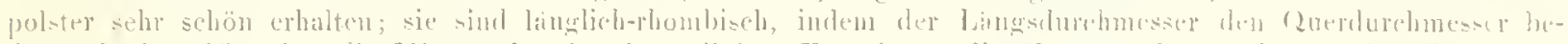

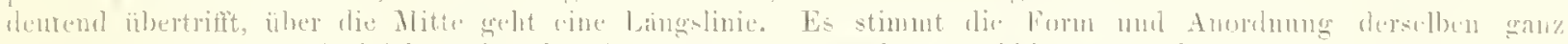

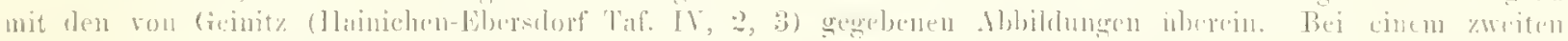

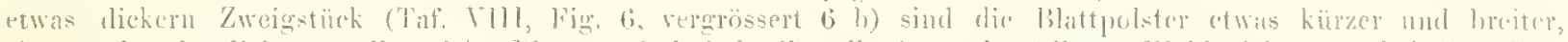

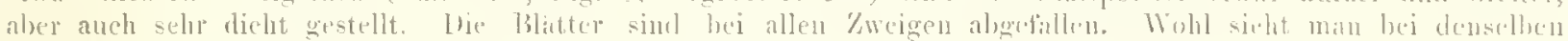

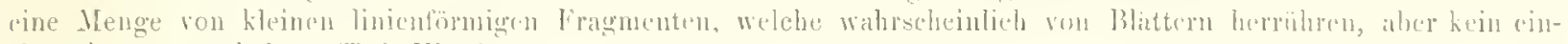
zige- ist gauz erlalten (Tai. IX, : $)$.

Bei den Lyeoporlien haben wir vieltach velastolte Murzelzasem. Die Aeste derselben lanten after in

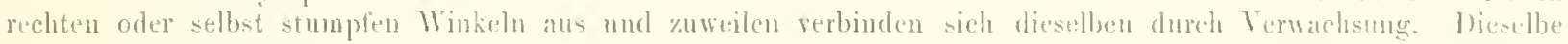

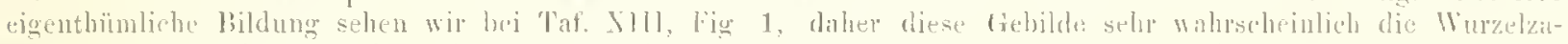

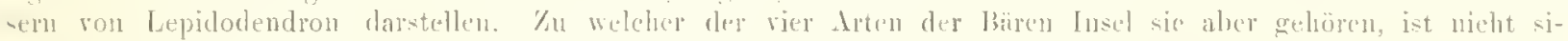

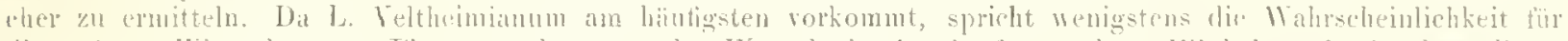

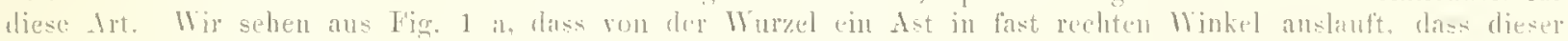

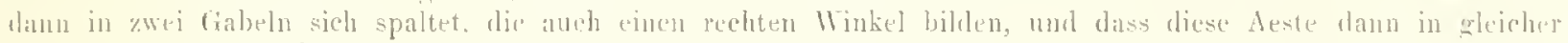

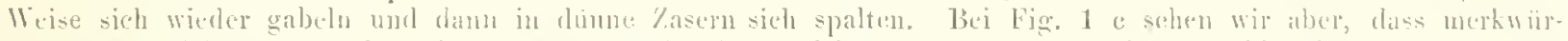

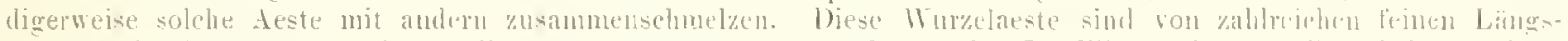

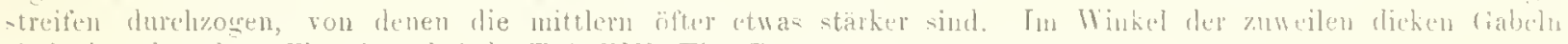

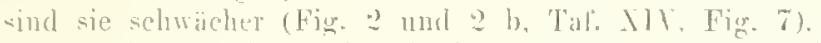

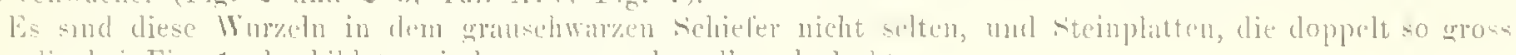

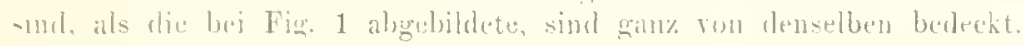

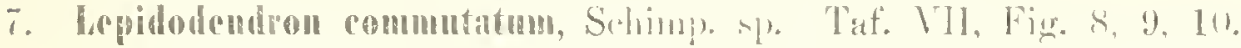

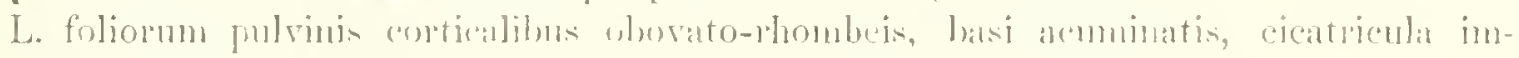
mersa sulmrhomboidea, sulbapieali.

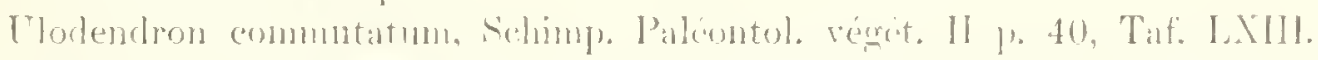

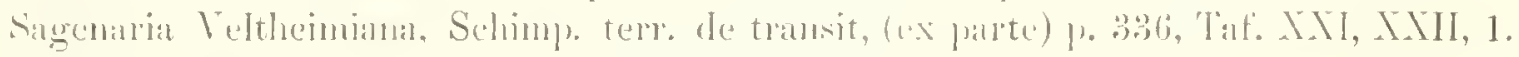

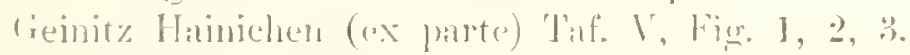

Zirmulich selten.

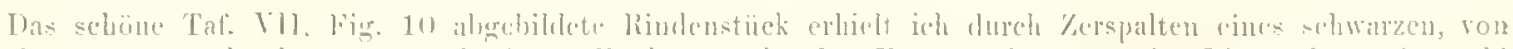

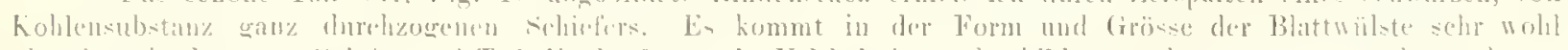

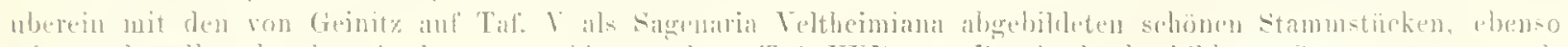

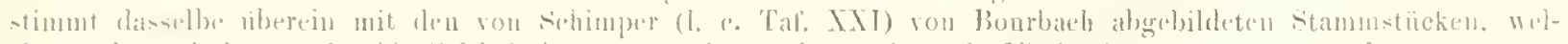

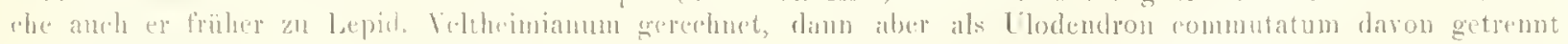

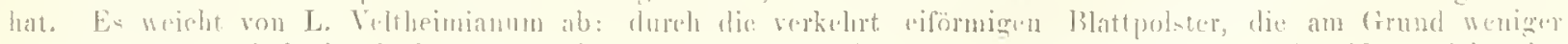

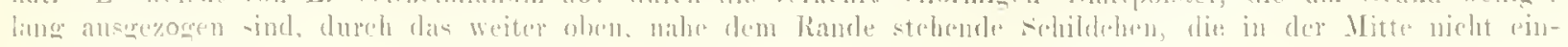


gebogene Querlinie und den Ilangel der Längstinic. In allen diesen Punkten stimmt es mit den Exemplaren der Togesen überein, nur fehlen bei der Rinde dor Bären Insel đlie grossen runden Seheiben, welche Ulodendron auszeichnen. Da aber die Blattwiilste und Blattnarben der Ulodendren ganz mit denen ron Lepidodendron überrinstimmen und bei kleinern Stücken, wie es die đer Bären Insel sind, es mmöglieh ist zu entschciden ob sio zu Ulodendron oder Lepidodendron gehören, thun wir besser sie nicht zu trennen, und ich muss in dieser Beziehung den IIrn Geinitz und Gocppert beistimmen, welehe Ulodendron eingezogen haben. Es ist diess um someln der Fall, da noelı in Frage komnen kann, ob die vorliegende Art ron L. Teltheimianum zu trennen sei, oder zu den vielen Formen derse\}ben gehöre, worüber erst ein reicheres Material entseheiden kann. In den kleinern Blattnarben und ihrer Form eriunert die Art aneh an L. dichotomum Sternb. (l. Sterubergi Lindl.).

Bei Tal. V1l, Fig. 10 haben wir auf der linken Seite die gewölbten Blattpolster, auf der rechten aber dic vertieften Eindriieke von solchen. D)as kleine rhombische Schildchen (die Cientricula) ist an obem gerundeten Ende des Polsters, wo dasselbe am meisten gewölbt ist, die weiter oben liegende Parthic, die in eine Spitze ansläult, ist nur angedeutet. Naeh unten ist das verkeln't eiförmige Blattvolster verselnmälert und iu eine gerade Spitze auslanlend. Die Mittellinie lehlt bei den meisten vollständig und ist nur bei wenigen sehwach angedeutet. Die Länge des Blattpolsters beträgt vom Schildchen bis zur Spiłze 7 Mill., die grösste Breite 4 IIillin.

Bei Taf. III, 9 sincl zwar die Blattwülste klein, halen aber dieselbe verkelurt eiförnige Gestalt, wit bei Fig: 10.

Fig. 8 ist cin entrindeter, junger Zweig, bei welchem nur punktfömige Tertiefungen geblieben sind.

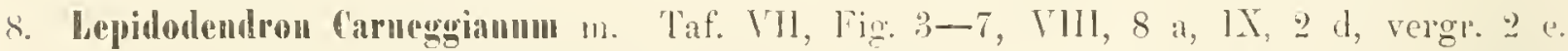

I. ramulis elongatis, eleganter tesselatis, folionum pulvinis quadrato-rhombeis, cicatriculit certitali.

Nicht ran\% selten.

Taf. VII, Fig. 4 stellt einen langen, diumen zweig dar, ler dicht mit quadratisch-rhombischen Blattnarben bedect ist. Sie schliessen ein gleichgestaltetes Feldchen ein, in welehem drei neben einancler liegende Punkte sich finden, von denen (ler mittlere der grösste und bei der Mehrzahl der Narben allein siehtbar ist (Fig. 5 vergrössert). Einen ähnlielıen nur diekern Zweig stellt Fig. 6 (einzelue Narben vergrössert Fig. 7) dar; cin kleines $/$ weiglein Fig 3 (vergrössert Fig. 3 b), Tal, VIll, Fig. 8 a mol Taf. IX, Fig. 2 d (rergr. 2 e)

Hat rhombische Blattnaben, wie die jungen Zweige des Lepid. dichotomm stbe. (Geinitz Steinkoh! Sachsens Taf. III, 3), doeh sind sie viel kleiner und weniger dieht zusanmensehliessend: Aehnljeh ist auch Lepid. Gaspianum Dawson (foss. Plants from the Devon Rocks ol Canadn. Quartrrl. Journ. of London 1859) p. 457), bei welehem aber die Blattnarben länger als breit sind, wodurch sich dis L. Gaspianum näber an las Veltheimianmm anscliliesst, als an unsere Art. Von Cyclostigna minutum muterseheidet sie die rhombiselie Forn der Narben und lass diese in der Mitte drei Punkte haben.

9. Lepidodendron Wiikianum m. Tat. VII, Fig. 1 c, 2, VIII, 2 e, IX, 1.

L. foliorum pulvinis corticalibus distantilus, rhomboideo-obovatis, cicatricula apicali rotundata; interstitiis evidenter striatis.

Selten.

Zcichnet sich durch die weit anseinander stehenden Blattpolster, das an d'r Spitze derselben stehende runde Schildehen und die dentlichen dieht stehenden Längsstreifen, welche dic Zwischemrïume zwisehen den Blattpolstem ausfiillen, ans.

Tal. VI1, Fig. 1 c ist ein ziemlich diekes Stammstïck. Die Blattpolster stehen (von dem Sehildehen ans gemessen) 11 Vill. von einander ab. Sie sind rhombisch-verkehrt eiförmig, die untere Parthie melır verschmälert als die obere; uber die grösste Breite läuft cine seln schwache, offer verwisehte Querlinie; das Sehildcheu ist an der obcrn Ecke, die lüngslinie fehlt gänzlich. Dic ziemlieh grossen Zwisehenrame zmischen den Blattpolstern sind von zalılreichen und dicht stehenden parallelen Längslinien durehzogen, welehe der Rinde ein fein gestreiftes Ausschru geben. Die Blattpolster stehen in regeluässigen, ziemlieh steil aufsteigenden Parastichen.

Zu dicser Art gehört wahrseheinlich nueh Fig. 2, bei welcher aber die regelmäsige Stellung der Blattpolster gestört ist. Iliese sind auch viel kleiner als bei Fig. 1 c, haben aber diesulbe Form, und auch an illrer" Spitz\& stehende, runde Schildehen und fein gestreifte Zwischenräume.

Tal'. IX, Fig. 1 ist ein ähnliches Stiek, mit auch unregelmissig gestellten Blattpolstern. In dem fust kreisrunden Sehildehen bemerkt man drei Punkte, die in einer Reihe stehen. Die Polster treten in der obern l'aldhip warzenformig hervor und sind ghatt, nach unten sind sie undentlich begrenzt. Dic \%wischenräume sind deutlich gestreift (ein Stiick vereröossert Fig. 1 b).

Bei Taf. TIll, Fig. 2 e hahen wir dieselbe parallele Streifung, aber von den Blattpolsteru siud nur kleitu unde Wir\%chen geblieben, welche den Durehgang der Gefïssbündel bezeichnen. 


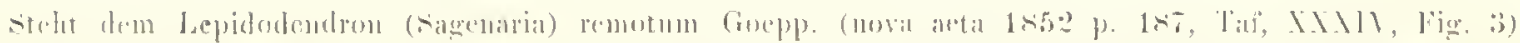

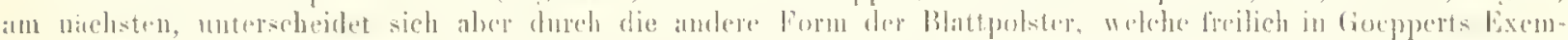

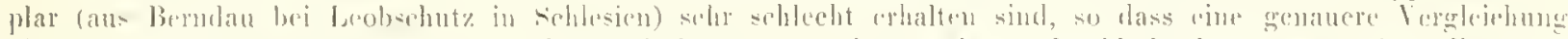

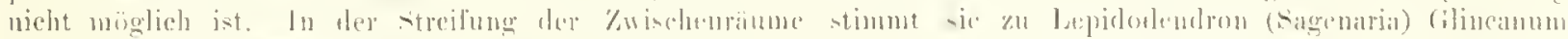

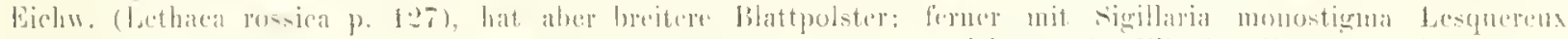

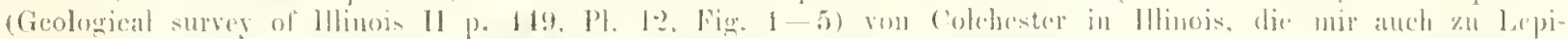

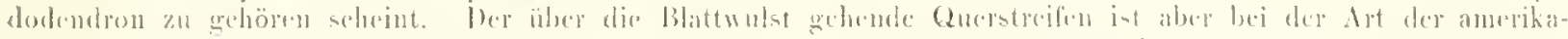

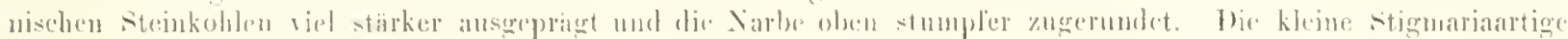

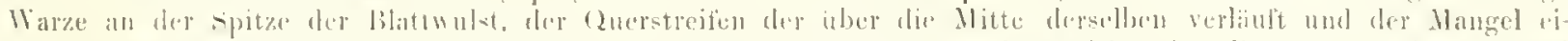

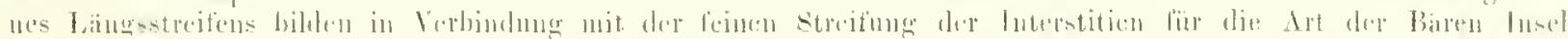

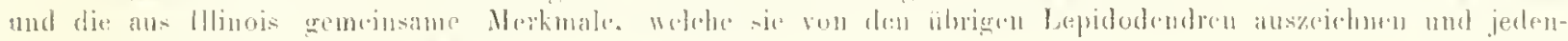

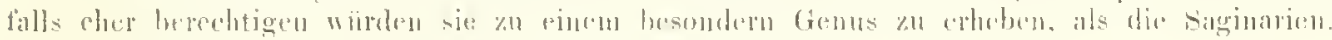

10. Lepidophyllnm Boemeri n. Tilf. IX, lig. 7 a, 8.

L. lintare, $4 \frac{1}{2}-1+$ millim. latum, medin eapinatmm, obsolete longitudiualiter striatum, nervo submariniali panto fortiore.

In eivenscliüssigen Thonplatten.

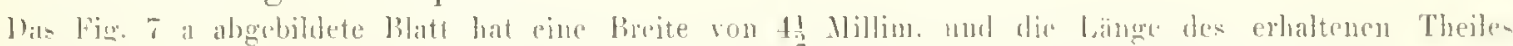

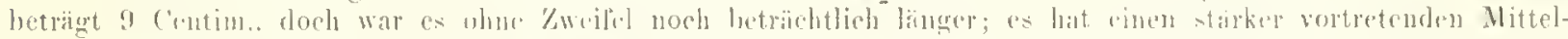

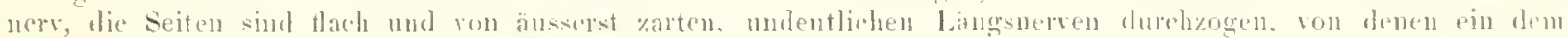

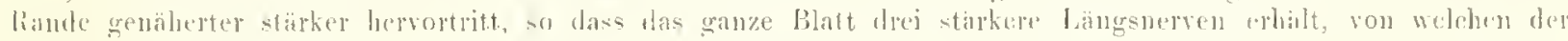
mittlere die seitlichen an stinke ibertritlt.

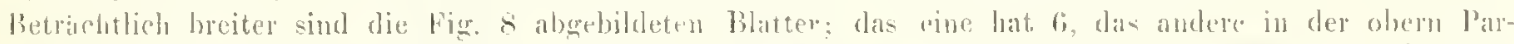

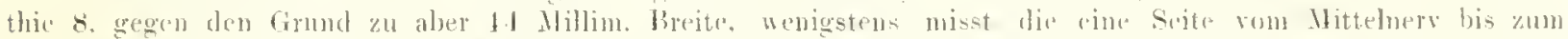

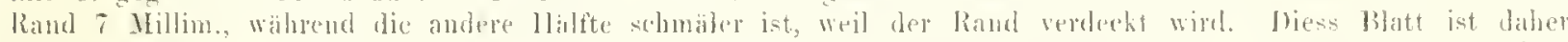

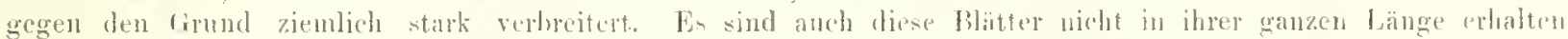

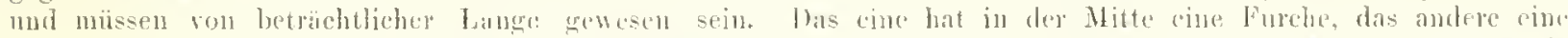

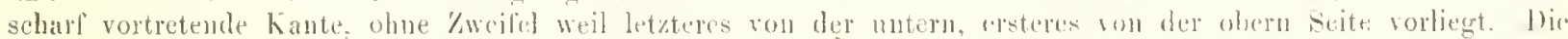

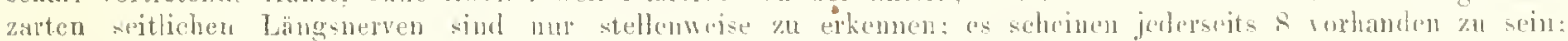

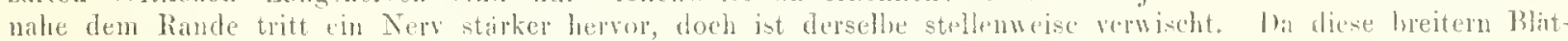
ter in elor Nervation mit den sehmailern gan\% ubereinstimmen, habe sie rereinight

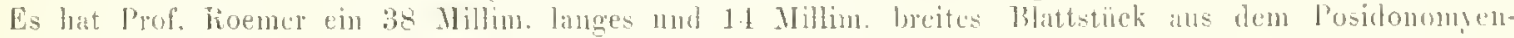

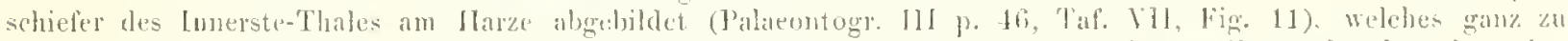
unserer Pllanze passt. Es hat genau lieselse Brejte, wie das hreiter Fig. is dargenillte und neben der mitt-

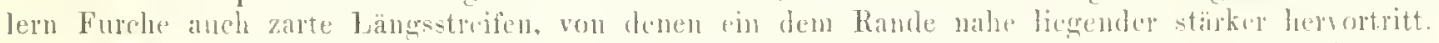

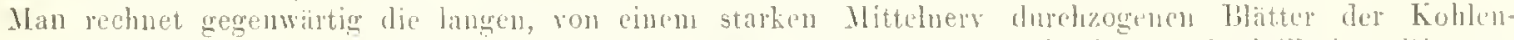

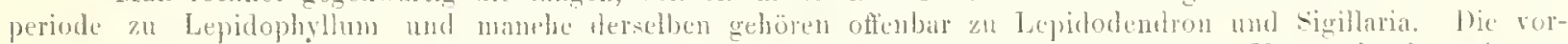

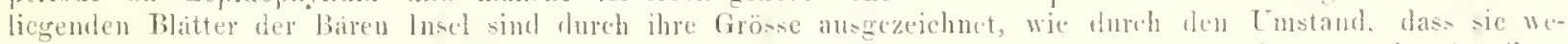
niger steif und bederartig sind als dic Blitter der Lepidolendren und Sigillarien, was schom aus der Art ihrel

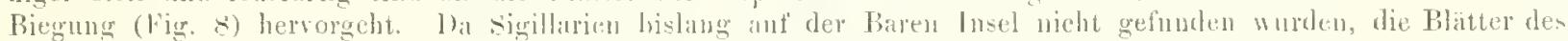

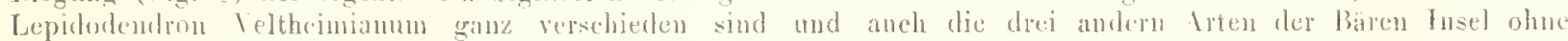
\%weifel viel schmälere Bläter besessen halen, wie schon die Grüsse der Blattnarben zejgt, miissen die vortiegenden Blatter andern Gattungen angehöres, und ihre zartere structur macht pa nicht nuwahrocheinlich, das- sit

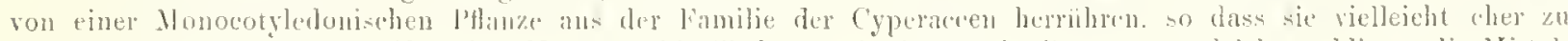

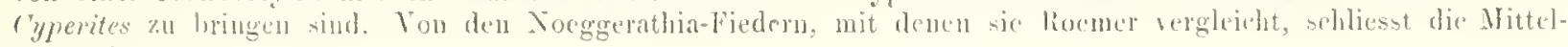
rippe sie ans.

11. Konoria imbricata Sternb. 'Taf. X, Fig. : X, Xl.

Kn. truncis corticatis cicatricibus rotundatis, medio umbilicatis, decorticatis rermeis magnis adpresso-ereetis, lanceolatis oblongisque obsitis.

Sternberg, Flora des Vorwelt IT p. 125.

Gocppert, nova acta 1852 p. 198. Schmper, terman de transit. p. 3939 , Taf. XIll. Palćontol. véget. Il p. 46. Gicinity, Hamiches-Eberstorf p. 57, Taf. V1ll. Fig. 3, IX, Fig. $1-4$.

Sehr hänfig in den Kohlen und deren Zwischengestein.

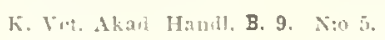


Es sind alie Knomien, welche in dem Unter-Carbon sehr verbreitet sind, zwar leicht zu erkemnen, doch ist ihre Etellung im System noch sehn bestritten. Goeppert hat in seiner ersten Arbeit über lie Pflanzen des Uebergangsgebirges (nov. aet. 1852) 12 Arten unterschieden, wälnend er diese in seiner zweiten Arbeit (nov. act. 1860) sämmtlich einzieht und die meisten mit Lepidodendron Teltheimianum rereinigt. Sehimper dagegen (terrain de transition p. 331 und Palcontolog. véget. II j. 41) sueht nachzuweisen, dass Knorria von den Lepidodendren versehiedeu sei, da bei den letztem die unter der Rinde liegenden Blattpolster niemals eine solehe Form und Entwieklung zeigen, wie bei den Knorrien. Die Untersnehung der Pflanzen der Bären Insel hat mich ebenfalls zn der Ansicht gebraeht, dass Knorria und Lepidodendron zu trennen seien. Ws kommt allerdings eine knorrienartige Form bei Lepidodendron Veltbeimianum vor, nenliclı die innere Rindenparthie mit den luervortretenden, grossen Warzeu (Tal. LX, Fig. 1), allein diese Warzen sind immer an beiden Enden versehmälert, wie diess atuch bei den von Goeppert auf Taf. XLI und XLIl abgebildeten Stiicken der Fall ist, die er als Knorriatorn zu Lepid. Teltheimiannm bringt. Davon versehieden sind aber die Stämme mit den langen, am Grunde nicht in eine Spitze anslaufenden, sundern breit endenden und abgeplatteten Warzen, welehe allein ich zu den Knormen bringe. Bei dliesen haben wir eine äussere Rinde, welche ganz anders anssieht, als bei Lepidodendron. Es ist diese bei Fig. 4 wenigstens theilweise noch erhalten. Diese Rinde bekleidet die an den stämmen angedrïekten, vorn verschmälerten Warzen, sie ist von zahlreichen lüngsstreifen durchzogen, die alle ziemlich gleich stark and und fast parallel vorlaufen. Luf Jer Rinde treten kreisrunde Blattnarbeu auf, die zwei Millim. Breite und in der Vitte einen runden Punkt hahen, weleher wahrscheinlich den Dureligang des Gefinssbündels bezeichnet. Diese Blattuarben sind in regehnässige schiefe Reihen gestellt. Es scheint, dass jede anf die Spitze einer Warze \%n stehen kommt, so dass die unter der Rinde liegenden langen Warzen iu diesen Blattuarben enden. Die Warzen sind bei Fig. 4 lanzettlieh und vorn zugespitzt und ziemlich weit von einander entfernt. Es wurde diese Form von Goeppert früher als Knorria acutifolia bezeiehnet. Die Form und die unehr oder weniger diclıte stellung der Warzen ist variabel. Wir können folgende Formen unterseheiden:

1. Mit langlichen, vorn stumpien IFarzen. Tall. $\mathbf{X}$, Fig. 2, 5. Es sind die Wirzen sehr gross, indesen flach und voll einander abstehend, so dass die Oberfiache des Stammes zu selıen ist. Die Zwischeuräume and stellenweise feiu gestreif́t. Bei [rig. 5 b sieht man einzelue runde Narben, welehe wahrseheinlich von den Blattuaben Jeruihren. Die Forn der Narben ist wie bei Knomin princeps Goepp., aber sie stehen nicht so diclut beisammen.

2. Mit länglich lanzettichen, dicht beisammen stehenden Warzen. Tal. 1X, Tig. 6. Die Warzen sind lang, vorn stärker versehmälert und decken den stamm ganz. Sehimper hat diese Form als Knolria Jongifolia alggebildet. Der P'flanz'nlest, den aber Goeppert mit diesem Nanen belegt lat, ist sehr zweirelhafter Natur.

3. Wit langlich-lanzettlichen von rinander abstehenden IYaraen. Taf. X, Fig. 1, 4. Die Warzen sind vorn in eine spitze verschmälert, wie diess besonders bei fig. 4 der lall ist. Knorria aentifolin Goepp. Nova aeta 1852 p. 202. Roemer, Pallaeontogr. 111 p. 96, Tal. Xiv, Fig. 4. p. $20 \%$

4. Mit am Grunde etwes verschälerten IFuren. Taf. X, Fig. 3. Knorra Sehrammiana Goepp. 1. c.

\section{Linorria acicularis Goepp. Taf. X, Fig. 6, 7, VIII, 2 d.}

Kin. truncis decorticatis, veluncis lineari-lanceolatis, apize acutis, aeque distantibus.

Goeppert, nova acta 1852 p. 200, Taf. XXX, Fig. 3. Goeppert hat spater auch diese Form zu Lepidodendron Veltheimianm gezogen (nova acta 1860 p. 521 ), worin ich ihm in meines Flora aretica I p. 131 gefolgt bin.

Ist vielleicht nur Varietät der Knorria imbricata, iudessen dureh die selu sehmalen, linienförmigen Warzen ansgezeichnet. Dass soldu: linienfömigen Warzen nieht allein bei dünnew, juugen Zweigen, sondern in gleicher Weise bei dicken Stammstiieken vorkommen, zeigen Taf. VIII, 2 d und $X$, 7 , daher die Ausielnt, dass die mit solehen Warzen versehenen Stücke nur die Kweige der dickwarzigen seien, jedenfalls unriehtig ist.

'Ta1'. $X$, Fig. 7 stellt cin Stüek eines ziemlieh dieken Stanmes dar, nit vorn zugespitzten, dünnen Warzen: Hig. 6 aber cincn diunern Zweig, bei dem die Warzen etwas weiter auseinanderstehen. 1]icrher gehört inch das Stïck der Mfelville-lusel, welches ich auf Taf. XX, Fig. 9 a meiner Flora aretica abgebildet habe.

llerr Baily sandte mir zwei stueke von der Tallowbridge Grafschalt Waterlord in Irland, welche, wie ich ylanbe, hierher geloören; sie haben dieselben schmalen, linientönigen Warzen, welehe an den Stamm angedrüekt sind, nur stelien sie dichter heisinmen als bei den Exemplaren der Bären Lnsel; da alser dieses Mcrkmal bei

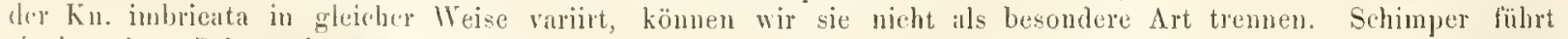
siv in seiner Palcontol. Vigét. 11 p. 18 als Knorria Bailyana auf. Das Cyelostigna minutum IIaught., das Schimper lier "rwähnt, grehört nicht hioher. Bei vinem sehönen Stärk von Kiltorkan ist die äussere Rinde theilweise prlalten und zeigt die lür Cyclostigma bezeichnenden Wärzchen, theilweise ist aber die Rinde abgafillen, diese von dar inssem Rinele entb]östen Stellen zeigen aber keine sjum von knorrien-Warzen. 


\section{Fyclostiguna Kiltorkense llaught. Thuf. Xl.}

Chalatcter Generis:

Truncus apborens, dichotomus, corticatus pulvinis foliomun delapsormu minutis, sulsglobosis rel deplanatis, apee foveolatis. Folia linearia, medio carinata.

C. Filtorkense, cortice rugroso, pulvinis foljorum delapsomun distantibus.

S. Hanghton, on Cyclostigma a new genus of Fossil l'ants from the Ohe Red Sandstone of Kilorkan. Mmals and Magarine of matural Hisory, Tol. V, thirel Series. p. 444.

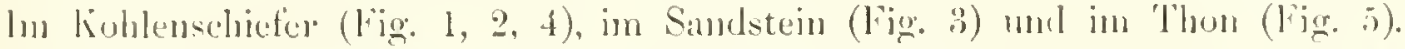

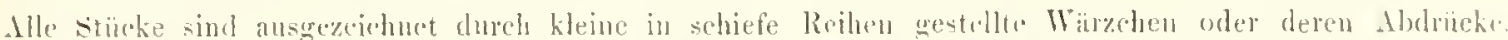

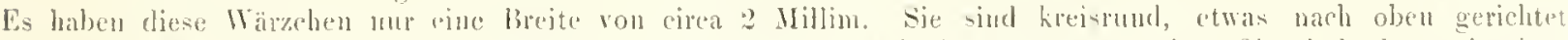

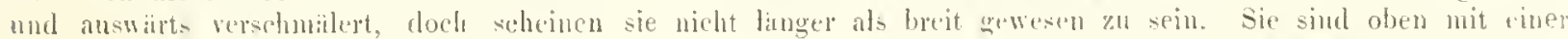

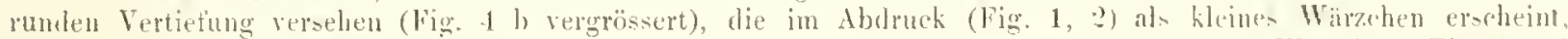

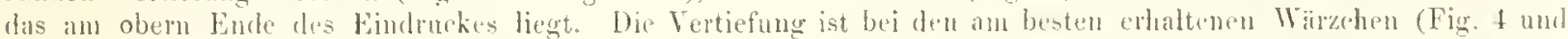
4 b), ron einem scharfen, ringförmigen Rand umgeben, an wedchem zuneilen (lig. 5 e) 2 lois :3 setn kleine lirha-

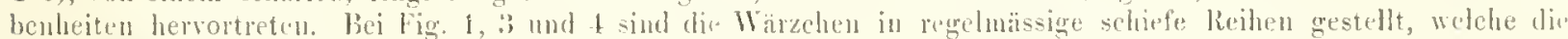
regelmässigc spiralige Lnordunug angeben. Der Abstand der Wärchen hetrigt hei Fig. 38 Mill., bei Fig. 1 aber 7 Mlill. Bei dem grossen Stammstïck Fig. Z beträgt die Entfermng hei den meisten Wärzchen 7 bis o Mill.: an einigen stetlen aber ist. die Orelunug gestört, und dasselbe ist der Fall hei Fig. 5.

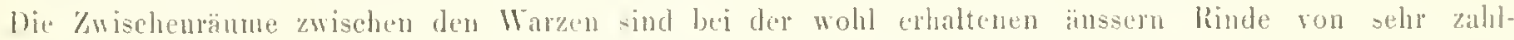

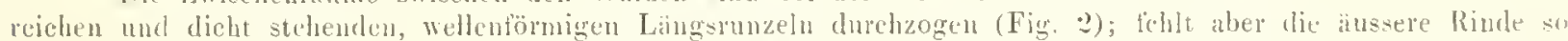

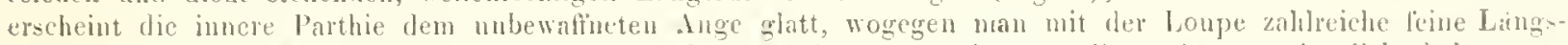
mnzeln sieht (Fig. :3 und 4). Aber anch feine Längstreifen treten hervor, die meintens sehr dicht beisanmen

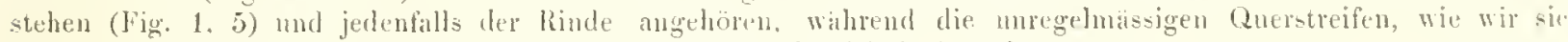
bei Fig. 1 sehen, rein zufällig sind und von spriingen der Rinle tuerribluren.

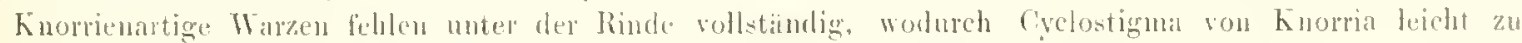

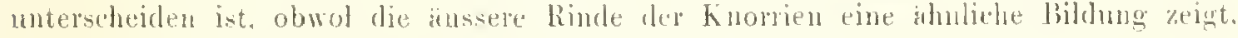

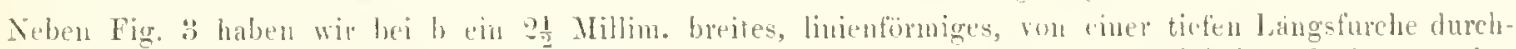

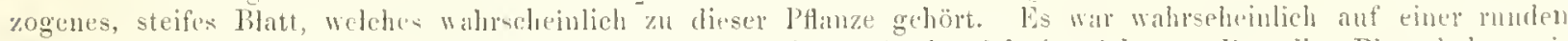
Warze befestigr, feren mittlere Parthie den Durchgang des Gefïssbündels lweichnet. Dasselbe Blatt haben wir

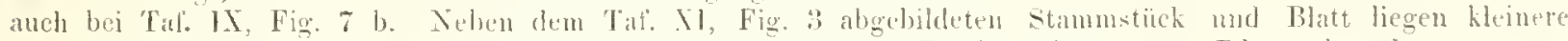

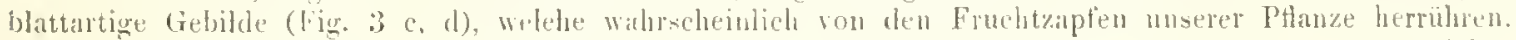
gencin hat.

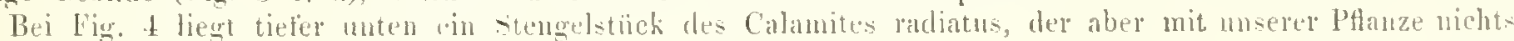

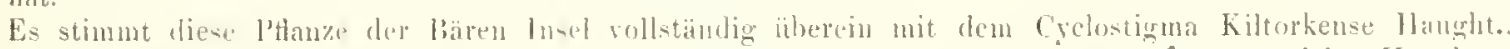

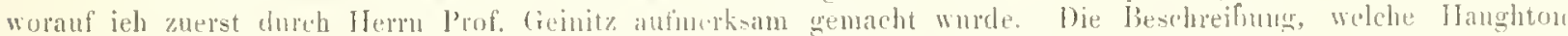

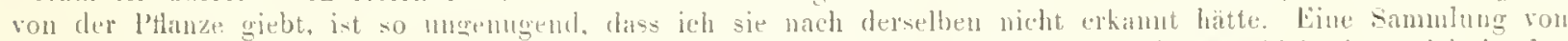

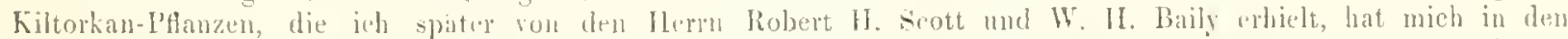

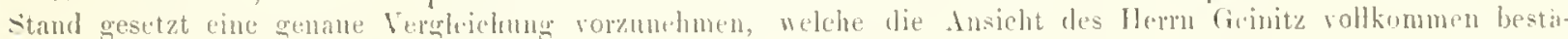

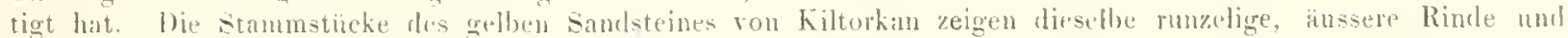

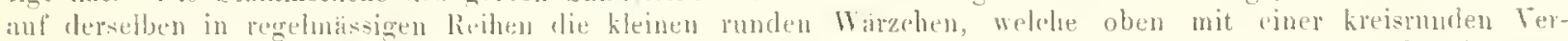
tiefung versehen sind, die ron einem hervortetenden Rimde nmgeben ist. Zuweilen seten diese Wärzchen wis

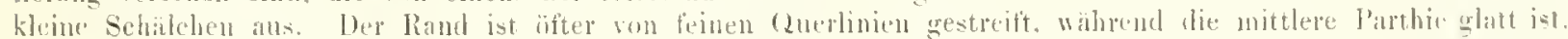

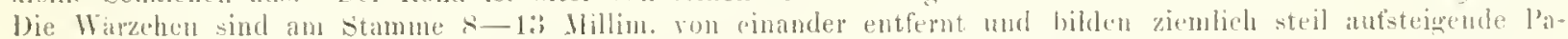

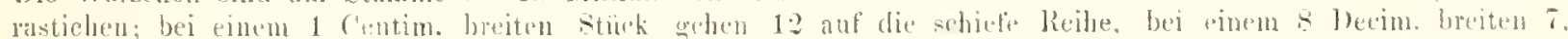

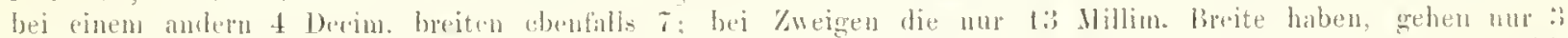

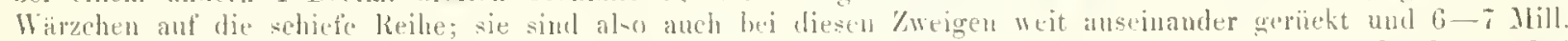

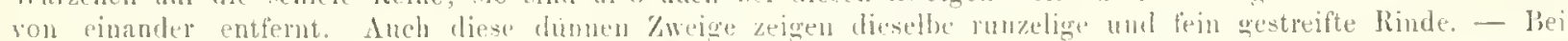
einigen stammstïrken ist die linde mu husserst fein und dicht gestreift und bei cincm fast gan\% glatt. Diese'

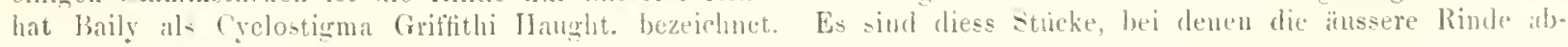
gefillen ist.

Noben Resten dieser Pflange und zum Theif unnittelfbar neben den Rinden, findet sich in Kiltorkan der

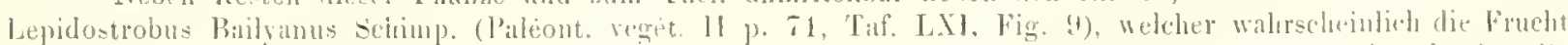
derselben darstellt. Wie bri Lepidodendron besteht das beckblatt ans einem verloriterten Grundstück, das die

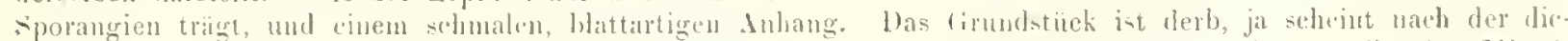

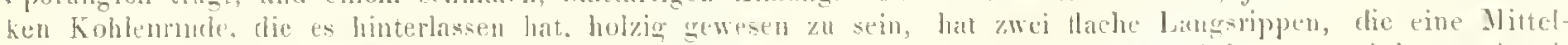

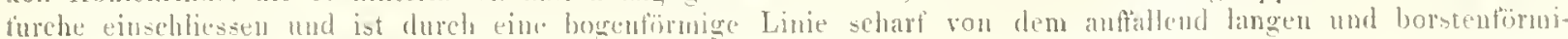


gren Inbang getrennt (vgl. Taf. Nl, Fig. 6). Jedes Deckblatt scheint dort cine ovale Marze besesscn zn haben. Das Grundstiiek ist mit kreisrundeu Sporen ron 1 Millim. Durchmesser (Macrosporen) bedeckt. Tebeu dense]ben sah ich riel kleinere schwarze Köruchen, welehe die Mikrosporen darstellen dïrften. Kahlireiche solehe Deckblätter stehıu an einer Längsaehse und bilden einen Zapfeı.

Dass solelıe Deckblätter auch auf der Bären Insel vorkommen dürlten die Taf. NI, Fig. 3 c und d abvebildeten 13lattreste zeigen, welche numittelbar neben dem Stamm des Cyclostigina licgen. Fig. 3 c entspricht ganz der Basis des blattartigen Anlanges des Deckblattes, leider felult aber das sporentragende Grundstiick, welches entscheident sein wiirde.

Gehört der Lepidostrobus Bailyanus Schimp. wirklich zu Cyelostigma, wïrde die Gattung nahe an Lepidodendron sich anschliessen, von welcher sie sich aber leicht durch die anderc Bildung der Rinde unterscheidet. Durch diese nähert sie sich den Stigmarien, doch sind die Wärzchen nicht nm viel kleiuer. sonderu aucls viel sehär'er abgesetzt und von anderer Bildung, indem bei den stigmarien im Centrum der scheibe eine kleine Warze sitzt. - Tou Halonia unterscheidet sie der Itangel der grossen Warzen und dass bei Halonia die kleinen Warzen oben mit keiner Oeffuung versehen sind.

Eichwald hat ein ähnliches mit kleinen Warzen besetztes Stammstiek als Selaginites verrucosus bezeichnet (Let], rossica p. 111), jedoch laben die Wärzchen eine andere Form, und unter Selaginites versteht man ganz andere P'tlanzen. Noch ähnlicher sind unserer Art der Bären Insel das Ulodendron Selılegelí Eichw. (Leth. ross. p. 138) und Uloderdion tnmidum Eichw. (Leth. 1. 143, Taf. $\mathrm{X}$, Fig. 1, 2). Auch bei diesen ist der Stamm mit kleinen, in regelmässigen schiefen Reilen stehenden Wärzchen besetzt, doch scheinen diesen die Höhlngen an dur. Spitze zu fehleu und sie stehen ferner dichter beisammen. Inmerhin können diese in der Steinkohlenforuation Russlands vorkommenden Pflanzen in Betracht kommen nnd verdienen eine sorglältige Vergleichung: Bei ihnen finden sich neben den kleinen Wärzchen noch grosse mude Scheiben, wie bei Ulodendron, welche bei den Cyclostigmen felalen.

Bei Botluyodendron punctatum Lindl. (Halonia punctata, Geinitz, Kohlenf. Sachsens III, 16, Ulodendrou Lyndlyamun Stemb., Röhl, Palneontogr. XVIll, Taf. XXII, ?) sitzen die Warzen in rlombischen Feldern, ebenso bei Knorria Jugleri Roemcr (Pilaeont. I11, Tat. VII, 17), welehe dem Crelostigma gänzlich fehlen.

Vielleicht gebört bierber cin von $\Lambda$. Roemer als Sagenaria spec. abgebildetes Stammstiick aus der jüngern Grauwacke bei Lauterberg im Har' (Palaeontogr. 1854 111, Taf. NIT, 3), das ganz ähnliche, regelmässig angeorduete Wärzhen ze'igt, doch ist aus der Zeichung nicht zu crsehen, ob dic Wärzchen die eigenthümlielse Bildung der Cyelostigna-Warzen haben, und eine Besebreibung hat Roemer nicht gegeben, daher die Bestimmung zweifellaft blcilht. Dasselbe gilt ron dem Lepidodendron (Sagenaria) cyclostigma Goepp. (nova acta 1852, p. 969, Taf. XXXIV, Fig. 6) aus 1]er Grauwacke von Landslut. Es ist vielleicht ein junger Zweig unserer Art.

14. Cyclostigma minntum Haught. Taf. VII, Fig. 11, 12, vergrössert 11 b, 12 b, VIII, $5 \mathrm{~b}, 1 \mathrm{X}, 5 \mathrm{a}$.

C. cortice longitudinaliter et transversin striolato, pulvinis foliorm delapsomm confertis, approximatis.

Haughton, l. c. p. 444. Lepidodendron minutum Hanght., Joum. of geolog. soc. Dublin VI p. 235. Lepidodendron spec., Lyell Elements of Geology, sechste Aufl. p. 521, Fig. 585. Filicites dichotomus Inanght. und Sigillaria dichotoma Hanght. 1. c. p. $234^{*}$ ).

Ich erhielt ron ler B̈̈ren Inscl nur kurze Zweigstücke und Rindenreste, welche durch die dichte Stellung ilıer krejsmuden Blattnarben sich anszeichnen. Bei dom etwa 9 Mill. loreiten /sweig Taf. VII. Fig. 12 (vergrösert 12 b) haben wir steil aulsteigende Parastichen, jede Reilue besitzt 10-12 kleine Blattnarben, die

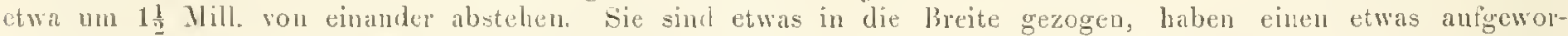
fenen Rand und in der Nitte einen Punkt. Im Abdruck sind sie selur scharf begrenzt. Dis /aveiglein zeigt zalılreiche und ziemlich dieht stehende parallele Querlinien. Dass diese nieht zutällig sincl, zeigt der Umstand, dass sie anch bei einem zweiten Zuneiglein in ganz gleicher Weise auftreten. Etwas grösser siud die Wärzchen bei Taf. VIl, Fig. 11 (vergrössert 11 b). Sie sind hicr fast kreisrund und haben einen Querdurchmesser vou 1

-) Die Abbildung, welele llingliton von seiner Sigillaria dichotoma giebt (l. c. p. 234), stimmt zu Cyclost. minutum, wogegen das Zweigstiek, das el 3.235 abbildet und Lepidodendlon minutun unnt (welches wio er glitubt whe trne "oating" der sigillaria diehotoma sei), eher an clas Lepidodendron Carmeggianum eriunert. Seine Filicites dichotonia nemut cr (1. e. p. 235) nonly the npper and delicate branclie of the Sigillaria di-

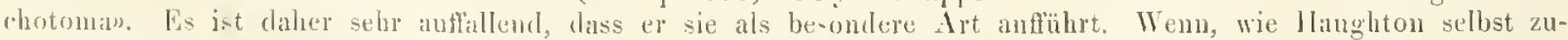
giebt, Filicites diehotomus, Sigillaria dichotona und bepidodendron minntum zu Einer Art gehtören, sind sic auch unter Einen Nimen zu vereinigren.

leh hatte anfangs die beiden (Yyelostigma-Arten auch für sigillaria genommen und rorläutig als Sig. Carneggiana und \&. Malmgreni bezeichnct (cf, die nenesten Entdeckmgen im hohen Norklen S. 21). 


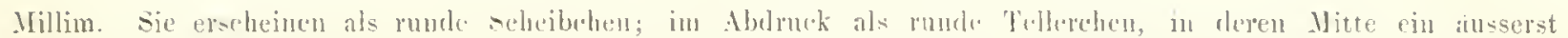

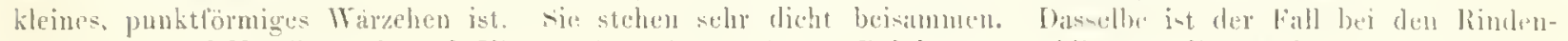

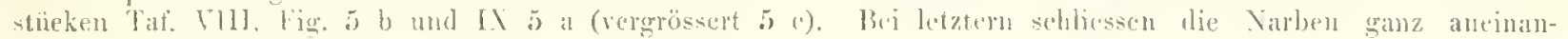
der ans.

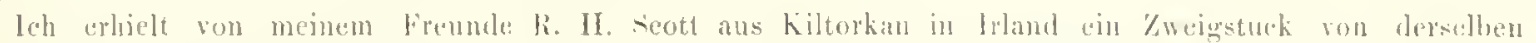

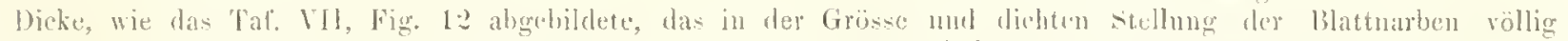

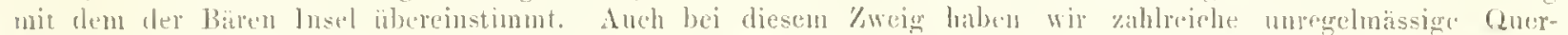

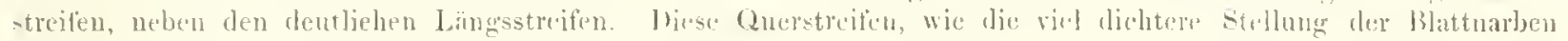

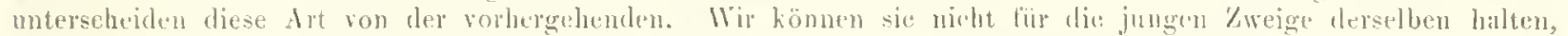

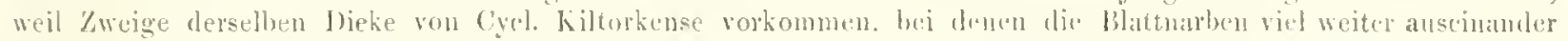

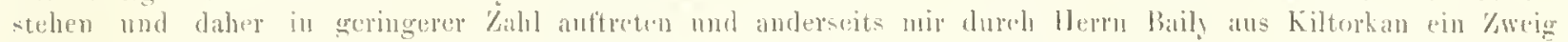

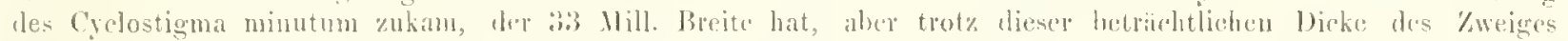

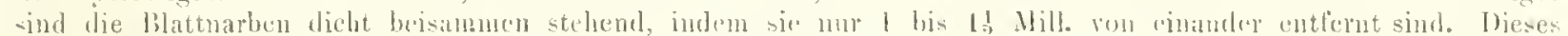

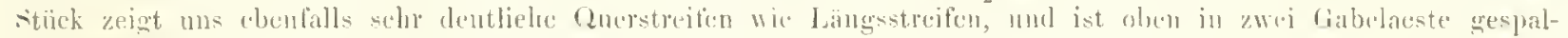

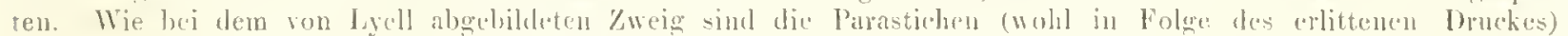

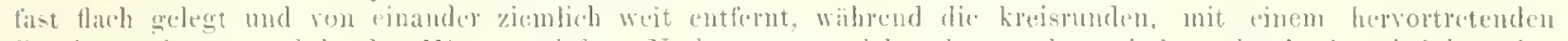

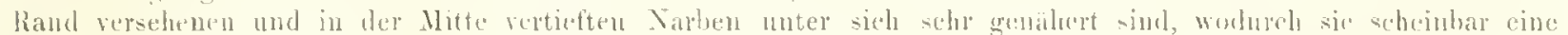

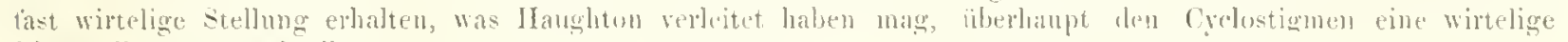
Blattstellung zuzuschreihen.

\section{Ilalonia tuloerculosa Brongur.? Til. XII, Fig. 7.}

11. Hunco tuberenlato, tuberenlis nagnis, spiraliter dispositis, aprice foreotatis, foreola parrula.

Brougniart, hist. des reget. foss. II, Taf. 28 , Fin. 1, 2. Geinitz, foss. Florit rou Hainichen-Ehersdorf p. 56, 'Tat. ITll, Fig. 1. Halonia tuberculata, Goepp., nova acta 1860 p. 529. Eichwild, Leth. ross. I p. 149, Taf. XI, 1-4.

11. tortuosa Lindl. et Hutt. Foss. Flura of Great Britain Il, 11, 'laf. 85.

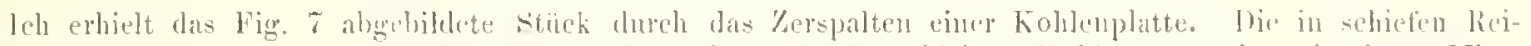

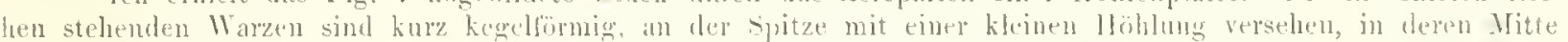
cin punktörmiges Wärachen ist. Um dje Oeffnng der Hohlung sieht man in cinem Falle einge kleine Wärzehen (Fig. i b vergrössert) und bei siner Warge haten wir einige von der llitte ansgehente strahlentömige

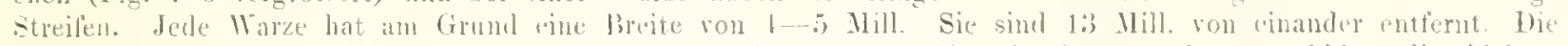

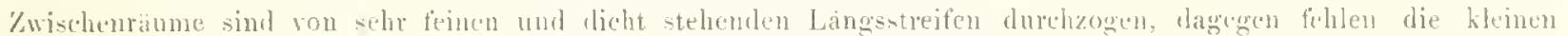

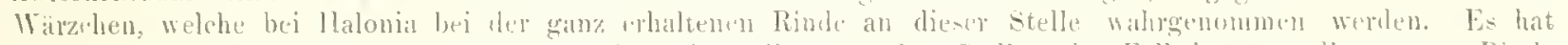

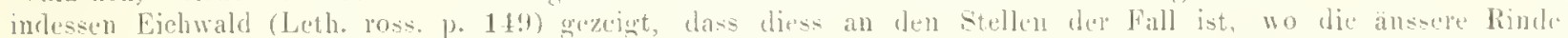

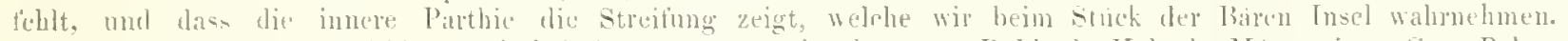

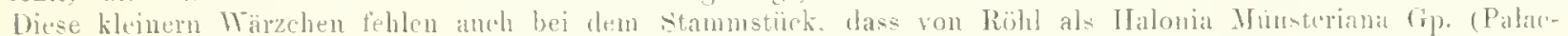

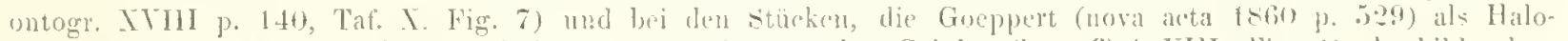

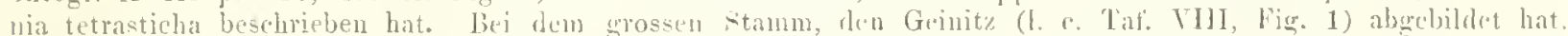

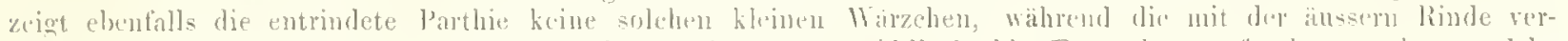

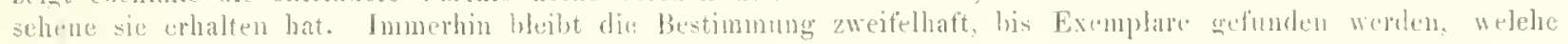
ance dic kleinem II arzen besitzen.

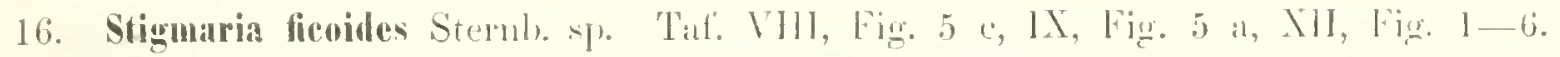

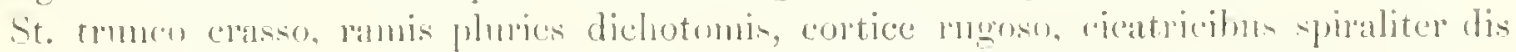

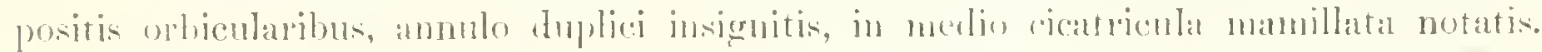

brougniart, Jém. Mns. dhist. natur. p. so, Taf. 7. Prudrom. p. si. Stemberg.

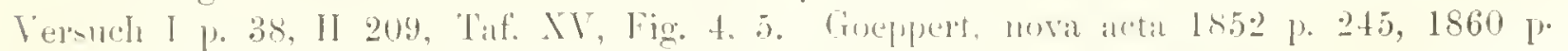

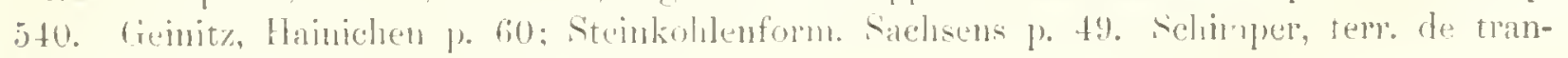
-it. 1'. 324; Palcontol. végeit. II 1) 114.

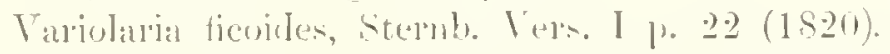

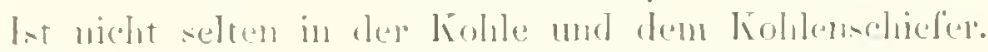

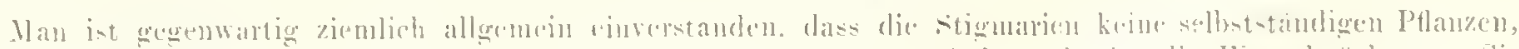

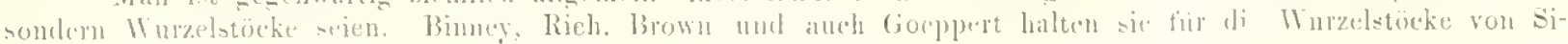


gillaricn. Wit Recht hebt aber Schimper herror, dass diese Stigmarien in den Kohlen der Vogesen liäufig seien. während keine einzige sigillaria bis jetzt daselbst gefunden wurde, wogegen die Knorrien und Lepidodendren dort sehr häutig erseheincu. Ind ganz dasselbe gilt aneh fiir die Bären Insel. Sehimper brinğt sie daher mit ten Knorrien und Lepidodendren in Verbindung und naeh einer briefliehen Mittheilung ist nenerdings in Lur. bach ein 4 Fuss holıer Stamm gefunden worden, welcher zeigt, dass die Form ron Stigmaria, welche Sehimper auf Taf. IX (veget, foss. du terr. de transit.) abgebildet hat, der Wurzelstoek der Kuorria ist, und dass an demselben Stamm die Stigmaria-artige linde durch Incistrophyllum und Didymophyllum (ioepp. den Uelocrgang zu Kuorria rermittelt und zwar zu del Form, welehe als Knorria longifolia unterschieden wurde (vgl. aueh Schimper Paléont. réget. II, 118). Anderseits kann aber wohl nieht in Abrede gestellt werden, dass die Sigillaria alternans ein Stigmaria-artiges Rhizon besitze, und ist ferner wahrseheinlieh, dass auch Lepidodendron älnuliche Trurzelstöcke habe. Warnaeh würden die Stigmarien die Rhizome melurever, allerdings nahe verwaudter, Gattungen darstellen, unt es wird nun die nächste Aufgabe sein, diese genaner zu ernittejn und die Species festzustellen. 'Zu1' \%eit ist diess noch nieht möglieh, wir sind daher genöthigt, die Stigmarieu noeh besonders aufzufiihren.

1. Stignaria picoiles rugosa: eortice rugoso, eieatrieibus rotundis, aeque listantibus, eirca 5 Mill. latis. Taf. XII, Fig. 1, : 2,3

Die Warzen sind ziemtich thaeh, der glatte Ring lat einen Durehmesser ron durehsehnittlich 5 Millim. und ein centrales rundes Wärzehen. Die Warzen stehen in.regelmässigen Abständen und diese sind von zahlreiehen und dieht steheuden Längsimnzeln durehzogen. Diese Runzelu biegen sich auf der obern und untern Seite der Warzen zusammen nurl laufen hier und da in einander. Es sind daher dieselben viel unregelmässiger, weniger tief und zalijeieher als bei Stigmaria undulata Goepp, nur bei Fig. 3 kommt in der Mlitte eine tiefere, sich un dis: Warze sehlingelnde Furche vor, wie bei Stigm. undulata. Hier bemerken wir auch bei einzelnen Waren strihlenförmig anslaufende Linien, die indessen neht dieselbe regelmässige Bildung zeigen, wie bei St. -tellata Goepp

Mit nuseru Stïcken rler Bären Insel stiumt die lesehreibung, welele Eichwald (Leth. ross. 1 p. 205) von cinem stïek ans dem Kohlenlager ron Longan giebt, sehr wohl überein. Er sagt: il y a autour de chaque ricatriee $u n$ enfoncement, et les espaces entre les cicatrices sont ocenpes par des rides ou plis ondules très rapprochès, qui courrent toute la surfaee du trone, laquelle devient ainsi sillonuce longitudinalement à sillons ondulés. Ein ähnliches Stüek hat Sehimper ron Bourbach abgebilclet (végét. foss. du terr. de transit., Taf. VIII, Fig. 2), un treten bei diesem die Runzeln stärker hervor. Da and der Bären lusel, wie in der Grauwacke der Vogeseu die Knorrien lıäufig sind, liegt die Vermuthung nahe, dass die vorliegende Stigmarien-Form zu Kuorria imbrieata gehöre.

b). Stigmaria ficoiles inaequalis Goepp.; cortice cicatricibus inaequalibus. Taf, 1., Fig. 5, XII, 5. Goeppert nora acta 1852 p. 246, Tal'. XXXII, 1.

Ein kleines Rindenstiek (Tat. IX, 5 a) zeigt uns Warzen von ungleicher Grösse, die grösste hat 7 Mill., die kleinste 5 Mill. Durchmesser. Sie sind ziemlich weit von einander entfernt und die zwischenrïune sind glatt.

Tied grösser ist Taf. XII, Fig. 5. Es stellt einen 2s Decim. langen Cylinder dar, weleler mit fester Sandsteiu-Masse ausgefüllt ist. Yon der Rinde sind nur schwache Reste geblieben, welche einen braunen Ueberzug über den sandstein bildet nud un stellenweise die runden Narben crkeunen lisst, welehe in der Zeichuung zu deutlich hervortreten. Sie haben theils 5, theils nu. 3 Nill. im Durehmesser und siud ziemlieh dicht zusammengedräugt

Gehört virlleicht als Rhizom zu Lepidodendron Teltheimianun.

c). Stiumuria ficoides minutu; eortiee cicatrieibus rotundatis, aequalibus, minutis, 3 mill. latis. Taf. IA. Fig. 2 e, Taf. Xll, lig. 6 .

Goeppert, Gatt. foss. PA. Taf. IX, 11; Novia aeta 185:2 p. 246

Die kreisiunden, flachen Warzen sind unter sieh gleich gross, dureh ziemlich weite, fein gestreitte Zwischersräume getremnt und in der Mitte mit einem kleinen Wärzchen versehen.

Bei Taf. T1I, Fig. 1 und YlIl, Fig. 5 c haben wir nur einzelne Stigmarien-Warzen, die sich aber durcl ihre Grösse auszcichnen und wahrscheinlieh zu Stigmaria lacvis Gocpp. (nova aeta 1852 p. 246) gehören.

Taf. XII, Fig. 4 haben wir die Wurzelzasern der Stigmaria. Man sieht, dass sie cylindriseh gewesen und an einen Linde stumpf \%ugermudet. Auch in 'Tat, I, Fig. 1 e haben wir solehe Wurzelzasern, welche indessen Schimper 'her für Niederblïtter halten möchte.

17. Cardiocarpum punctulatum Goepp. et Berg. Taf. XIT, Fig. 6.

C. fructibus planis, rotundato-subreniformibus, punctulatis.

berger, de fruct, et seminibus ex format. lithanthr. p. 24, 'Tab. Il, Fig. 26. Goeppert, nova acta 1852 \%. 208, Tat. 39, Fig. 4, 1860 1. 532.

In Kohlenschiefer. 


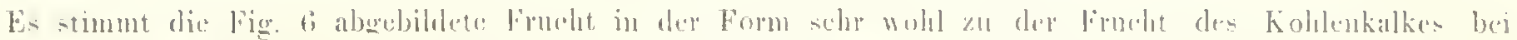

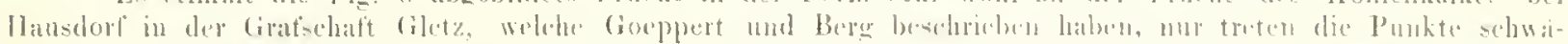

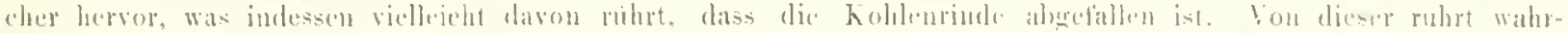

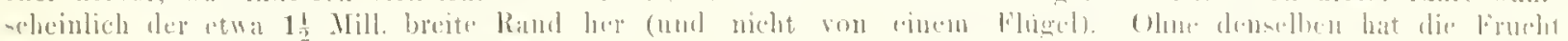

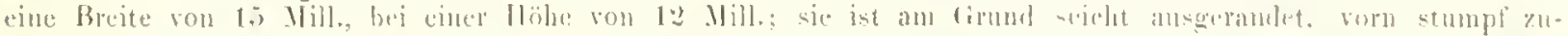

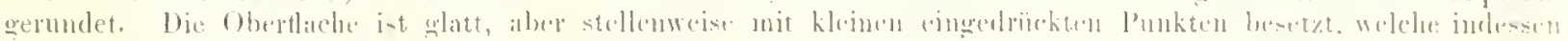

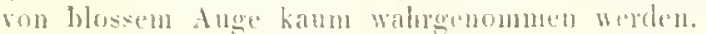

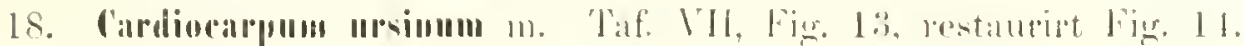

C. alatum, nucleo ovili, ala mignis, obsolete striatil.

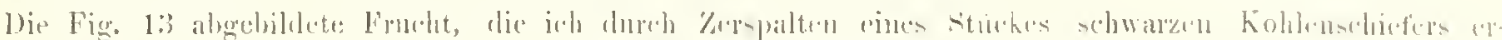

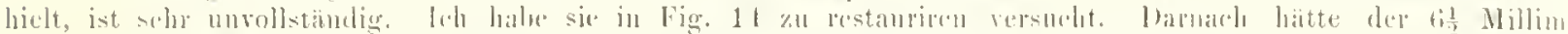

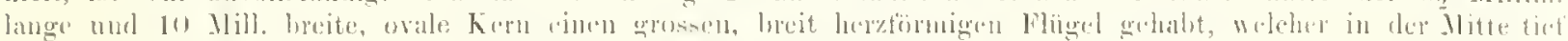

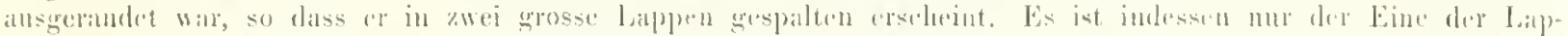

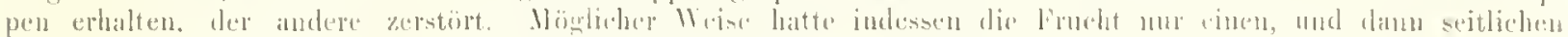

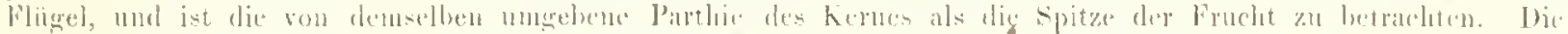

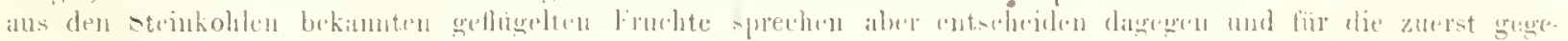
bene Auftassung.

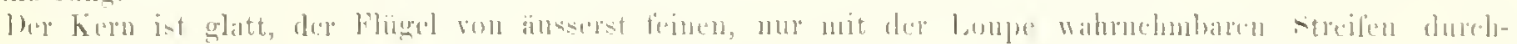

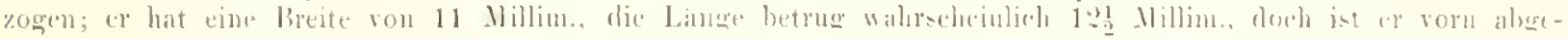
brochins.

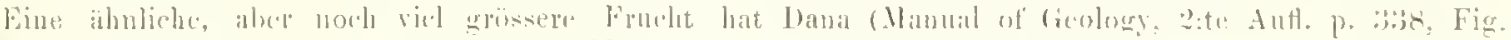

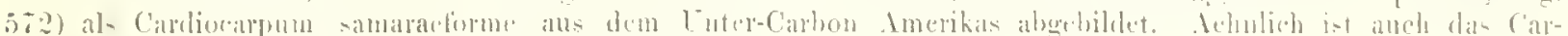

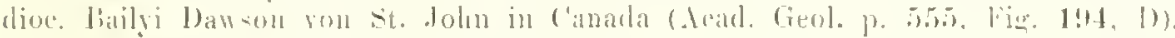

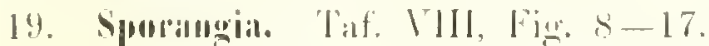

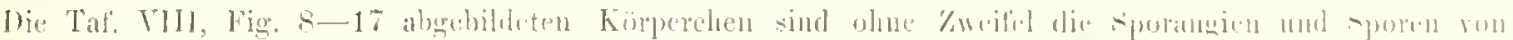

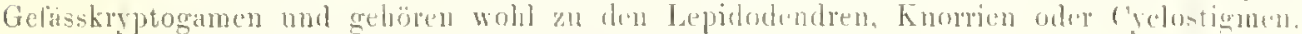

Es sind drei Fornen zu muterseluiden:

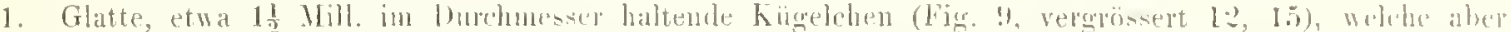

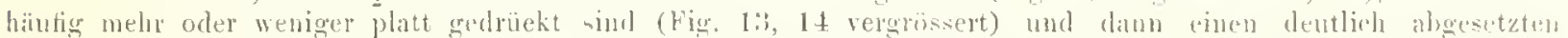

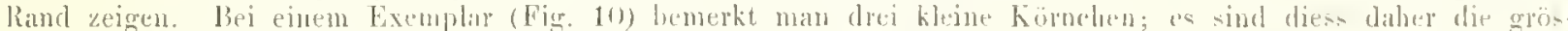

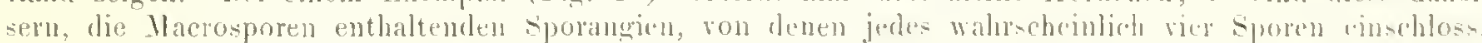

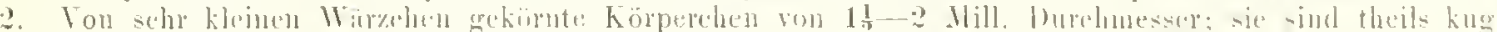

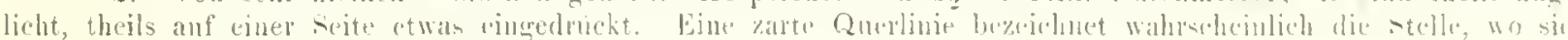
antepringen (Fig. 16, 17 vergrissert).

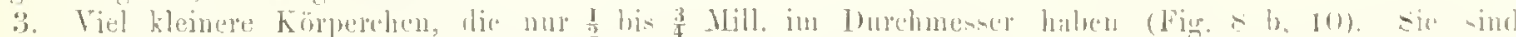

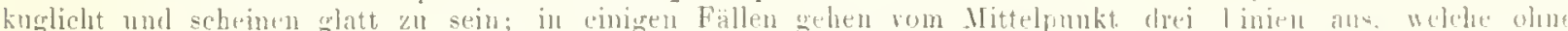

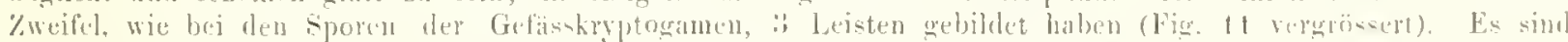

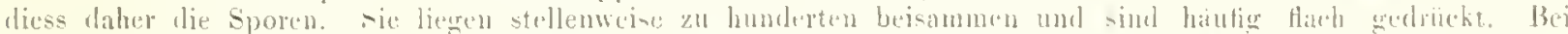

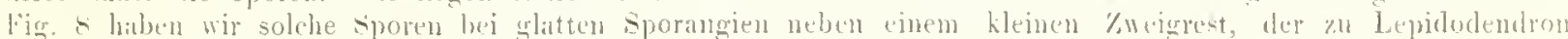

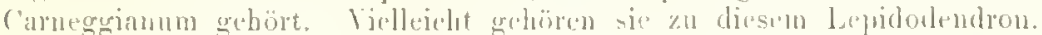

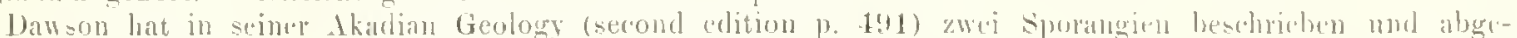

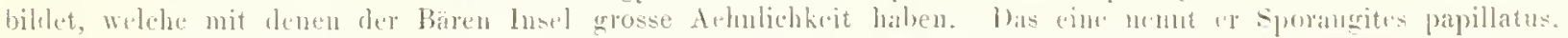

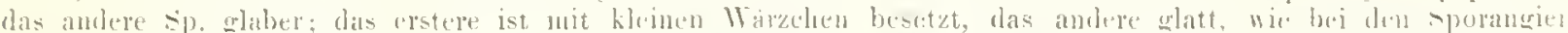

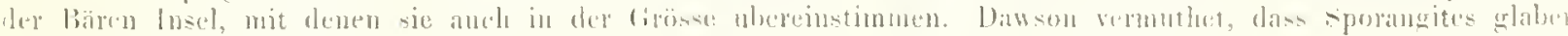

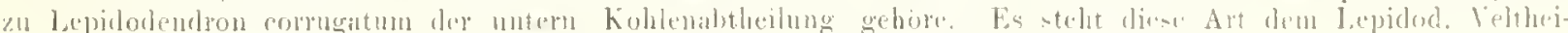

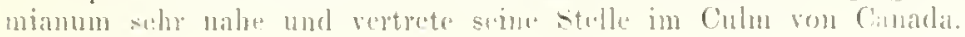




\section{ERKLÄLLN(i I)ER 'TAFELA.}

\section{Taf. I. Calamites radiatus Brgn.}

Fig. 1 im Sondstein. a. Stammstiuck, b. Querbjuch, c. Wurzelzasern ron Stigmaria.

Fig. 9. Abrluck eines Stammstïckes aus der Kohle mit breiten. den Furehen entsprechenden Rippen (C. laticostatus Ett.). Fig. 3 ebenso, Rippen aber stelleuweise unterbroclen. Fig. 4 mit enger stehenden Rinpen und Furchen.

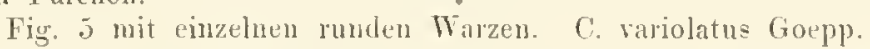

Fig. 6. Stammstïck aus dem Sandstein.

Fig. 7. Ans dem Kohleuschieler mit gewölbten Rippen.

Fig. 8. Abdruck vou zwei bei einander liegenden Stammstücken aus der hohle, mit breiten, den Furchen eutsprechenden, aber nuterbrochenen Rippen (Kuorria confluens Goepp.).

\section{Taf. II. Calamites radiatus Brgn.}

Fig. 1. Grosses Stanmstuich aus der Kohle Fig. ? Rhizom; b. Aeste mit Wurzelzasern. Fig. 3 Aeste Fig. 4 Rhizomaeste. Fig. 5 Zweig mit Knoten. Fig. 6 Wurzelzasern.

\section{Taf. III. Calamites radiatus Bron.}

Fig. 1. Grosses Stammstiick, an der rechten Seite mit stellenweise erweiterten Furchen. Fig. 2. Stammstück, mit theilweise zerstörter Rinde. Fig. 3. Abdruck eines Stammstïekes mit sehr breiten Furehen, die als Rippen erscheinen. Fig. 4. Zwrig mit Knoten und 2 Aestchen.

\section{Tiaf. IT. Calamites radiatus Brgn.}

Fig. 1. Rhizom mit Ast und Wurzelzasern; daneben breitere Wurzelzasern (Sphenophyllum furcatun Gein.) und Blatfetzen ron Fan, der Eine ummittelbar neben dem Calamit, ist obeu eiugerissen und an der rechtcn Seite zerstört; er muss ziemlich breit gewesen sein und gehört zu Cardiopteris polymorpha; der Andere besteht aus zwei an einer dümen spindel befestigten Fiederchen mud scheint zu Palaeopteris Roemeri zu gehören.

Fig. 2. Rhizom mit Knoten; daneben eine gablig zertheilte Wurzelzaser.

Fig. 3. Turzelzasern.

Fig. 4. Zwei Rhizonstücke mit angeschwollenen Knoten und runden Istnarben.

Fig. 5. Rhizom mit Knoten und Eindrüeken von Haaren.

Fig. 6. Rhizomstück mit Haaren.

\section{Taf. T. Calamites radiatus Brgn.}

Fig: 1 und 2. Dicke Rhizomstïcke. Fig. 3. Rhizomaeste.

\section{Taf. VI. C'alamites radiatus Brgn.}

Grosses, reraesteltes Rhizom.

\section{Taf. YII.}

Fig. 1 a. Calamites radiatus mit angeschwollenen Knoten; 1 b. Würzelzasern, zwischen denselben eine Narbe von Stigmaria; 1 c. Lepidorlendron Wiikianum $\mathrm{Hr}$.

Fig. 2. Lepidodendron Wiikianum $\mathrm{Hr}$, mit kleiuen Blattwïlsten. $3 \mathrm{~b}, 5,7$.

Fig. 3-7. Lepidodendron Carneggianum $\mathrm{Hr} ; 3,4,6$ junge Zweige mit Blattnarben; rergrössert Fig. 


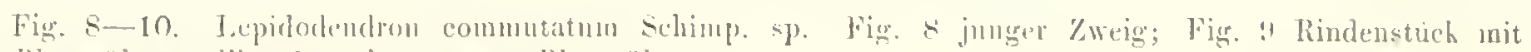

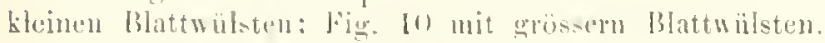

Fig. 11, 1: Cyelostigna mimutum Hamght.; Fig. 11 h, 12 b vererönert.

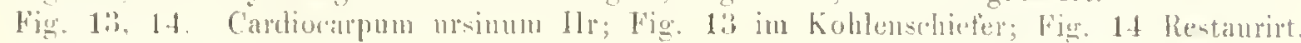

\section{Taf. I'lll.}

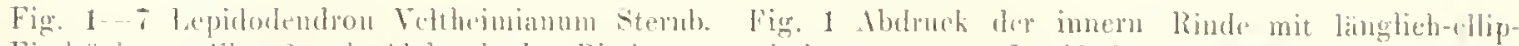

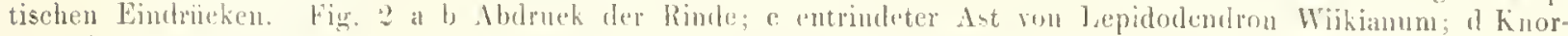

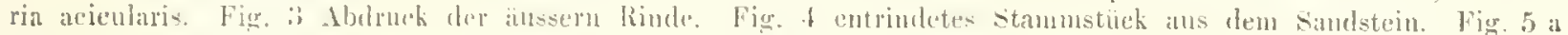

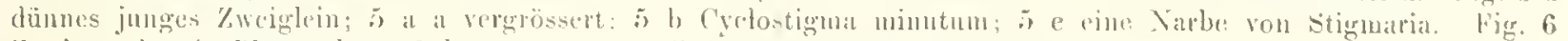

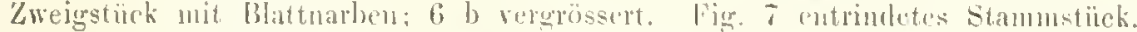

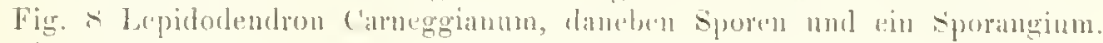

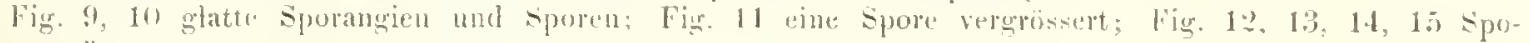
rangien bergrössert.

Fig. 16, 17 gekiirute sporangien, vergriossert.

\section{Taf. IX.}

Fig. I Lepidorlendron Wiikianum $11 \mathrm{r} ; 1$ b cin stuck rerorössert.

Fig. : a a tepdodendron Veltheimianum, entrindet; 2 b Calanites radiatus, mit runden Findricken; 2 a Stigmaria minuta; $: 2$ d bepirtodemilon C'arneggianum; : e veroröscert.

Fig. :3, 4 \%weige voll Lepidodendron Tettheimianum.

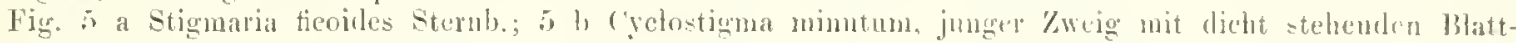
narben; 5 e rergrössert.

Fig. A Knorria imbricata longifolia schimp.

Fig. 7 a, \& Lepidophythm Roemeri IIr; \& h Btatt von Cyelostigma; c Fumspindet.

\section{T'at'. X.}

Fig. 1-5 Knolria imbrieata sterub.

Fig. I und 4 Kuorria imbricata aeutifolia (toppy. Fig. :3, 5 nit vorn stumpton Wargen. Fig. 3 Knorria imbricata Schrammiana Goepp.

Fig. 6, T Knorril acieuturis (isepp.

Fig. 8 Calamites radiatus, junger Spross.

\section{Taf. XI. Cyrlostigmu Kiltorkense Haught.}

Fig. 1 Abrlnck cines Stammstïckes, äussere Rinde abgefallen (Cyel. Griflithi Hauglat.).

Fig. 2 erosses woeh mit der runzeligeu Rinde bekleidetes stannstiek,

lig. :3 Stannstiek im Sandstein; :3 b Blatt; :3 e und d Reste der Deckblätter (Lepidostrobus Bailyanns).

Jig. 4 kiullenstïck aus der Kohle, mit kugliehten Wiirzehen; 4 b diese verurössert. Neben dem Cyelostigma ein Stengedrest ron Calamites radiatus.

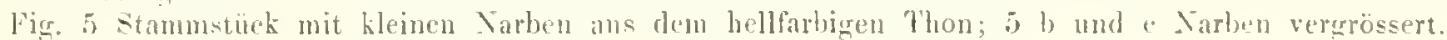

lig. 6 ent Deckblatt dos lepidostrobus Bailyanus Setrimp. von Kiltorkan.

\section{Taf. Xil.}

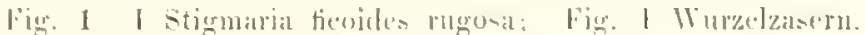

Fig. :5 stigmania tieodes inaeguatis Gorpp.

Pig. li Stigmaria ficoides mimuta.

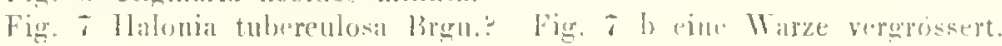

\section{Talf. XIIl.}

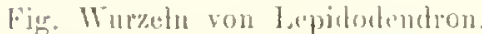

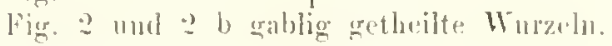

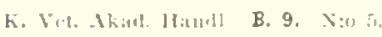


Fig. 3 Reste einer Sphenopteris.

Firg. 4 Sphenopteris Schimperi Goepp.; a, b, c, d Blattepindeln; e Fiederchen. Fig. 6 vergrössert.

$$
\text { Taf. XIT. }
$$

Fig. 1, 2 Cardiopteris polymorpha Goepp. sp.

Fig. 5 Palaeopteris Roemeriana Goepp. sp.

Fig. 6 Cardiocarpum punctulatum Goepp.

Fig. 7 Turzeln von Lepidodendrum.

\section{Zusatz.}

Letzten sommer haben zwei junge schwedische Naturforscher, die Herm Wilander und Xathorst, in der Klatas Billen Bai des Eistiorles. Spitzhergens Steinkohlenpflanzen entdeckt, welche mir zur Tutersmehurg zugeschiekt worden sind. Sie liegen in einem grobkömigen Sandstein, ler unter dem Bergkalk und nit demselben, an dieser Stelle, discordant gedagert ist. Die ziemlich zalulreichen

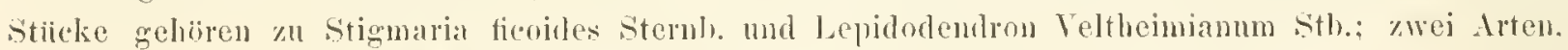
welche wir ambh anf der Bären lnsel kemen gelernt haben und die zu den allgenein verlureiteten Pflanzen des Unter-Carbon gehören. Es gehört demnarh dieser šandstein Spitzbergens anch zur Ursastufte. Die Stigmaria wurle in prachtollen Exemplaren gefunden, welehe ganz nit denen der Steinkohlenperiode ïbereinstinnen. Diese Spitzberger-Pllanzen hestitigen, dass dic Ursastufie den Juter-Carlon und nicht dem Devon einzureilien ist. Horr Caruthers dagegen rechnet die Pflanzen der Bären Insel, wie die von Kiltorkan zun Devon; ioh denke dass die anf s. 6 u. t. angegebenen Thatsiehen das Irrige einer soleluen Ansicht hinlinglich erwiesen haben. Mer ('aruthers stellt aber weiter die Meinung ant, dass die Stigmaria ficoiles, die kuorria arienlaris, das Cyclostigna Kiltorkense, (: minutum und das Lepidoulendron ron kiltorkin zu ein und derselben drt geehöre. welehe er als Lepidodendron Griffithi Brongn. bezeidnet. Bronguiart hat aber nirgends eine lejidodendron dieses Nauens beschrieben. Er erwilhnt nu in emem liricle an Herm Griltith (Natural History leview. London 18ñ) der lieste eines lepidodendron, dem er obigen Namen geben wolle. das er aber weder abbildet noeh beschreibt noch näler eharakterisirt, daher dieser Name nut Reeht ron Nienand anfgenommen worlen ist. Ls ist wahrscheinlich, dass er sich zun Theil (so weit el

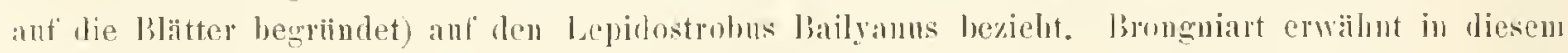
Briele noeh weiter ein Lepidodendron minntum, das ohne Zweitol das cyelostigna minutum Hght.

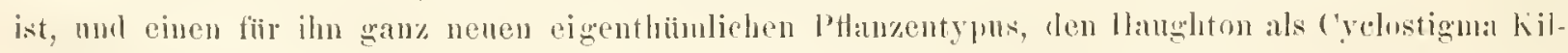
torkense besclirielen hat.

Wenn Herr Caruthers alle oben grenannten PHanzen ron Kiltorkan hn einer Art repeinigen will, so nuissen wir rerlangen, dass er diese Ansieht begribule. Jis diess greschehen ist, kann ich

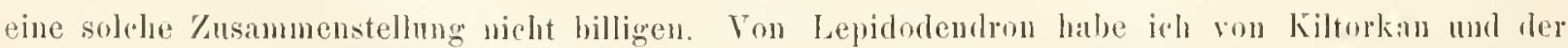

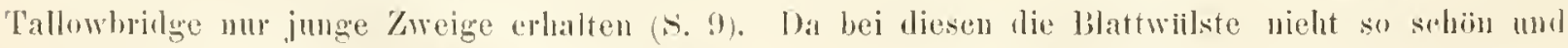

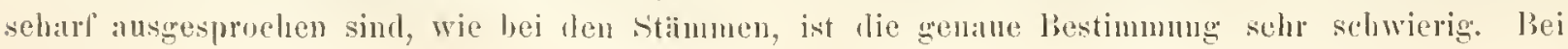




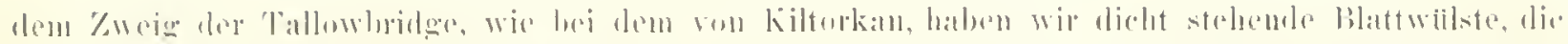

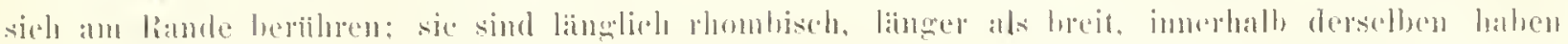

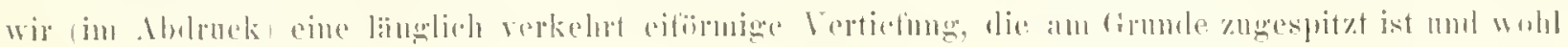

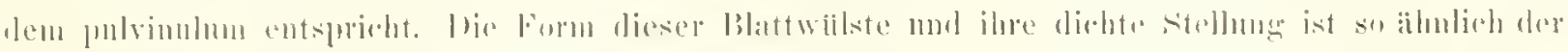

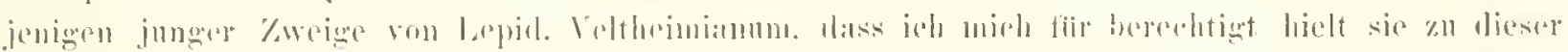

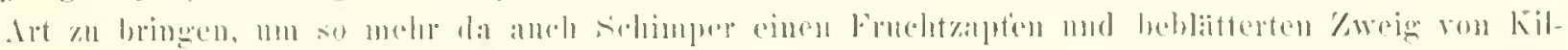

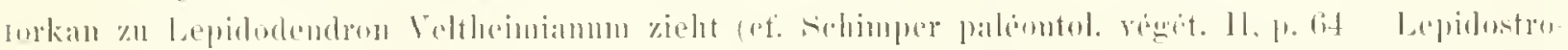

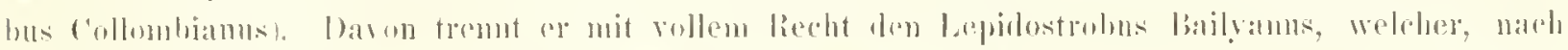

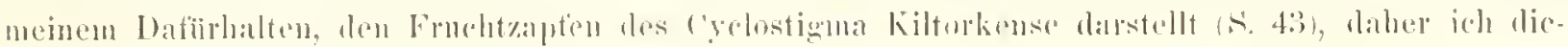

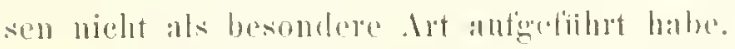

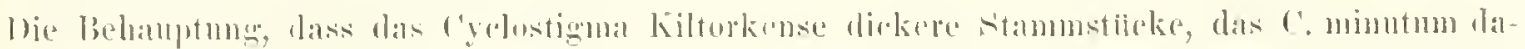

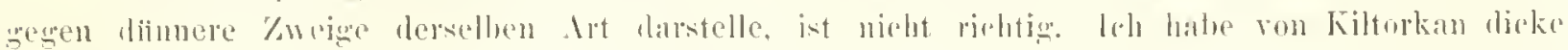
stammstileke ron 1'. minutum, mit den riuh stehenden klemon, rmolon Waren erhalten mud \%weige

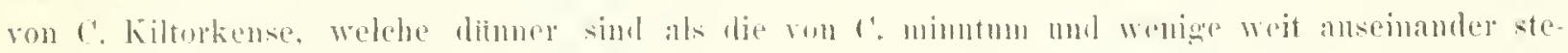

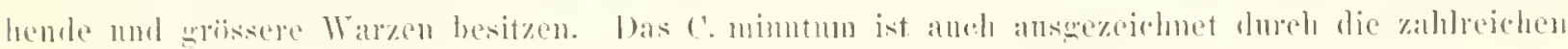

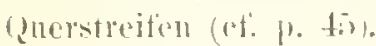

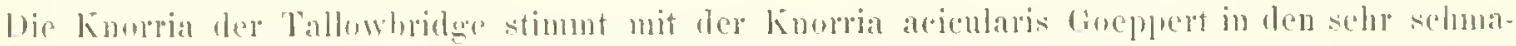

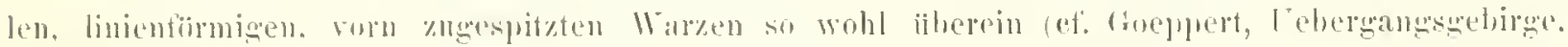

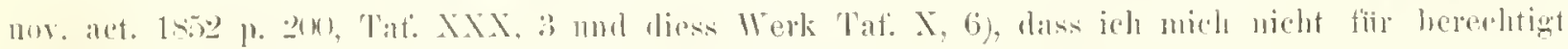

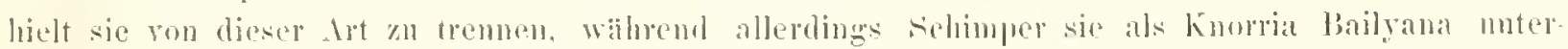

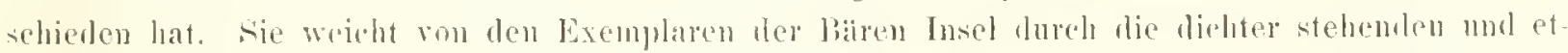

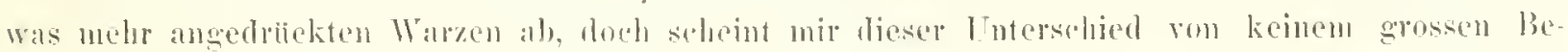

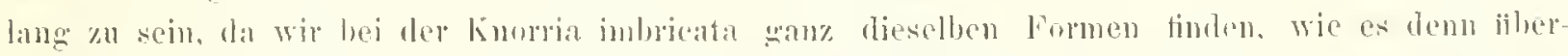

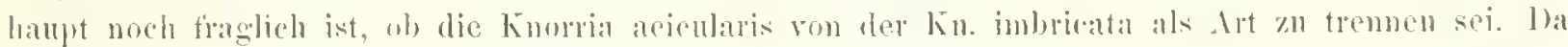

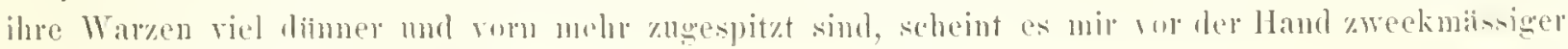
\% sein. sic wetrennt zu lasson. 



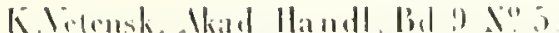

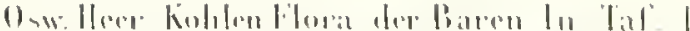

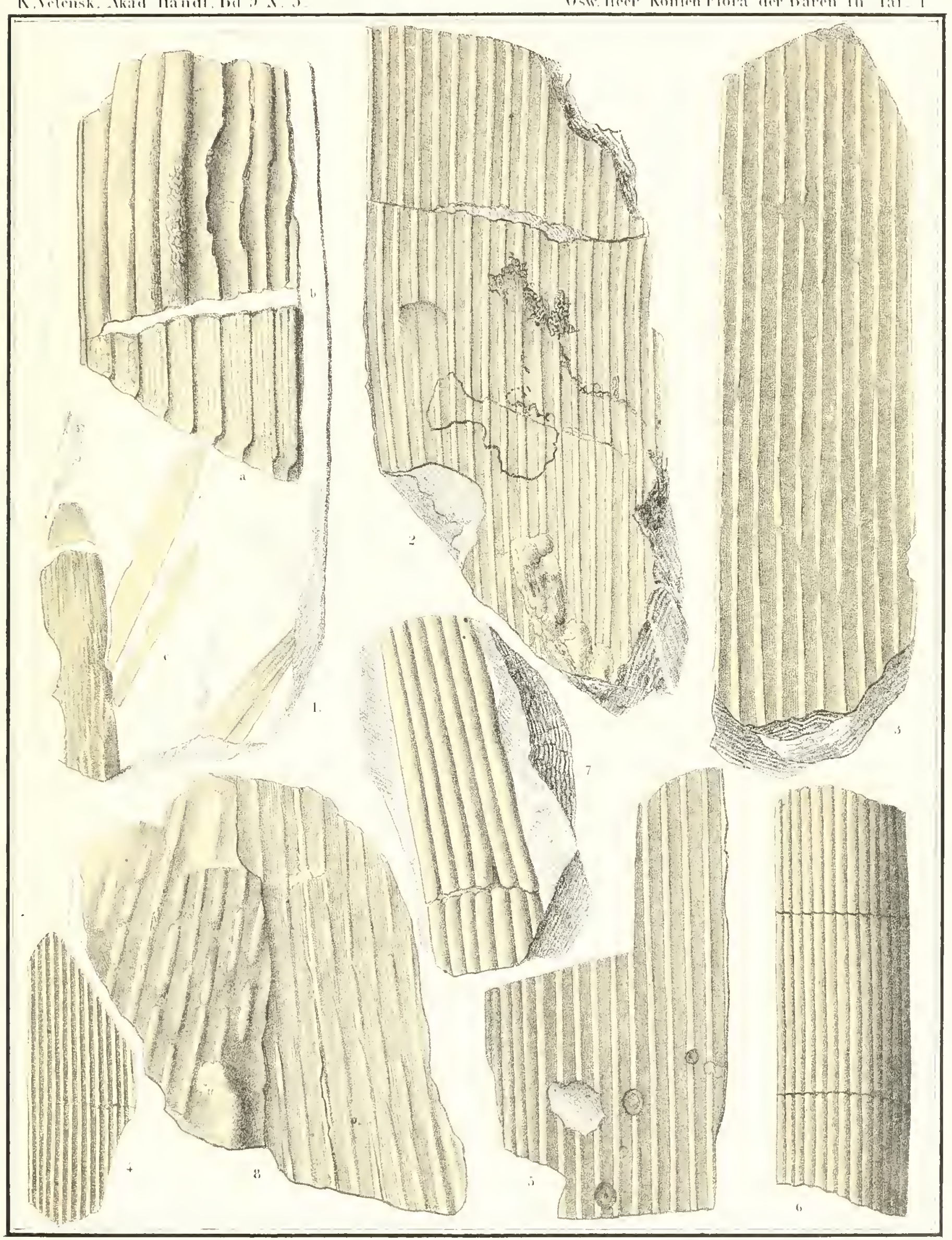

Cialimmtes lablatuss 


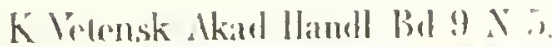

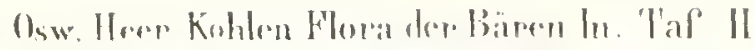

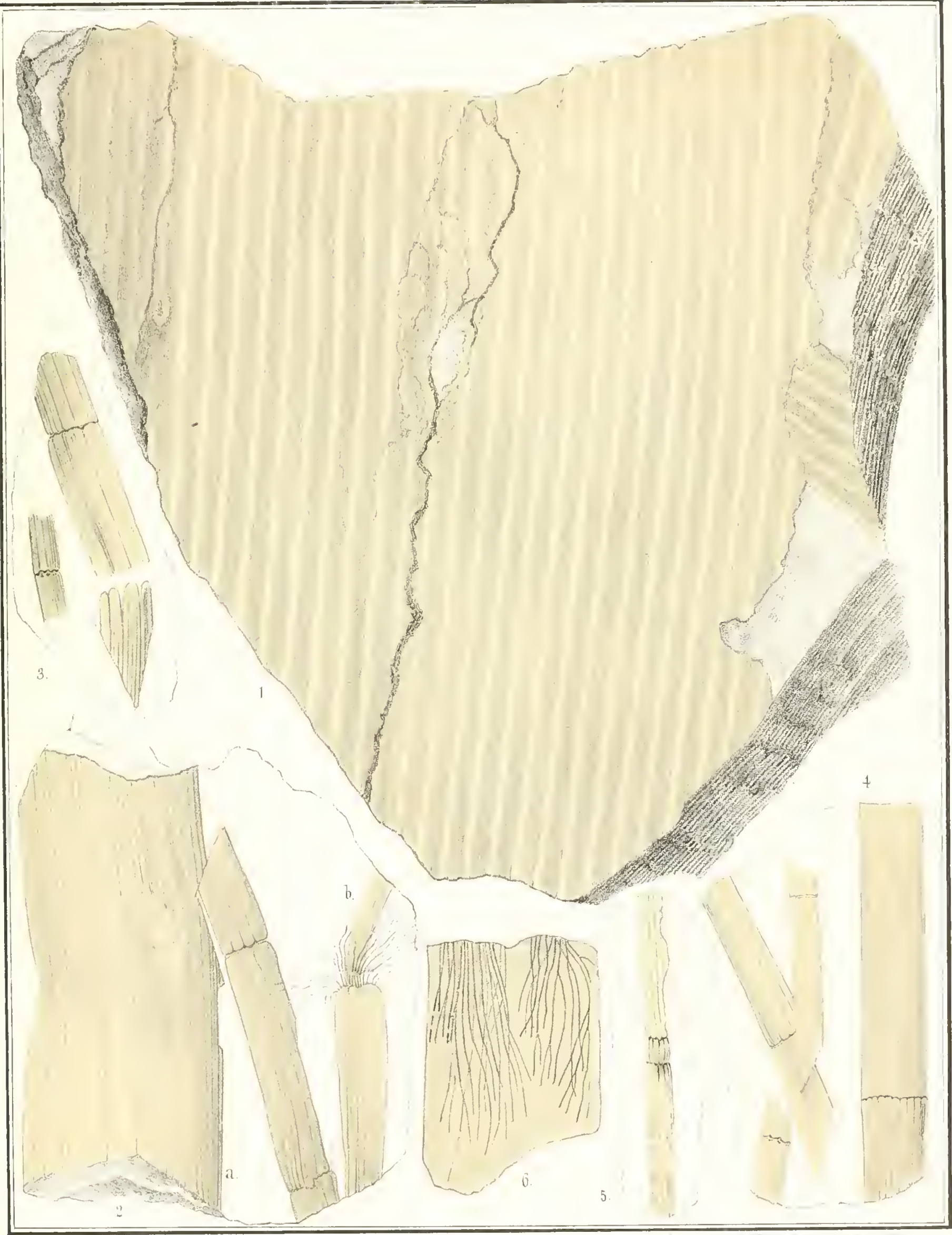

Tilamies padiatus 
K Veronsk Ikad Ilandl. Bd.9. Yos.

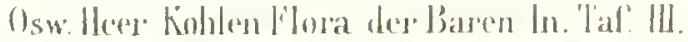

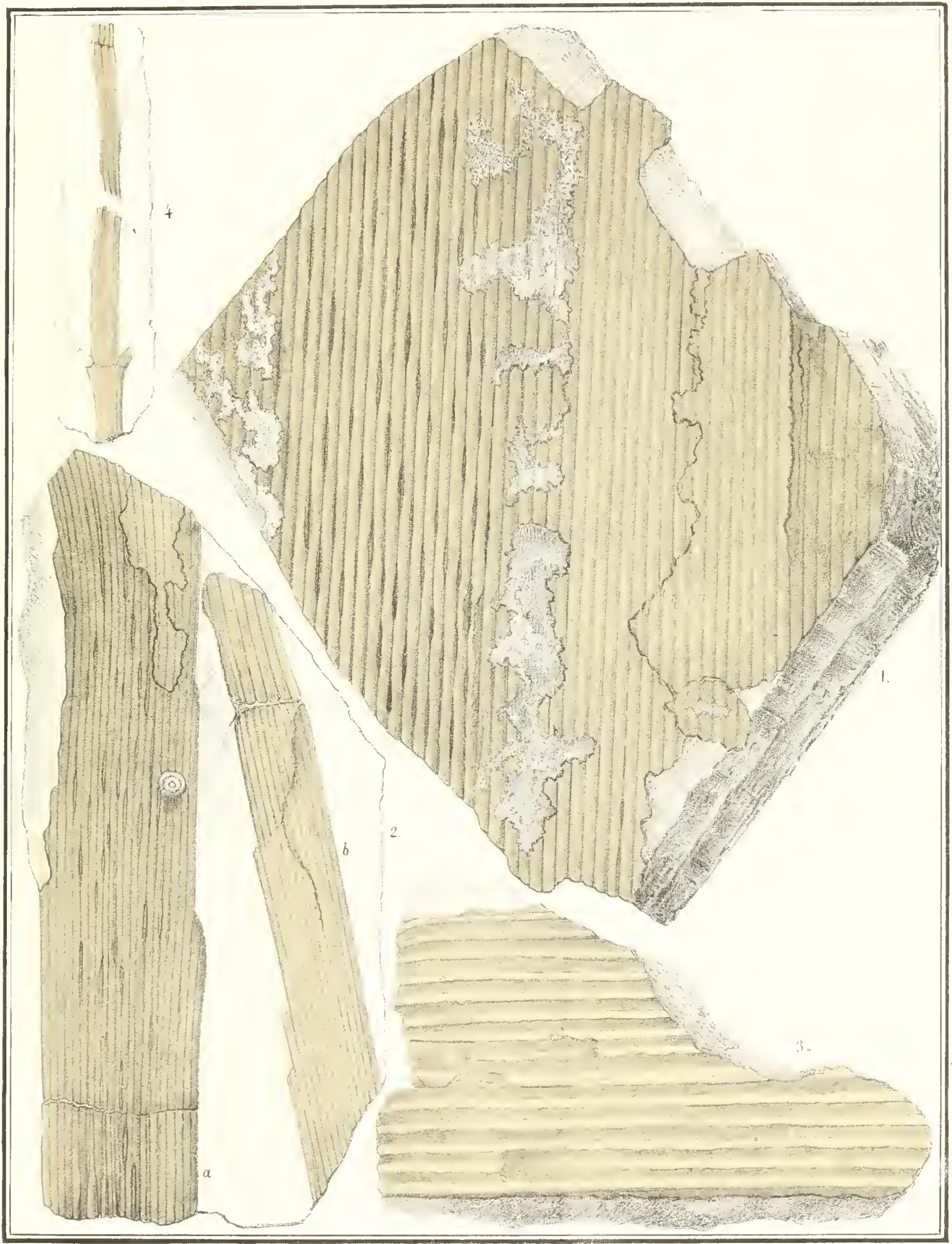

falameles radialus 


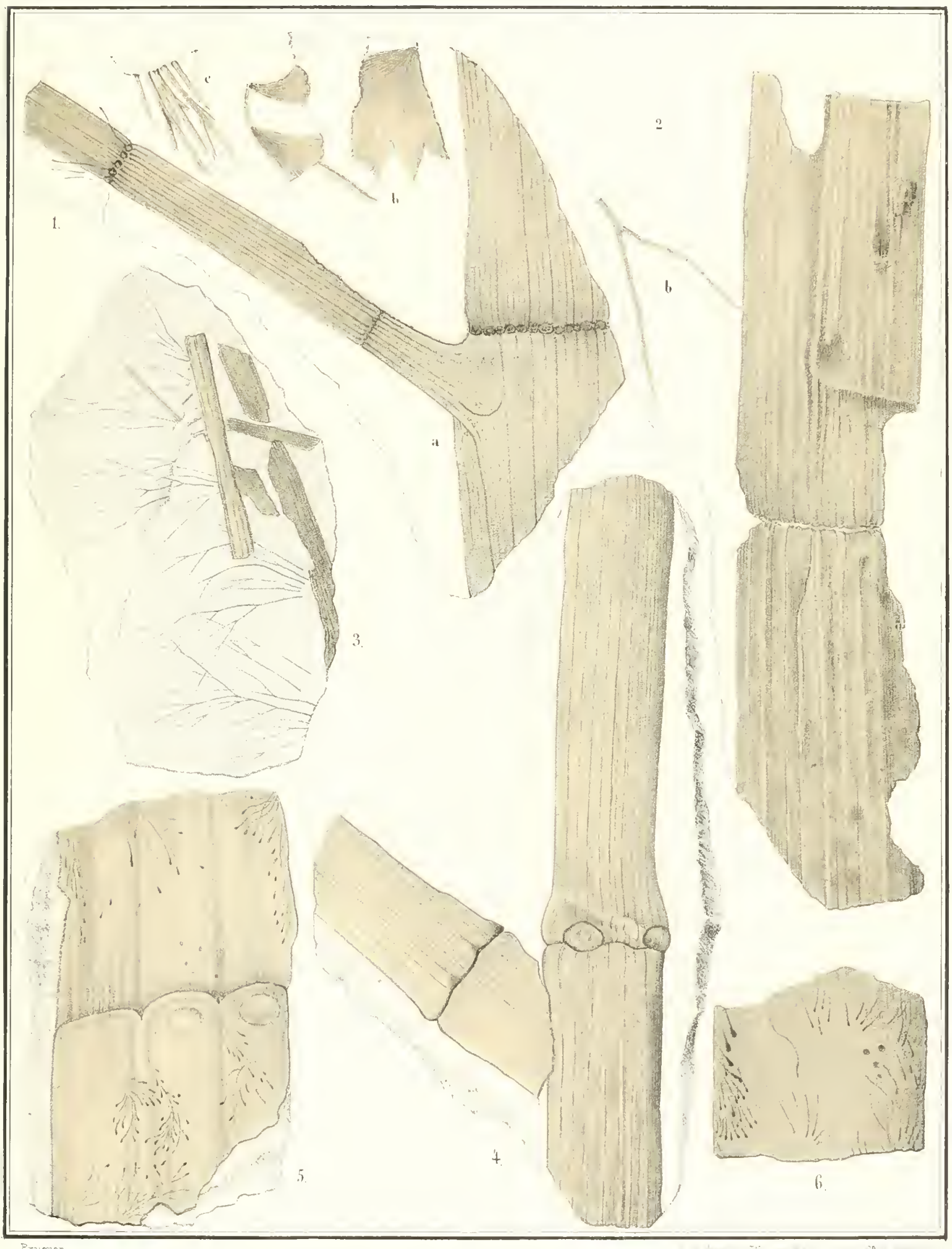

Calamises radialus 


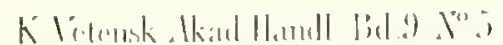

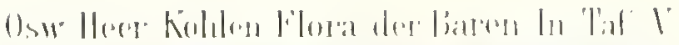

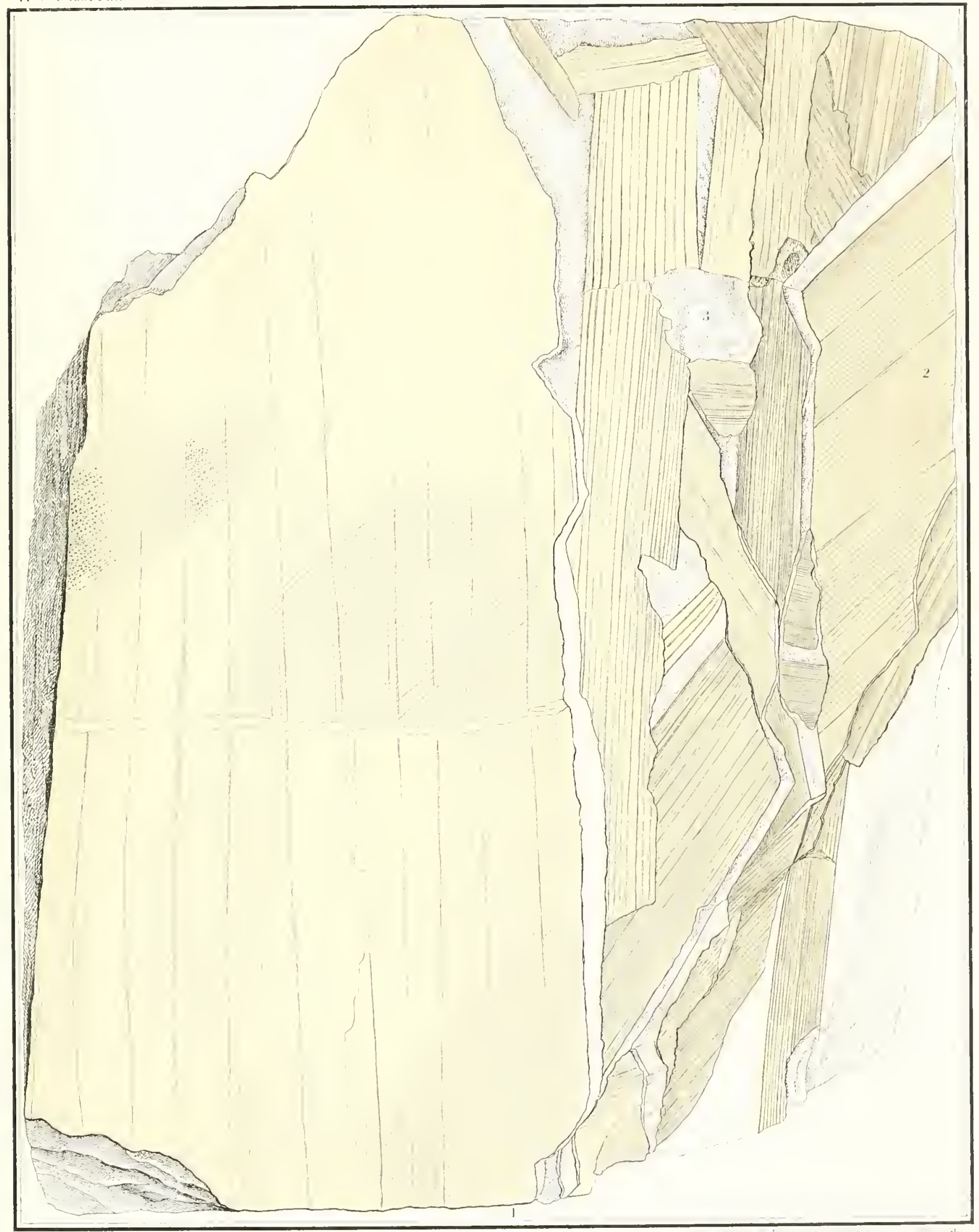

Calamoles iadalus 


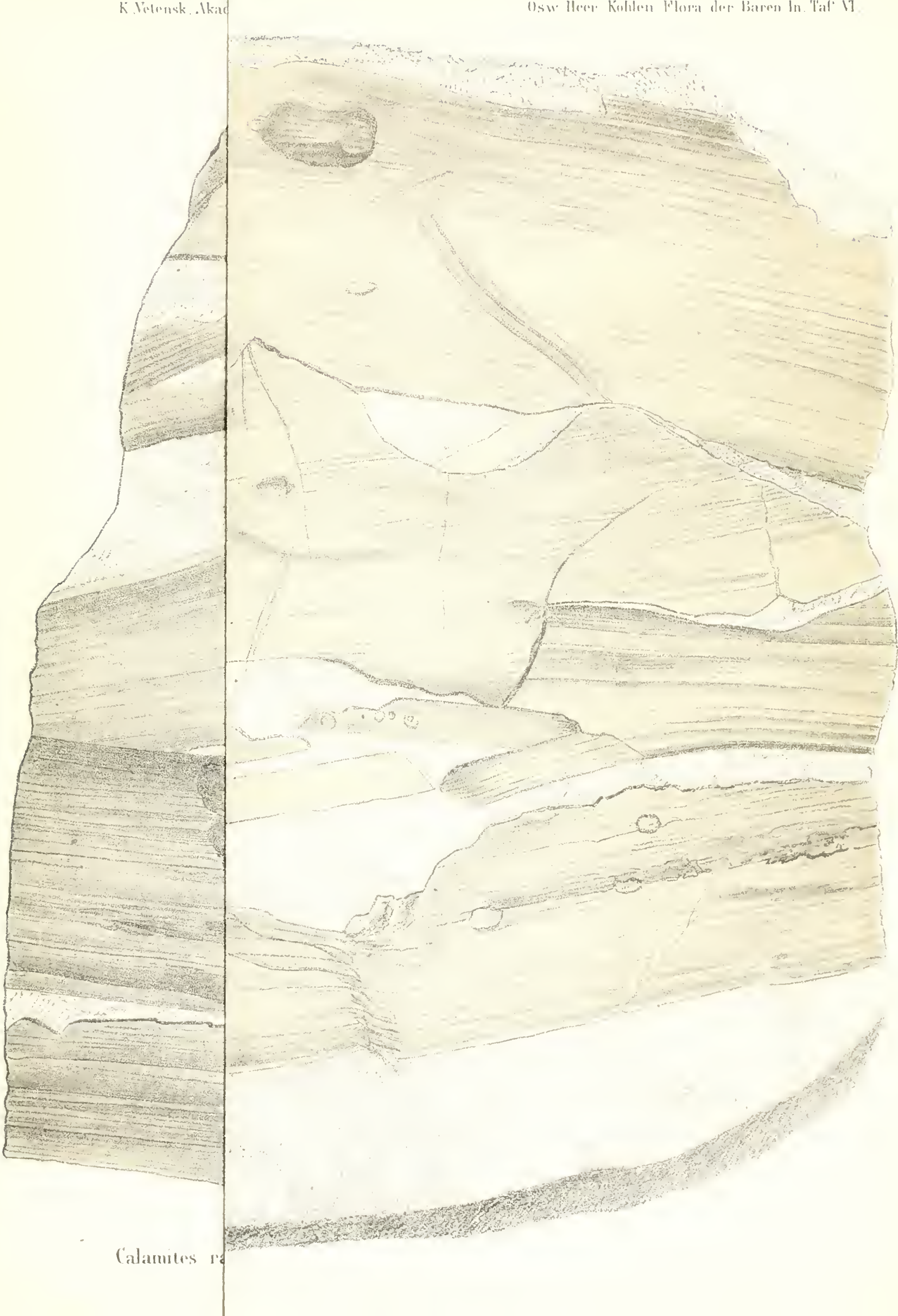




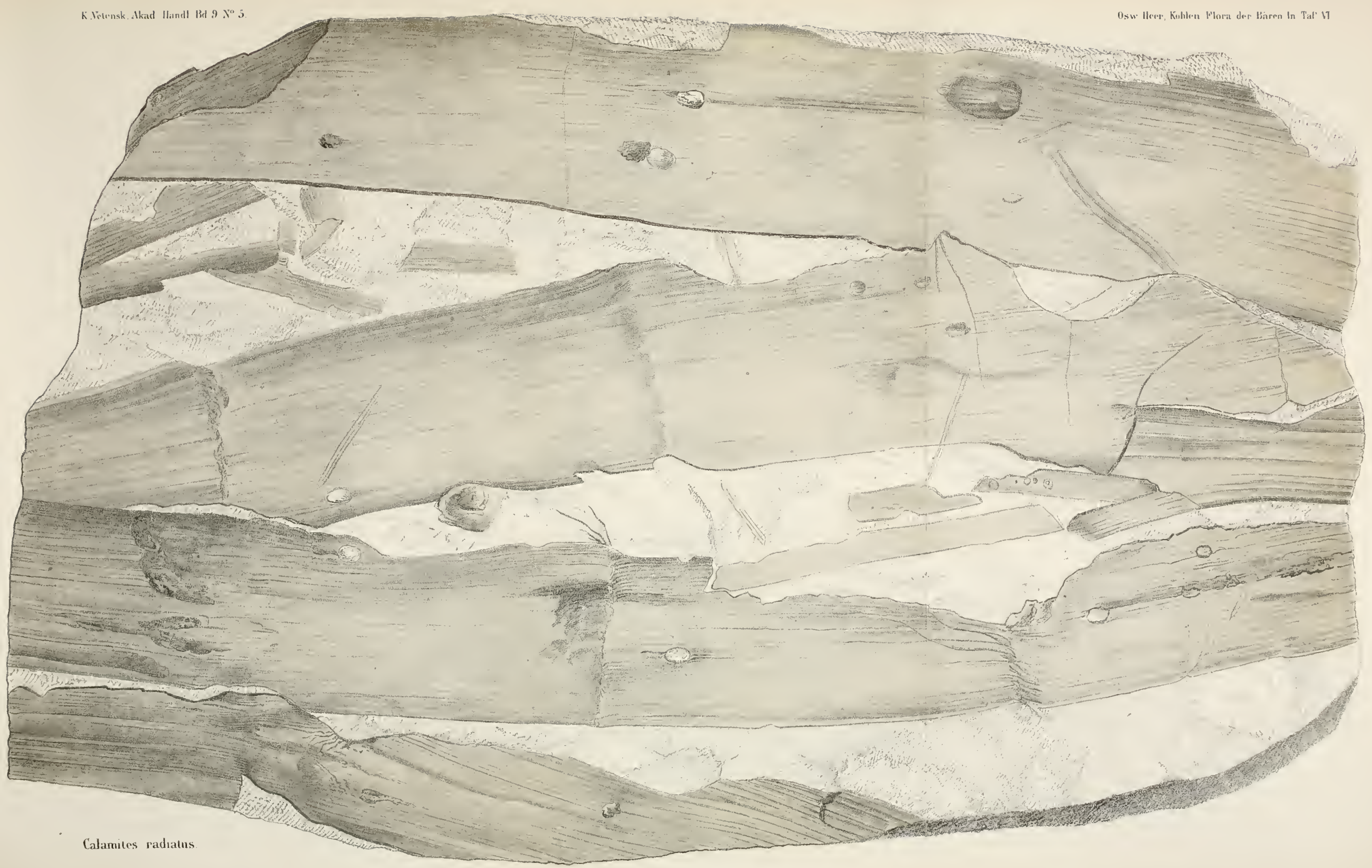




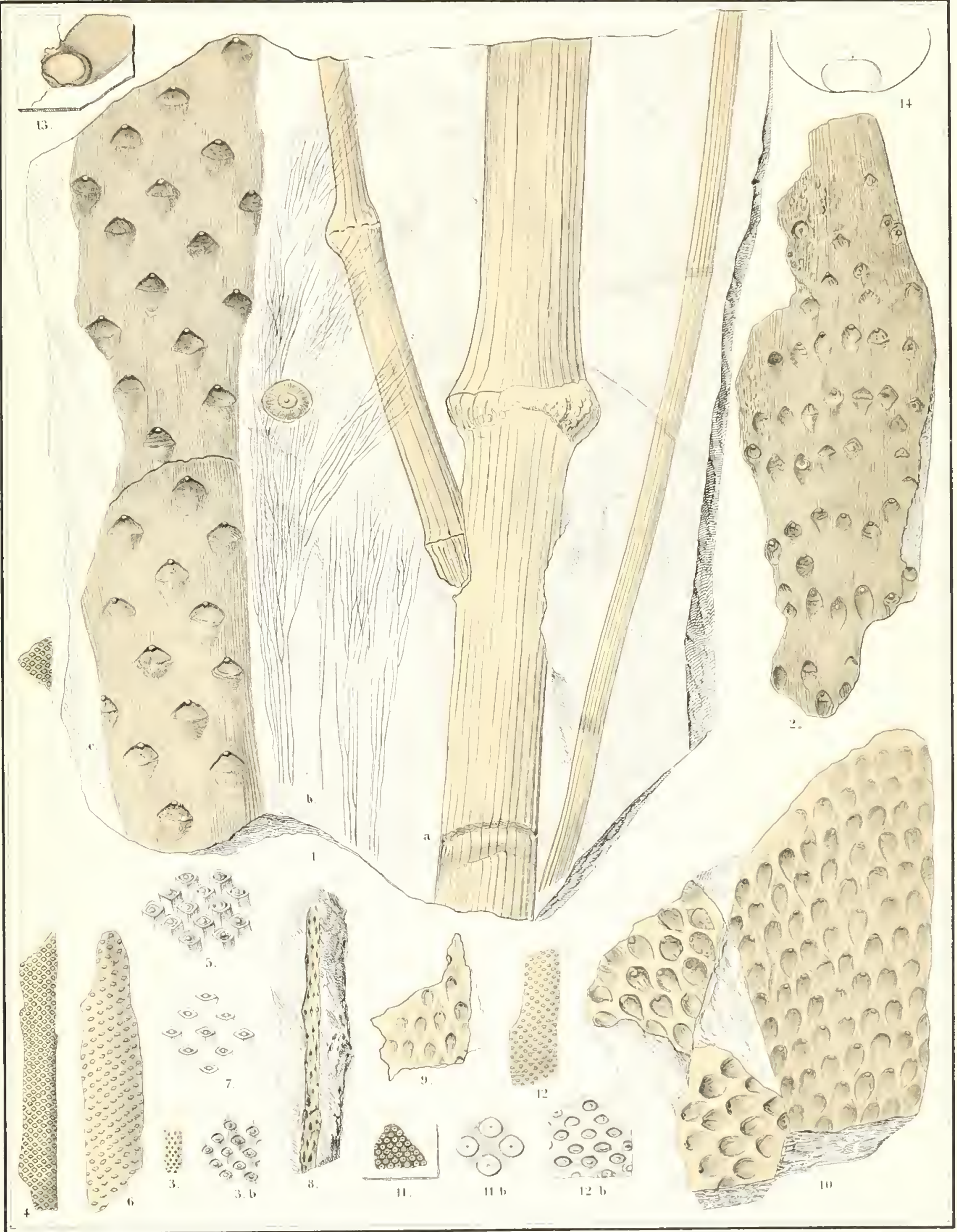

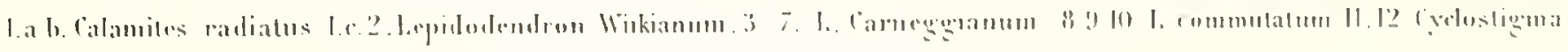
minulum 13 19 cardiararpum ursinum. 



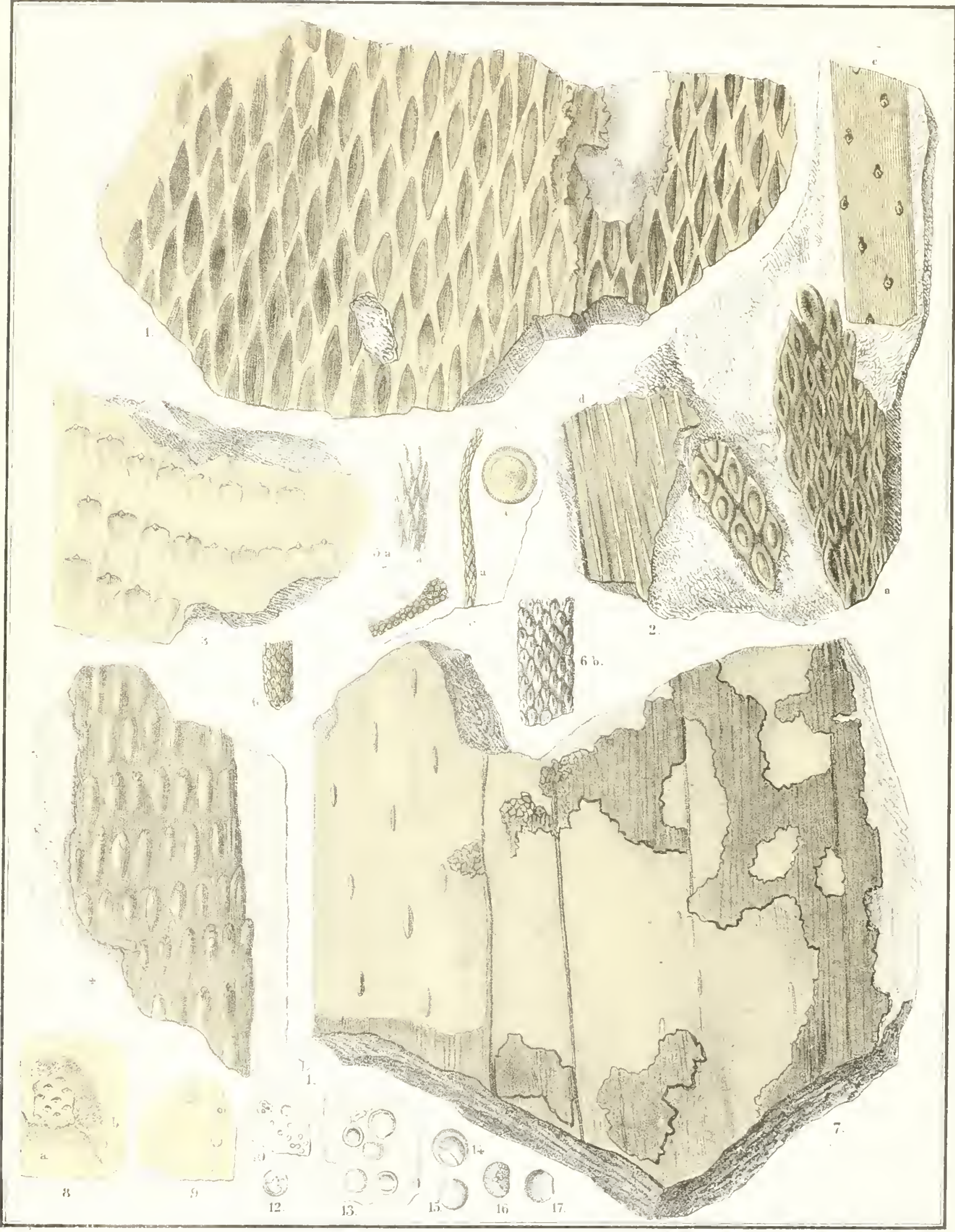

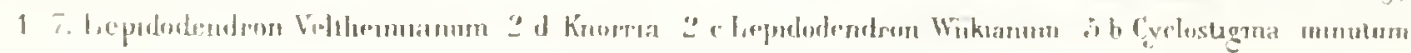





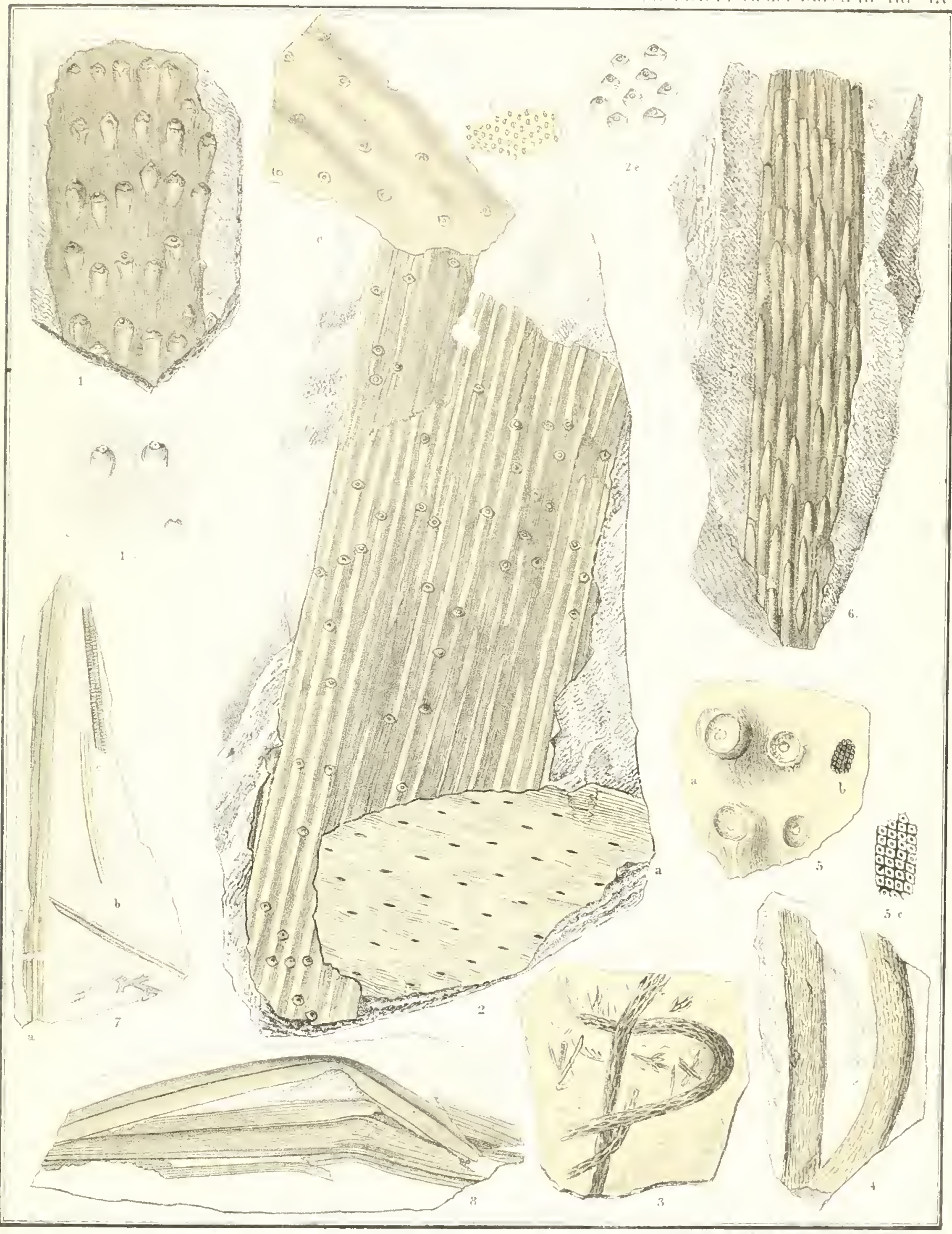

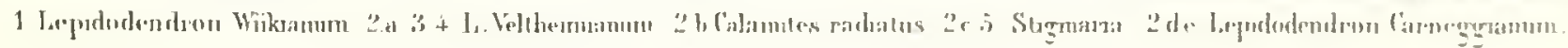

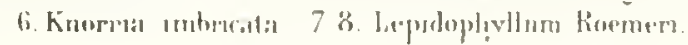




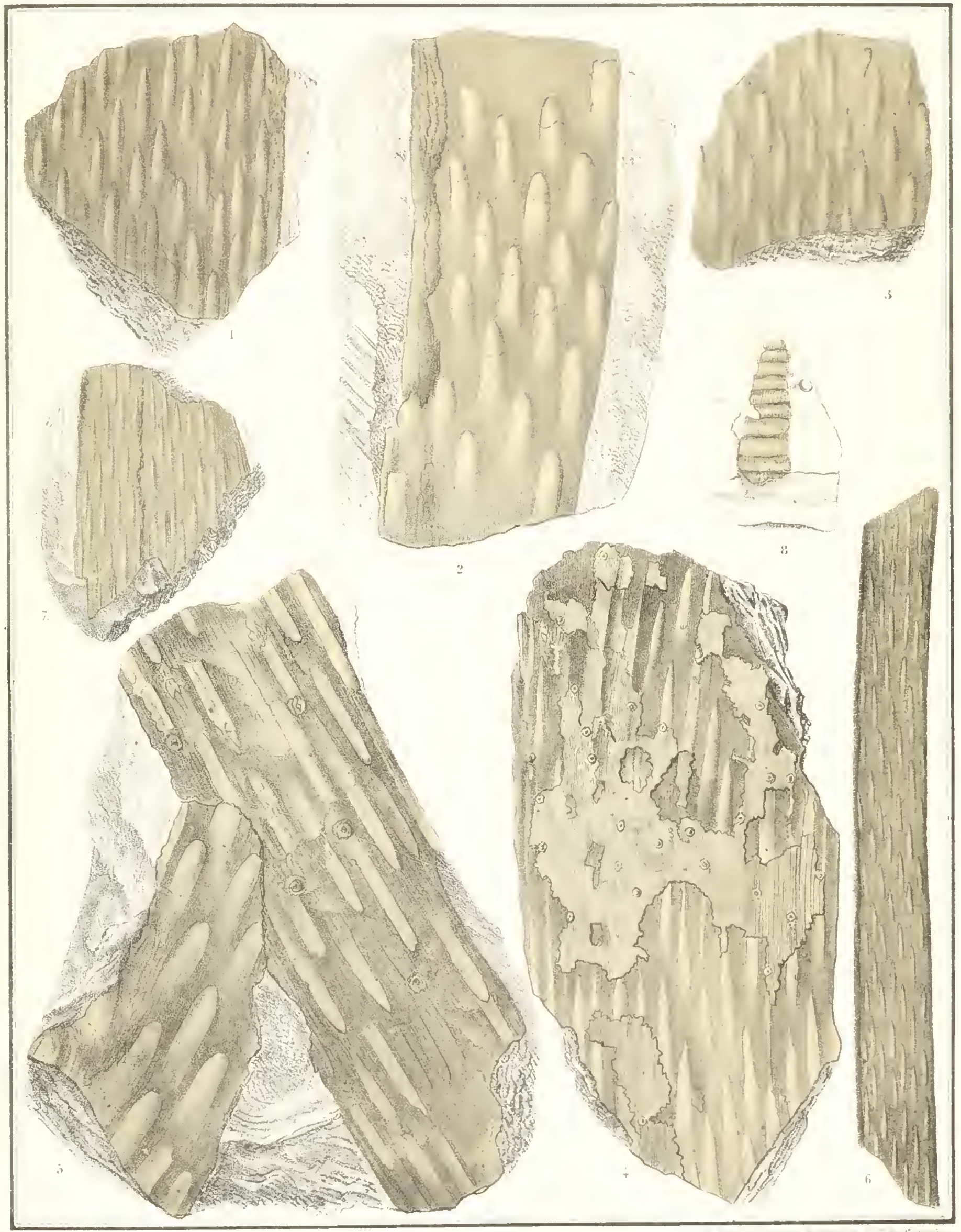





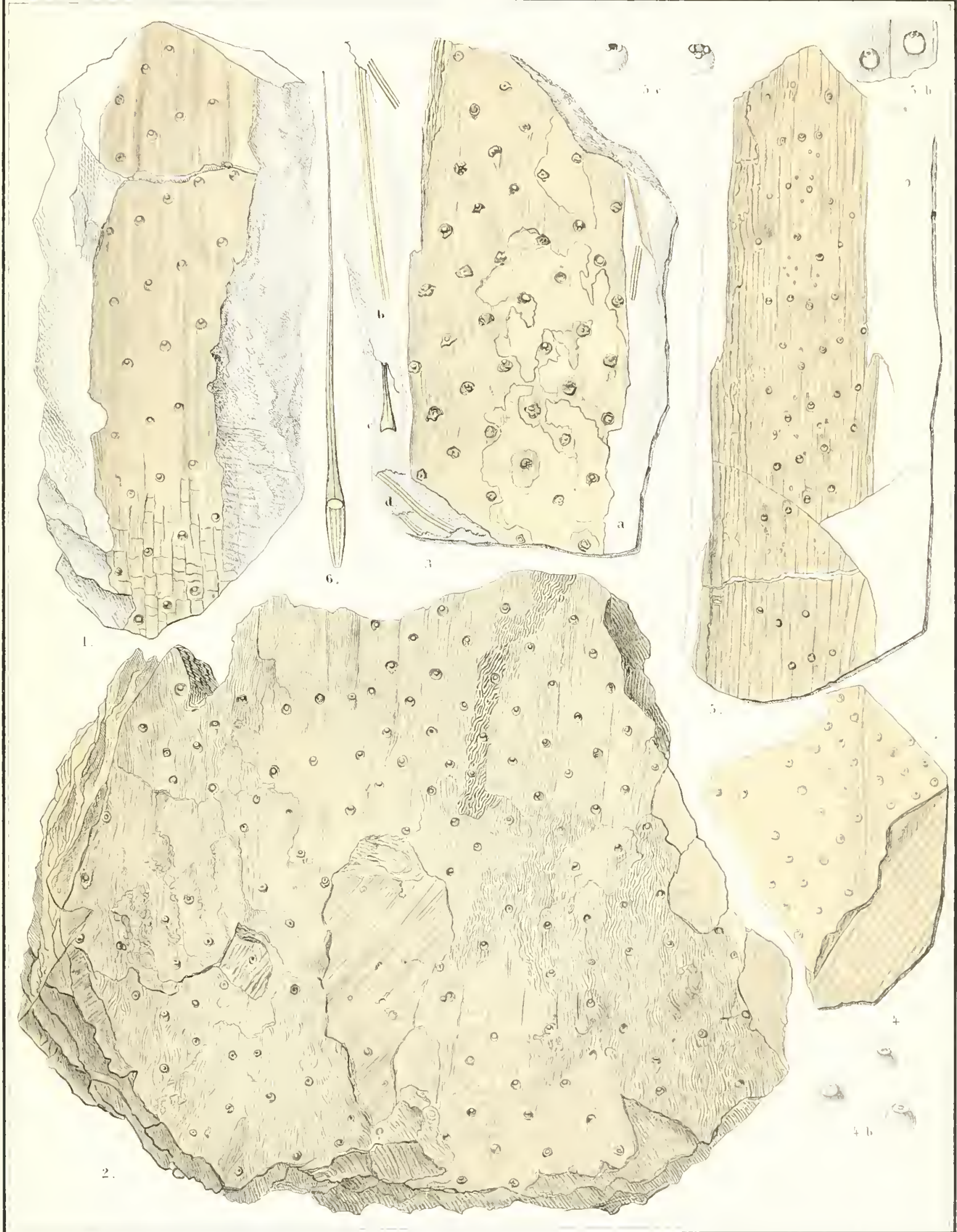




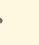




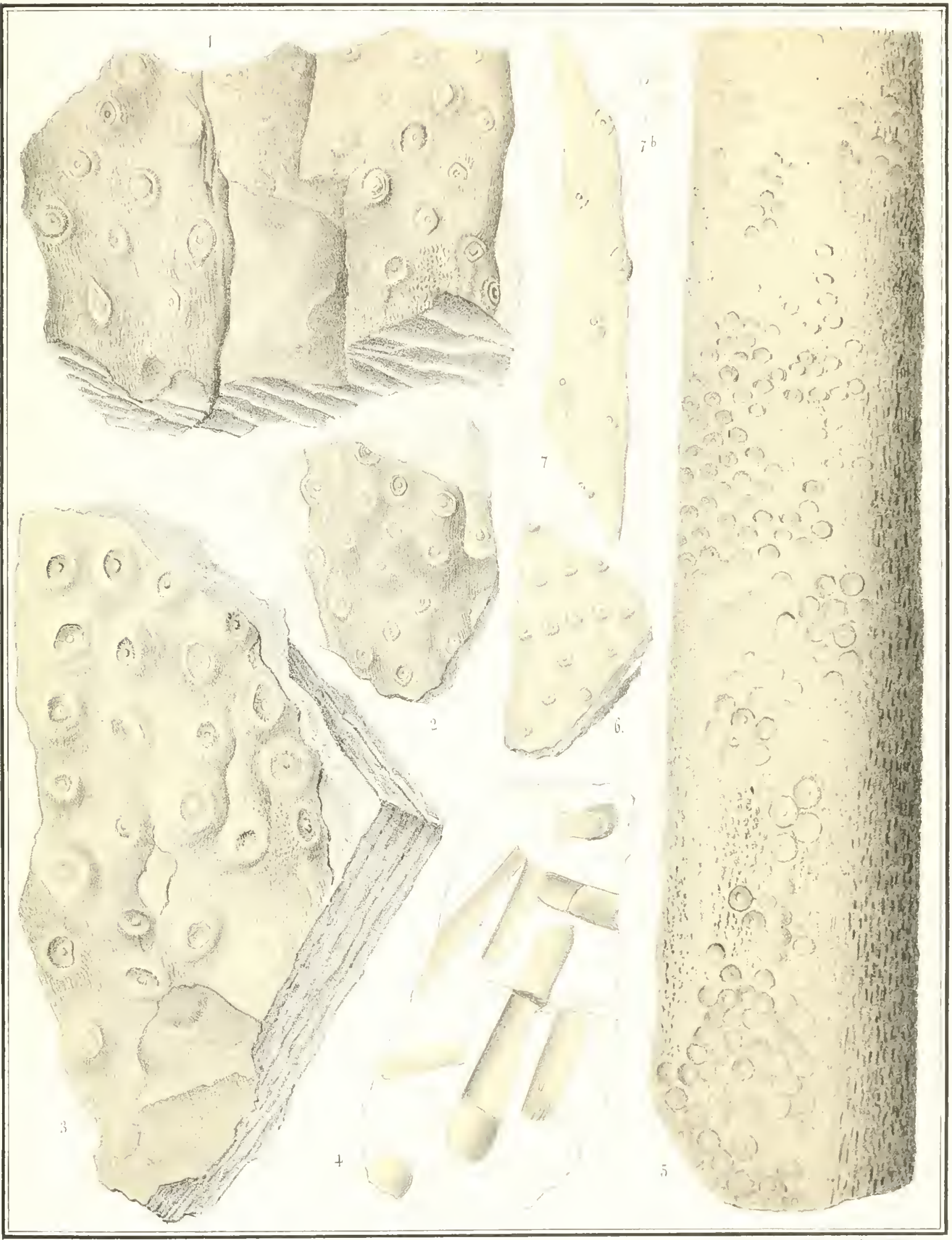

1 fi. Stigmaria 7 . Malmona tuhereculosa 



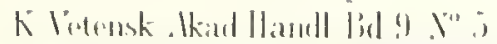

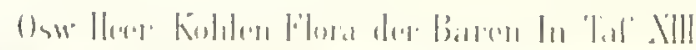

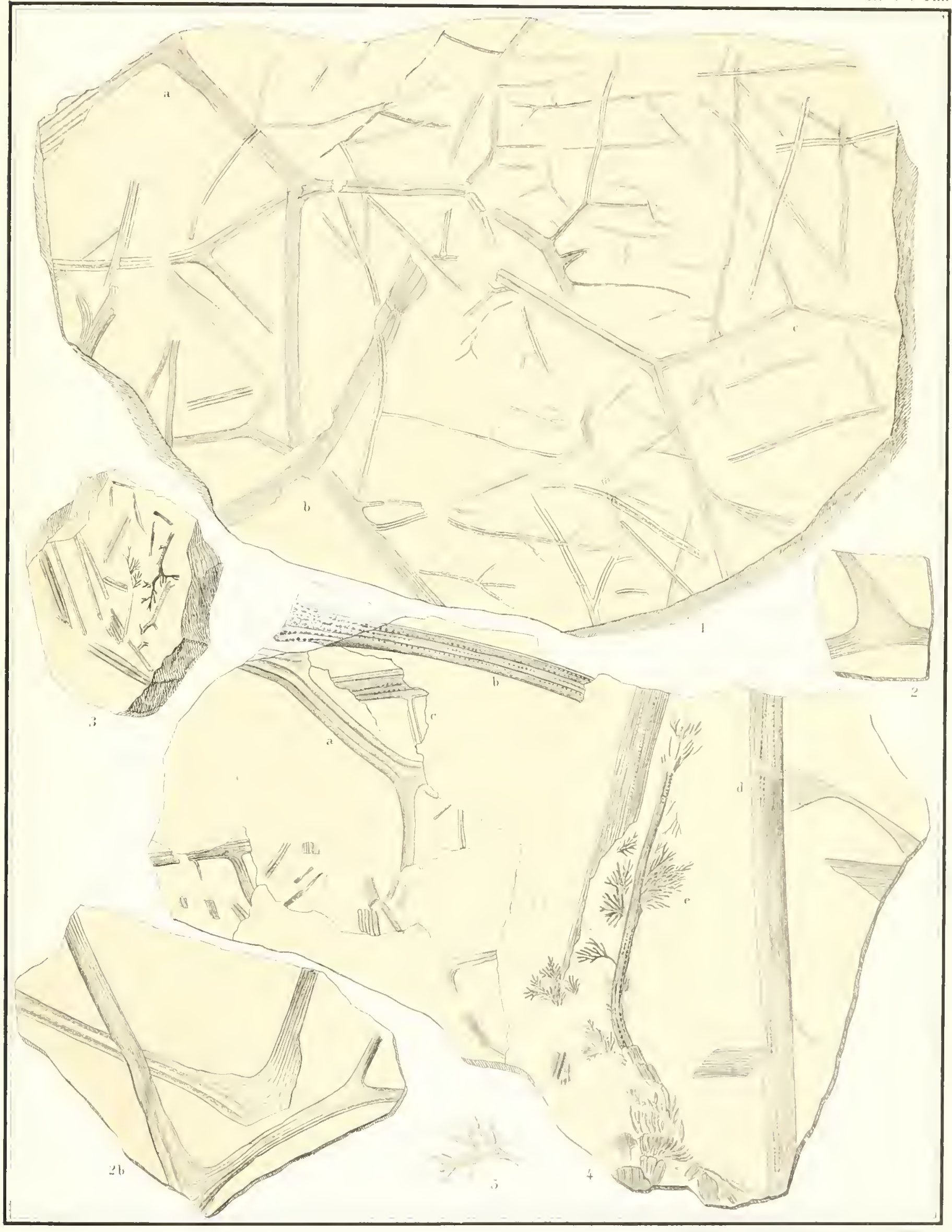

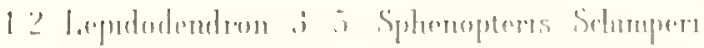




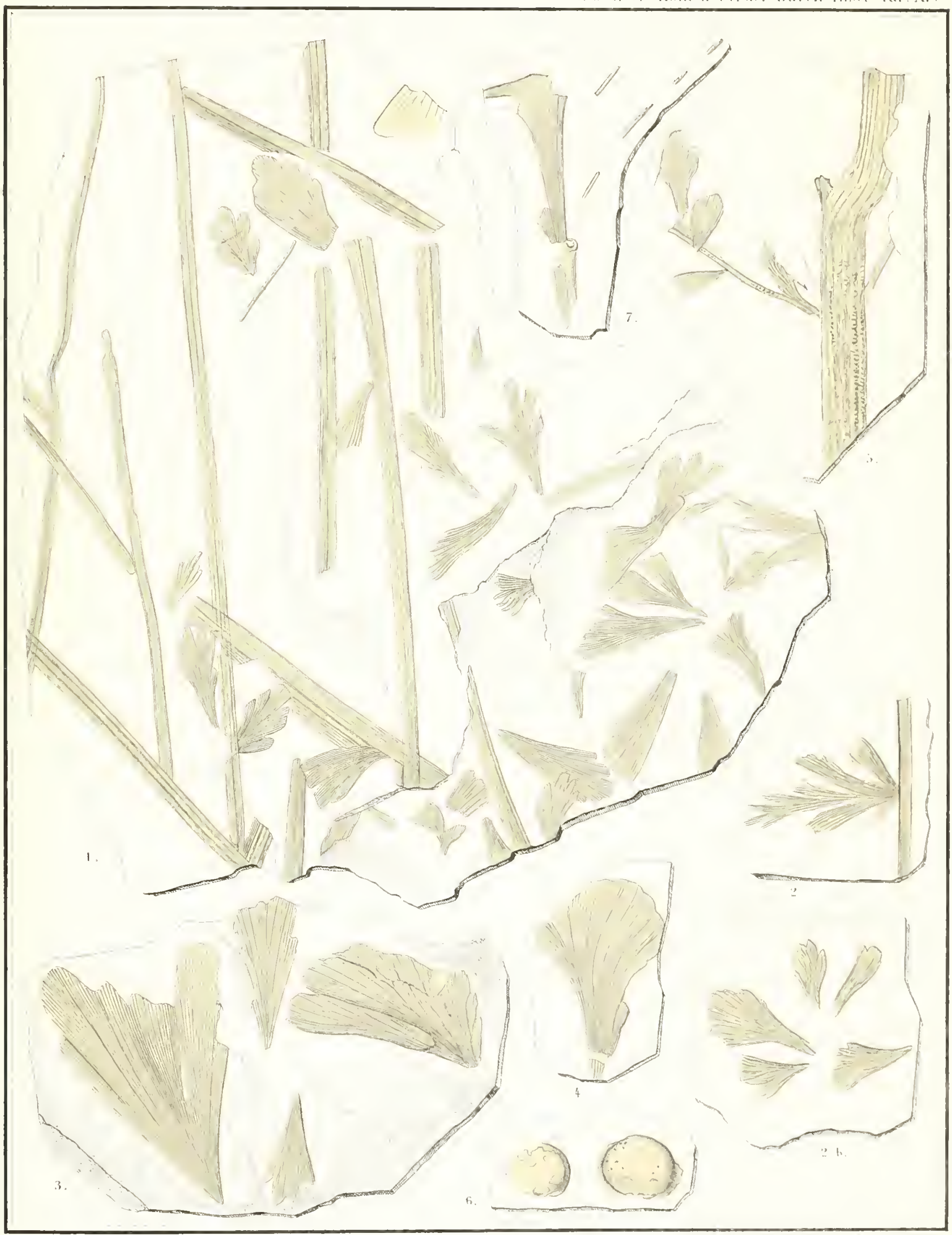

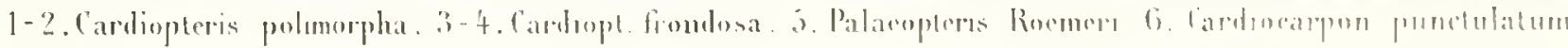


limhl I

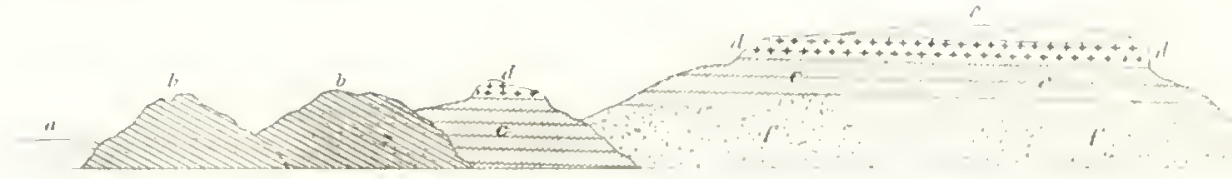

l'rofil rom westl loter der likman liall

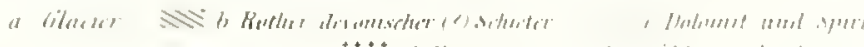

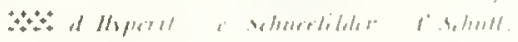

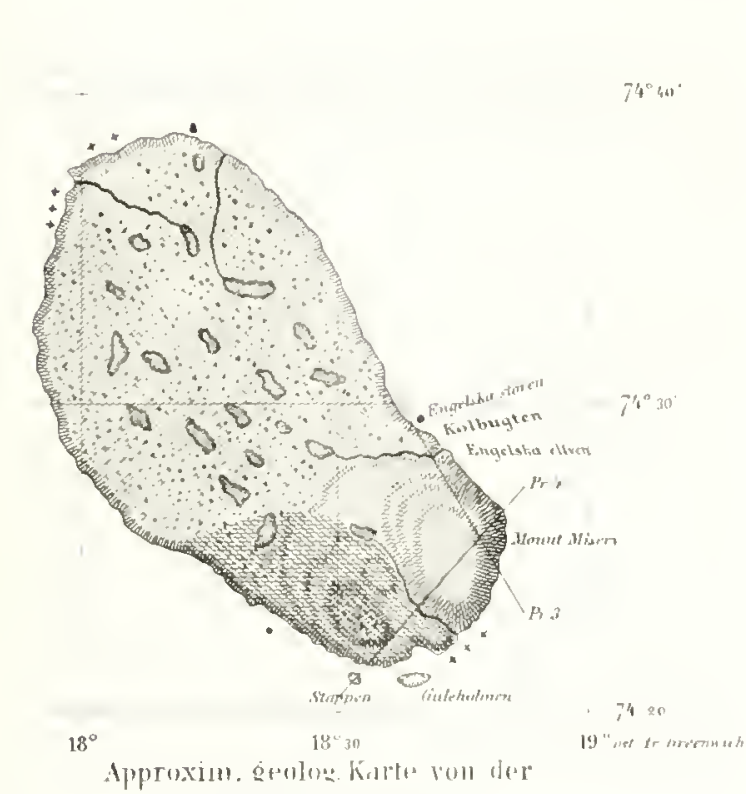

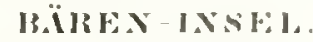

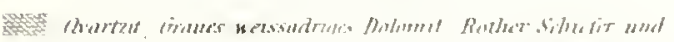

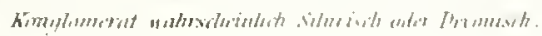
Romilusk

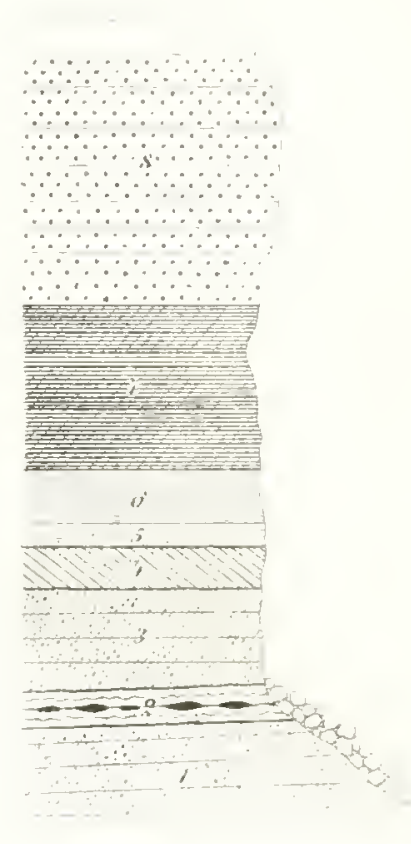

I'Iolıl $\because$

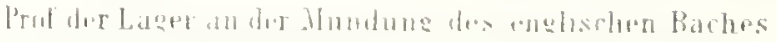

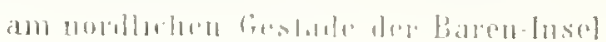

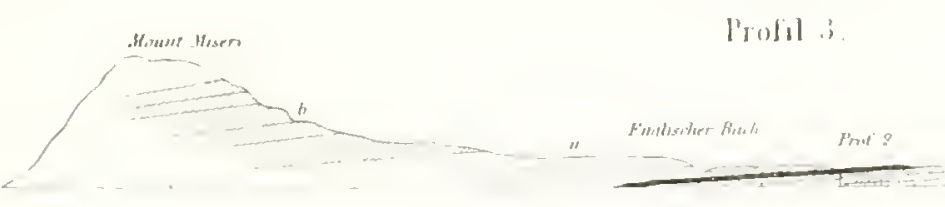

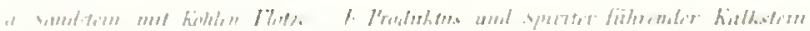

[']'ט1! '

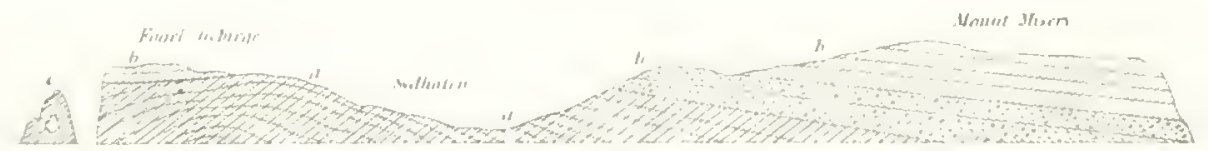

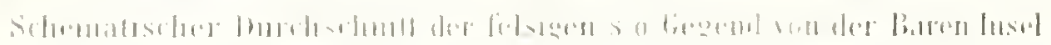

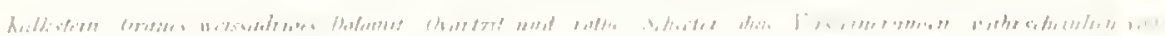

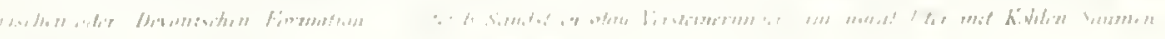

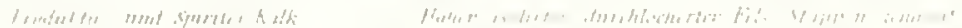




